\title{
Towards a representation of halogen chemistry within volcanic plumes in a chemistry transport model
}

L. Grellier ${ }^{1}$, V. Marécal ${ }^{1}$, B. Josse ${ }^{1}$, P. D. Hamer ${ }^{1}$, T. J. Roberts ${ }^{2}$, A. Aiuppa ${ }^{3,4}$, and M. Pirre ${ }^{2}$

${ }^{1}$ GAME/CNRM, Météo-France, UMR3589, CNRS - Centre National de Recherches Météorologiques, 42 av. G.Coriolis, 31057, Toulouse, France

${ }^{2}$ LPC2E, UMR7328, CNRS-Université d'Orléans, 3A Avenue de la Recherche Scientifique, 45071 Orléans, Cedex 3, France

${ }^{3}$ Dipartimento DiSTeM, Università di Palermo, Via archirafi 36, 90123, Palermo, Italy

${ }^{4}$ Istituto Nazionale di Geofisica e Vulcanologia, Via La Malfa 153, 90146, Palermo, Italy

Received: 3 April 2014 - Accepted: 14 April 2014 - Published: 28 April 2014

Correspondence to: L. Grellier (lisa.grellier@meteo.fr)

Published by Copernicus Publications on behalf of the European Geosciences Union.
Towards a

representation of

halogens in volcanic

plumes

L. Grellier et al.

\section{Title Page}

\section{Abstract}

Introduction

Conclusions

Tables

References

Figures

14

$\rightarrow 1$

4

Back

Close

Printer-friendly Version

Interactive Discussion 


\section{Abstract}

Volcanoes are a known source of halogens to the atmosphere. $\mathrm{HBr}$ volcanic emissions lead rapidly to the formation of $\mathrm{BrO}$ within volcanic plumes as shown by recent work based on observations and models. BrO, having a longer residence time in the 5 atmosphere than $\mathrm{HBr}$, is expected to have a significant impact on tropospheric chemistry, at least at the local and regional scales. The objective of this paper is to prepare a framework that will allow 3-D modelling of volcanic halogen emissions in order to determine their fate within the volcanic plume and then in the atmosphere at the regional and global scales. This work is based on a 1-D configuration of the chemistry transport model MOCAGE whose low computational cost allows us to perform a large set of sensitivity studies. This paper studies the Etna eruption on the 10 May 2008 that took place just before night time. Adaptations are made to MOCAGE to be able to produce the chemistry occurring within the volcanic plume. A simple sub-grid scale parameterization of the volcanic plume is implemented and tested. The use of this parameterization in a $0.5^{\circ} \times 0.5^{\circ}$ configuration (typical regional resolution) has an influence on the partitioning between the various bromine compounds both during the eruption period and also during the night period immediately afterwards. During the day after the eruption, simulations both with and without parameterizations give very similar results that are consistent with the tropospheric column of $\mathrm{BrO}$ and $\mathrm{SO}_{2}$ in the volcanic plume derived from GOME-2 observations. Tests have been performed to evaluate the sensitivity of the results to the mixing between ambient air and the magmatic air at very high temperature at the crater vent that modifies the composition of the emission, and in particular the sulphate aerosol content that is key compound in the $\mathrm{BrO}$ production. Simulations show that the plume chemistry is not very sensitive to the assumptions used for the mixing parameter (relative quantity of ambient air mixed with magmatic air in the mixture) that is not well known. This is because there is no large change in the compounds limiting/favouring the $\mathrm{BrO}$ production in the plume. The impact of the model grid resolution is also tested in view of future 3-D-simulations at the global scale.
GMDD

$7,2581-2650,2014$

Towards a

representation of halogens in volcanic

plumes

L. Grellier et al.

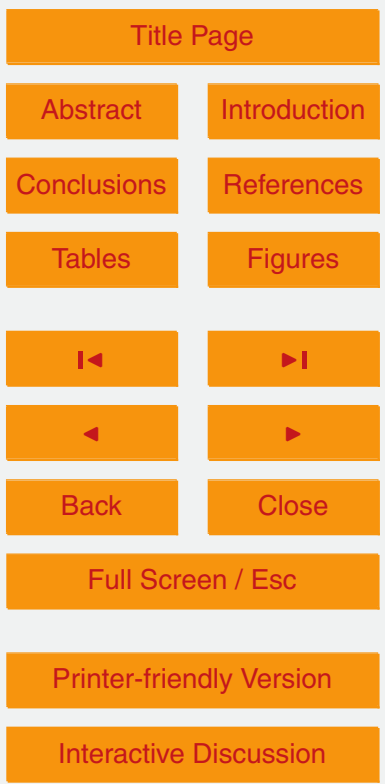


A dilution of the emitted gases and aerosols is observed when using the typical global resolution $\left(2^{\circ}\right)$ as compared to a typical regional resolution $\left(0.5^{\circ}\right)$, as expected. Taking this into account, the results of the $2^{\circ}$ resolution simulations are consistent with the GOME-2 observations. In general the simulations at $2^{\circ}$ resolution are less efficient at 5 producing $\mathrm{BrO}$ after the emission both with and without the subgrid-scale parameterization. The differences are mainly due to an interaction between concentration effects than stem from using a reduced volume in the $0.5^{\circ}$ resolution combined with second order rate kinetics. The last series of tests were on the mean radius assumed for the sulphate aerosols that indirectly impacts the production of $\mathrm{BrO}$ by heterogeneous reac-

10 tions. The simulations show that the $\mathrm{BrO}$ production is sensitive to this parameter with a stronger production when smaller aerosols are assumed. These results will be used to guide the implementation of volcanic halogen emissions in the 3-D configuration of MOCAGE.

\section{Introduction}

15 Bromine species have an important impact on the oxidation capacity of the troposphere, reacting with both $\mathrm{O}_{3}$ and $\mathrm{OH}$, which are the two most important oxidant species. The sources of bromine are from both natural and anthropogenic origins. Human activity releases emissions of various bromocarbons, mainly halons and methyl bromide. Once released in the atmosphere at the surface, these bromine compounds

can reach the stratosphere where they can react with oxidant species and photolyze to produce atomic bromine. These by-products can react to reduce ozone. This phenomenon is well known in the stratosphere (Wofsy et al., 1975; Yung et al., 1980). Volcanoes and the marine boundary layer also provide a sizeable contribution to the global bromine emission inventory, and are a source of inorganic and organic $\mathrm{Br}$ compounds (Dickerson, 1999; von Glasow and Crutzen, 2003; Bobrowski et al., 2003; Bobrowski and Platt, 2007; Oppenheimer et al., 2006). To quantify the impact of the bromine species on the chemical composition of the troposphere and the stratosphere,
GMDD

Towards a

representation of

halogens in volcanic

plumes

L. Grellier et al.

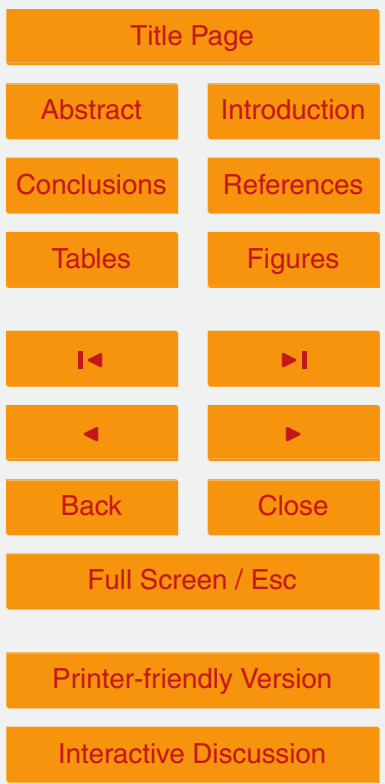


it is important to estimate the amounts emitted by natural and anthropogenic sources. The contribution of the longer lived human sources of bromine compounds is fairly well known but the natural emissions of shorter lived compounds, both organic and inorganic, are not well estimated (Law and Sturges, 2007). This is likely the reason why ob-

5 servations and results of numerical models show a difference in the total stratospheric bromine content (Salawitch et al., 2005): the emissions of the longer lived bromine compounds (halons and methyl bromide) known to participate to the total budget of bromine in the atmosphere are not sufficient to explain the observed value. One of the hypotheses suggests that a part of the missing stratospheric bromine could come from the inorganic Br emitted by volcanoes (Bureau et al., 2000; Law and Sturges, 2007).

Volcanoes are an important source of gases injected into the atmosphere. In addition to the main gaseous emission: water vapour, $\mathrm{CO}_{2}$ and $\mathrm{SO}_{2}$; volcanoes also emit inorganic halogen compounds mainly as $\mathrm{HCl}, \mathrm{HF}$ and $\mathrm{HBr}$ (Gerlach, 2004). The hydrogen halides $(\mathrm{HX}$, with $\mathrm{X}=\mathrm{Cl}, \mathrm{Br}, \mathrm{F}, \mathrm{I})$ are highly soluble meaning that $\mathrm{HCl}$ and $\mathrm{HBr}$ are scavenged onto the Earth's surface by wet deposition within a few hours to a few days. Consequently, their direct impact on the air composition in the troposphere was expected to be local and weak. Thus, the potential for tropospheric volcanic emissions to undergo transport to exert chemical impacts in the stratosphere would be even weaker.

However, this point of view was challenged when Bobrowski et al. (2003) observed bromine monoxide $(\mathrm{BrO})$ in the plume of the Soufrière Hills volcano, Montserrat. After this first observation, BrO has been measured in other volcanic plumes (Oppenheimer et al., 2006; Bobrowski and Platt, 2007; Theys et al., 2009; Boichu et al., 2011; Bobrowski and Giuffrida, 2012). The detection of this chemical species is important because, unlike $\mathrm{HCl}$ and $\mathrm{HBr}, \mathrm{BrO}$ is not water-soluble. Its observed presence several kilometers downwind also indicates occurrence of reactive halogen cycling in volcanic plumes. This implies a longer atmospheric residence time for volcanic bromine, and therefore opens conditions for regional scale impacts on tropospheric chemical compositions. The fate of $\mathrm{BrO}$ in the troposphere outlines its fate in the stratosphere because the deposition, the transport and the chemical processes important for the behaviour

Towards a

representation of halogens in volcanic

plumes

L. Grellier et al.

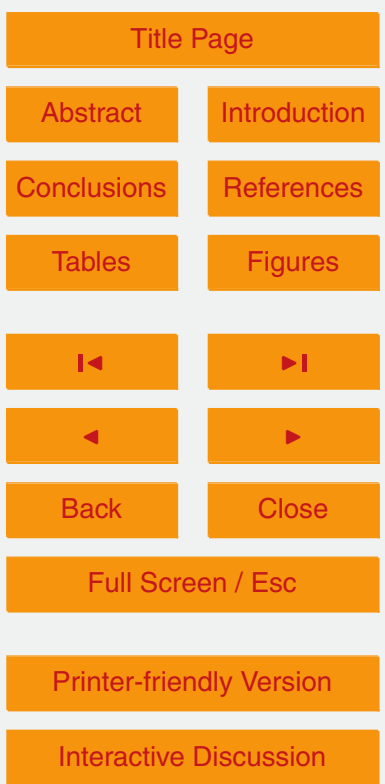

2584 
of $\mathrm{BrO}$ in the troposphere can determine the potential for such tropospheric volcanic bromine emissions to be transported into the stratosphere.

Regarding the source of volcanic $\mathrm{BrO}$, Gerlach (2004) first proposed that $\mathrm{BrO}$ is not directly emitted by the volcanoes, rather its formation is promoted by chemical reac5 tions in the high-temperature mixture of air and magmatic gases, immediately following emission. A variety of such mixtures, depending on varying proportions of air and magmatic gases, were later studied by Martin et al. (2006). However, this near-vent source of radicals $(\mathrm{Br}, \mathrm{Cl}, \mathrm{NO}, \mathrm{OH})$ cannot explain occurrence of $\mathrm{BrO}$ further downwind. Studies of the plume atmospheric chemistry (Oppenheimer et al., 2006; Bobrowski et al., 10 2007; Roberts et al., 2009, 2014b; von Glasow et al., 2009; Kelly et al., 2013) have focussed on catalytic reaction cycles as additional sources for $\mathrm{BrO}$ production in later stages of volcanic plume evolution, at temperatures closer to that of ambient air. The basis for this chemistry is believed to be heterogeneous chemistry occurring on sulphate aerosol. This process is similar to the so-called "bromine explosion" (Platt and 15 Lehrer, 1997; Wennberg, 1999) that was identified in the polar regions. The net reaction of the cycle consists of a rapid and strong production of $\mathrm{BrO}$. Ozone molecules are destroyed during this cycle. The environment, where the chemical cycle takes place, needs to have a $\mathrm{pH}<7$ (Fickert et al., 1999). In a volcanic plume, this is possible because of the presence of acidic aerosols, such as sulphate aerosols. It is expected that 20 the $\mathrm{BrO}$ production increases with the total surface area of the aerosols.

The previous numerical modelling studies describing halogen chemistry in volcanic plumes (Bobrowski et al., 2007; Roberts et al., 2009, 2014b; von Glasow, 2010; Kelly et al., 2013) focused on the local volcanic chemistry within the plume in a zero or onedimensional framework. The same thermodynamic model is used in the initialisation of the atmospheric chemistry models in these studies (Bobrowski et al., 2007; Roberts et al., 2009; von Glasow, 2010) to describe the high temperature mixtures of air and volcanic gases. This model is the "HSC Chemistry" software, described in more detail by Martin et al. $(2006,2009)$ following initial work by Gerlach (2004) for a volcanic emission. The model studies initialised using HSC show a rapid increase in $\mathrm{BrO}$ within
GMDD

Towards a

representation of halogens in volcanic

plumes

L. Grellier et al.

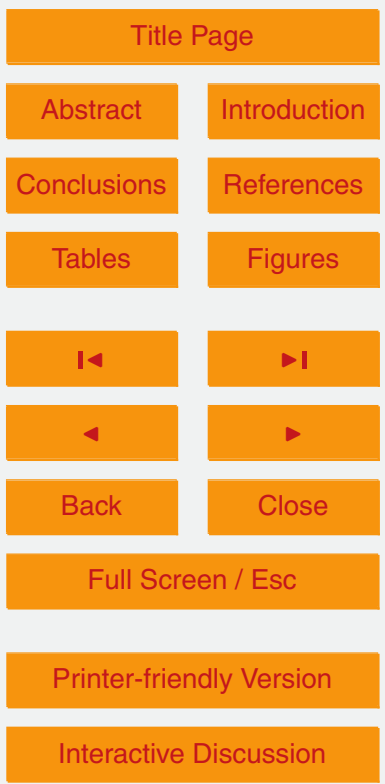


the plume in the few minutes after an emission, and a consequent ozone decrease. The numerical models compare better to plume observations of $\mathrm{BrO}$ than simulations run without initialisation using the HSC model, showing the need to include chemical reactions at high (close to the vent) temperature to accelerate the onset of the BrO 5 formation chemistry cycles at ambient temperature (within the plume).

All previous studies on the volcanic plume chemistry were at the plume scale. However, because $\mathrm{BrO}$ is not soluble it can be transported more easily, and therefore it is also interesting to study its effect at a larger scale. It is necessary to use a 3-D atmospheric chemistry model to examine this impact. However, the grid-size used in global atmospheric chemistry models (few $100 \mathrm{kms}$ ) is typically much larger than the spatial scale of the near-vent and near-downwind plume. Therefore, as a first step, the objective of this study consists of proposing and evaluating a representation of the halogen chemistry within volcanic plumes suitable for a 3-D model. Chemical transport models (CTMs) are commonly used to simulate tropospheric and stratospheric chemistry at the global or regional scales. Thus, the objective of future work is to estimate the impact of halogens produced by volcanoes on the global troposphere and stratosphere, using a CTM with a suitable representation of halogen chemistry in volcanic plumes. These objectives in the CTM framework are therefore different from those within previous studies that aimed at modelling the details of the chemical evolution in the plume the emission period and in the first used in global CTMs, there is no possibility to represent such detailed plume chemistry. What is important is the ability of the model to produce the effect of the plume on its environment at the regional scale.

To facilitate the introduction of a volcanic plume reactive halogen source into a CTM, 25 the tool used in this paper is a 1-D model (in the vertical dimension), with no transport, based on the 3-D CTM MOCAGE. It allows us to study in greater detail the sensitivity of the model simulations to the many different parameters, in order to determine the best configuration to be used in a 3-D framework in a following study. The chemical scheme used in MOCAGE represents the main chemical species and chemical cycles
GMDD

Towards a

representation of halogens in volcanic

plumes

L. Grellier et al.

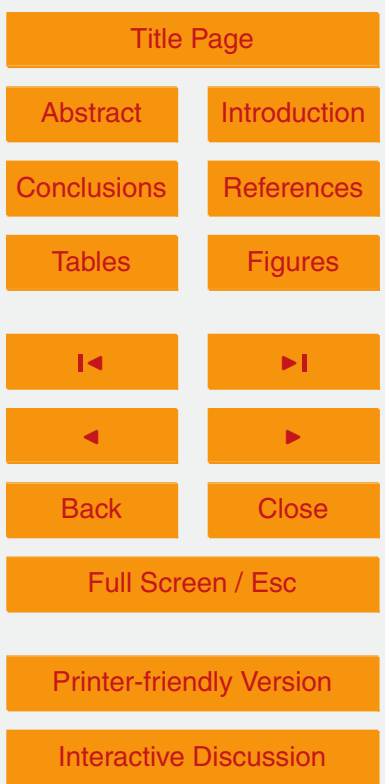


that occur in the atmosphere including the bromine chemistry. Heterogeneous chemical reactions on sulphate aerosols were added in order to fully represent the bromine cycle within volcanic plumes.

Following previous studies and in order to represent the processes which occur 5 within the plume, we use a thermodynamic model in our simulations to represent the composition of the volcanic plume after the air-magmatic gas mixing at high temperature. Sensitivity simulations on input parameters of this thermodynamic model will be presented. The heterogeneous chemistry depends on the surface area of the sulphate aerosols that is in turn linked to the size of the aerosols. Tests have been conducted to 10 evaluate the sensitivity of the chemistry to the average size of the aerosols. In our 1-D study, we examine two different horizontal model resolutions for MOCAGE, typically used for the regional and global studies. These typical MOCAGE horizontal resolutions are larger than the volume that was considered in previous modelling studies (Bobrowski et al., 2007; Roberts et al., 2009; von Glasow, 2010). These resolutions are also larger than the typical volcano plume size during the first few hours after its emission. With this difference between the model grid size and plume volume, the model may not be able to properly represent the impact of the volcanic eruption or degassing in such cases where a small volume is emitted. Therefore, a parameterization has been developed with the aim to represent the plume scale where emissions occur within MOCAGE. Sensitivity tests have been done for this parameterization.

In Sect. 2, a description of the volcanic eruption studied in this paper is made, and we describe the emission data used for the simulations. Then the numerical model is presented in Sect. 3, and in particular the bromine chemical mechanism important for the study of a volcanic plume. The different simulations are described in Sect. 4.
GMDD

$7,2581-2650,2014$

Towards a

representation of halogens in volcanic

plumes

L. Grellier et al.

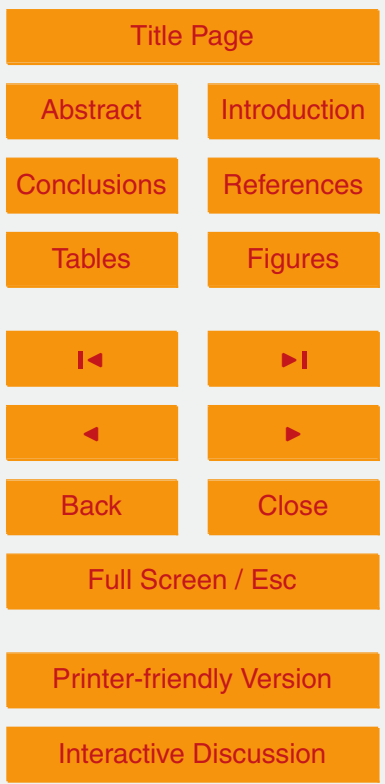




\section{Case study: Etna eruption of 10 May 2008}

\subsection{General description}

Mount Etna is the most active volcano in Europe and among the largest point sources of volcanic volatiles on the planet (Aiuppa et al., 2008). Gases and aerosols and possibly 5 volcanic ash are continually emitted by the craters by passive or explosive degassing. Four craters are currently hosted on the volcano summit; the volcano itself has a total surface area of 1200 square kilometres and the mean altitude of the volcanic plateau is at $3300 \mathrm{~m}$ of altitude.

This study focuses on the eruption of Mount Etna that occurred on the 10 May 2008 10 (see Bonaccorso et al., 2011, for more information about this eruptive event). There are three reasons for the choice of this volcano. The first reason is the fact that Mount Etna is one of the largest known emission sources of halogens (Aiuppa et al., 2005). In their paper, Aiuppa et al. (2005) conducted filter-pack measurements of the near-vent Etna's crater plume during January and October 2004, and showed an enhancement of four orders of magnitude in the bromine concentrations within the volcanic plume relative to background air. Etna volcano is also continuously and extensively monitored by INGV (Istituto Nazionale di Geofisica e Vulcanologia), and therefore a variety of gas composition information is available. These data are used to simulate the eruption with the numerical model. The third reason is that satellite observations have been made above the Etna region, close in time of the eruption. In the Supplement of Hörmann and al. (2013), the tropospheric columns of BrO have been retrieved from GOME-2 instrument one day after the eruption of 10 May 2008.

The eruption on the 10 May 2008 that we study started at 14:15 UTC and lasted until 18:15 UTC (from monitoring reports of INGV-Osservatorio Etneo; available at www.ct.ingv.it). The eruptive cloud was injected up to $5 \mathrm{~km}$ in height. The time-averaged $\mathrm{SO}_{2}$ daily release on the day of the eruption was evaluated at 10000 tonnes (obtained averaging results of car traverses made with an Ocean Option USB2000 + spectrometer and DOAS retrieval technique). During May 2008, passive emissions from the

Towards a

representation of halogens in volcanic

plumes

L. Grellier et al.

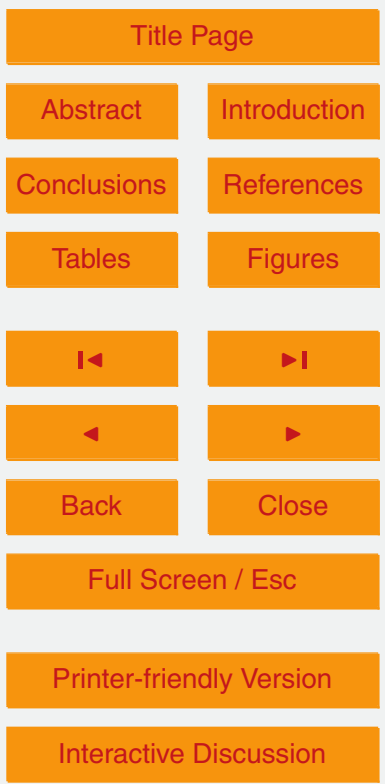


volcano contributed an average of 2000 tonnes of $\mathrm{SO}_{2}$ per day (from monitoring reports of INGV-Osservatorio Etneo; available at www.ct.ingv.it and from G. Salerno, personal communication, 2013).

\subsection{Gas composition of the eruptive plume}

5 The composition of the gas plume released by Etna has extensively been characterised in recent years by both in-situ (e.g. Aiuppa et al., 2007, 2008) and remote sensing (Allard et al., 2005) techniques. These studies have shown that, as for volcanic gas emissions in general (Oppenheimer, 2003), Etna's magmatic volatiles are dominated by $\mathrm{H}_{2} \mathrm{O}, \mathrm{CO}_{2}$ and $\mathrm{SO}_{2}$, in proportions varying both in time (depending on activity state)

10 and space (e.g. from crater to crater). Etna's magmatic gases also include smaller amounts of halogen species ( $\mathrm{HCl}, \mathrm{HF}$ and $\mathrm{HBr}$ ). Upon emission into the atmosphere, magmatic volatiles are mixed with ambient air, so that the final composition of the plume will ultimately reflect both the magmatic conditions at source and the extent of mixing and dilution with atmospheric gases.

15 Remote sensing techniques (e.g., Fourier-Transform Infrared Spectroscopy, FTIR), that can be operated from more distal - safer - locations, are inherently more appropriate to investigate the compositional gas features during eruptions. Passive open-path FTIR, in particular, has often been used to study the chemistry of gas jets propelled by lava fountains at Etna (Allard et al., 2005). Unfortunately, no similar data are avail20 able for the 10 May 2008 eruptive episode. Even more importantly, bromine (the main target of the present work), which is thought to be emitted by magmatic systems in the $\mathrm{HBr}$ form (Gerlach, 2004), is systematically below the detection threshold of FTIR. No report of near-downwind volcanic $\mathrm{BrO}$ (the product of $\mathrm{HBr}$ oxidation; Oppenheimer et al., 2006; Bobrowski et al., 2007) is available during Etna paroxysms. Passive (non25 eruptive) Br emissions from volcanoes can, however, be satisfactorily derived by direct sampling of both fumaroles (Gerlach, 2004) and plumes (Aiuppa et al., 2005).

The magmatic gas composition for the Etna's eruption for the 10 May 2008 is not available. Therefore, we use the magmatic gas composition for the Etna's passive
GMDD

7, 2581-2650, 2014

Towards a

representation of

halogens in volcanic

plumes

L. Grellier et al.

Title Page

Abstract

Conclusions

Tables Introduction References Figures

14

4

Back

Full Screen / Esc

Printer-friendly Version

Interactive Discussion $\rightarrow 1$

ose 
plume (Table 1), derived on 14 May 2008 by a combination of techniques (MultiGAS for $\mathrm{H}_{2} \mathrm{O}, \mathrm{CO}_{2}$ and $\mathrm{SO}_{2}$ and filter packs for halogens; see Aiuppa et al., 2005, 2007, 2008 for analytical details), as an analogue for the 10 May 2008 eruptive plume composition. This assumption, which is implicitly inaccurate, is motivated by the hydraulic continuity 5 between the central craters (where passive emissions concentrate) and the South-East crater (the eruptive vent), for which there is now plenty of seismic (Patanè et al., 2003), gas (Aiuppa et al., 2010) and infrasonic (Marchetti et al., 2009) evidence. We still admit that more quantitative information on $\mathrm{Br}$ content in eruptive plumes from Etna would be necessary to better initialize the model.

10 The first interaction between the ambient air and the magmatic gases occurs at high temperature $\left(1100^{\circ} \mathrm{C}>T>500^{\circ} \mathrm{C}\right)$, as the magmatic gases begin to mix with background air in the near-vent plume. The chemistry occurring in this high temperature near-vent plume environment differs from that at ambient atmospheric temperatures, e.g. it includes thermal dissociative reactions, generating oxidised species and radi-

cals. New chemical species that are believed to be produced in the near-vent plume include $\mathrm{HO}_{\mathrm{x}}, \mathrm{Cl}_{\mathrm{x}}, \mathrm{Br}_{\mathrm{x}}$ and $\mathrm{NO}_{\mathrm{x}}$. We represent this process using a thermodynamic equilibrium model software (HSC is a thermodynamic model software (HSC; Outokumpo, Finland), following studies of Gerlach, 2004; Martin et al., 2006, 2009, and Roberts et al., 2014b). HSC computes the equilibrium composition of the near-vent plume after pute this high-temperature gaseous composition are: (i) the temperature of the plume mixture (calculated from the temperatures of the magmatic gases and ambient temperature); (ii) the magmatic gas composition and (iii) the volumetric mixing ratio $V_{\mathrm{M}} / V_{\mathrm{A}}\left(V_{\mathrm{M}}\right.$ : magmatic gas volume, $V_{\mathrm{A}}$ : atmospheric gas volume). A degassing pressure of $1 \mathrm{~atm}$ is commonly assumed. In this study we use two $V_{\mathrm{M}} / V_{\mathrm{A}}$ ratios (discussed in Sect. 4.3).

Thus, with the magmatic composition information and the HSC model at high temperature, the plume composition at vent can be calculated. The outputs of HSC become the input emissions needed by MOCAGE to simulate the chemical reactions at lower temperature, occurring within volcanic plumes.
GMDD

Towards a

representation of halogens in volcanic

plumes

L. Grellier et al.

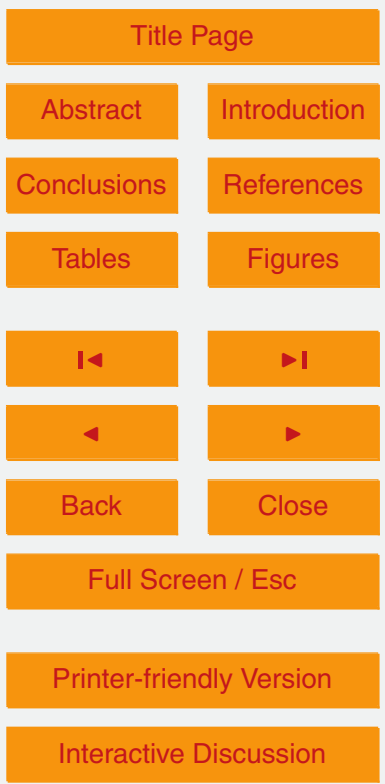




\section{Model description}

\subsection{General description of MOCAGE}

\subsubsection{1-D model for the simulations}

The numerical model used for the simulations is a 1-D configuration of MOCAGE 5 (Model Of atmospheric Chemistry At larGE scale). A number of aspects of the 1-D model are similar to MOCAGE. The vertical splitting of the atmosphere in the 1-D simulations is similar to the splitting defined in MOCAGE. The vertical resolution is divided in 47 levels. It starts from the ground up to about $5 \mathrm{hPa}$. Seven levels are within the planetary boundary layer, 20 are in the free troposphere and 20 in the stratosphere. These levels use the sigma hybrid coordinate: near the surface the levels follow the topography and the higher levels follow isobars.

The chemical reactions present in the 1-D model are the same as for MOCAGE. There are the chemical reactions in both the troposphere and the stratosphere. To describe this chemistry, the model uses two schemes: REPROBUS, which describes the posphere (Stockwell et al., 1997). With the two schemes gathered, the model contains 118 species. There are 375 chemical reactions describing mainly the homogeneous reactions, but also the photolysis and some heterogeneous reactions. The rates of destruction and production of the chemical species linked to the chemical reactions are calculated every $15 \mathrm{~min}$.

\subsubsection{3-D model for the initial conditions}

The initial atmospheric conditions of the 1-D simulations are determined using output from the 3-D MOCAGE: a multi-scale Chemical Transport Model (CTM), computing the chemical state in the atmosphere for several horizontal resolutions (see Josse et al., 2004; Bousserez et al., 2007, for further details). MOCAGE is forced using

Towards a

representation of halogens in volcanic

plumes

L. Grellier et al.

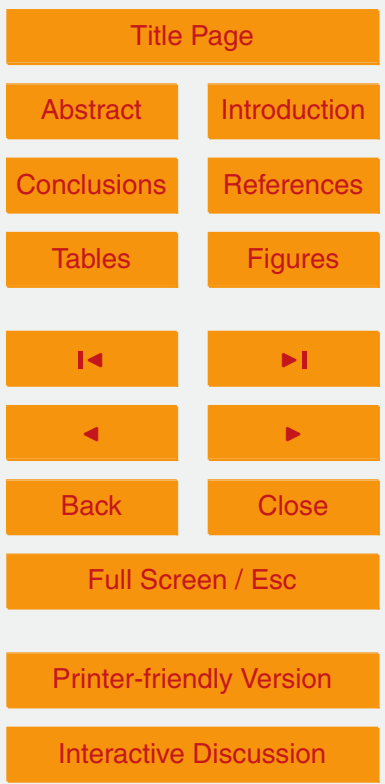


meteorological data from ARPEGE, an operational numerical weather prediction model (Courtier et al., 1991).

The 3-D MOCAGE simulations calculating the initial conditions for the 1-D sensitivity study presented here take into account different physical processes. The large scale

5 transport uses the semi-lagrangian advection scheme proposed by Williamson and Rasch (1989). For the convective transport, the numerical model uses the scheme of Bechtold et al. (2001). The species are diffused by the turbulent mixing in the planetary boundary layer (PBL) as described by the scheme of Louis (1979). Different parameterizations are used to describe the wet and dry depositions. The parameterization of Wesely (1989) is for the dry deposition. Wet deposition by convective and large scale precipitation is based on Mari et al. (2000), Giorgi and Chameides (1986) and Liu et al. (2001). The physical time step (transport, deposition, washout) is one hour.

\subsection{Halogen chemistry}

\subsubsection{Chemical overview}

15 The halogen cycle leading to the BrO production within a volcanic plume is similar to the so-called bromine explosion. This cycle is described in detail in Roberts et al. (2009), Oppenheimer et al. (2006), Platt and Hönninger (2003), and Bobrowski et al. (2007). Hereafter, there is a rapid description of the chemical reactions involved in this chemical cycle.

20 Volcanic emissions contain halogen species and in particular $\mathrm{HBr}$ and $\mathrm{HCl}$. $\mathrm{HBr}$ provides the bromine atoms needed to initiate the cycle. The other halogen species $\mathrm{HCl}$, also contributes to bromine chemistry through heterogeneous reactions. $\mathrm{HBr}$ is oxidised by $\mathrm{OH}$ radicals, present in the volcanic plume (Reaction $\mathrm{R} 1$ ). Br then reacts with $\mathrm{O}_{3}$ to produce $\mathrm{BrO}$ (Reaction $\mathrm{R} 2$ ). BrO reacts to produce the species $\mathrm{HOBr}$ and

$25 \mathrm{BrONO}_{2}$ via Reactions (R3) and (R4). These two species are involved in heterogeneous reactions on sulphate aerosols, Reactions (R5a), (R5b), (R6a) and (R6b). Sulphate aerosols are also present in volcanic plumes. They provide the surface substrate

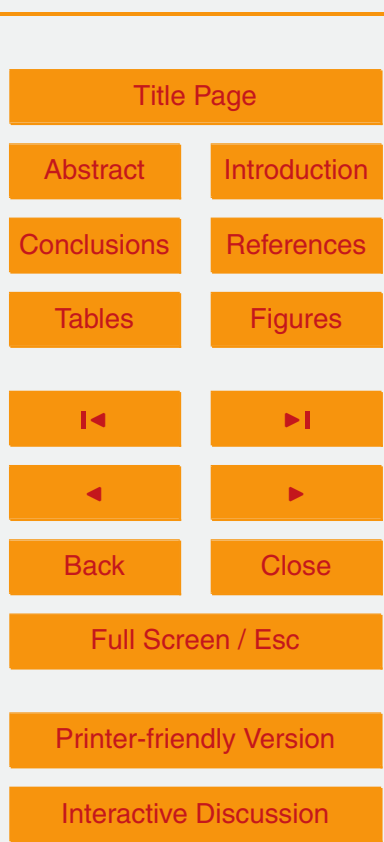

Towards a

representation of

halogens in volcanic

plumes

L. Grellier et al. 
where the heterogeneous reactions can take place.

$$
\mathrm{HBr}+\mathrm{OH} \rightarrow \mathrm{Br}+\mathrm{H}_{2} \mathrm{O}
$$

$$
\mathrm{Br}+\mathrm{O}_{3} \rightarrow \mathrm{BrO}+\mathrm{O}_{2}
$$

$\mathrm{BrO}+\mathrm{HO}_{2} \rightarrow \mathrm{HOBr}+\mathrm{O}_{2}$

$5 \mathrm{BrO}+\mathrm{NO}_{2} \rightarrow \mathrm{BrONO}_{2}$

$\mathrm{HOBr}+\mathrm{HBr}$ (sulphate aerosol) $\rightarrow \mathrm{Br}_{2}+\mathrm{H}_{2} \mathrm{O}$

$\mathrm{HOBr}+\mathrm{HCl}$ (sulphate aerosol) $\rightarrow \mathrm{BrCl}+\mathrm{H}_{2} \mathrm{O}$

$\mathrm{BrONO}_{2}+\mathrm{HBr}$ (sulphate aerosol) $\rightarrow \mathrm{Br}_{2}+\mathrm{HNO}_{3}$

$\mathrm{BrONO}_{2}+\mathrm{HCl}$ (sulphate aerosol) $\rightarrow \mathrm{BrCl}+\mathrm{HNO}_{3}$

The notation for the heterogeneous reactions of " $\mathrm{HBr}$ (sulphate aerosol)" and " $\mathrm{HCl}$ (sulphate aerosol)" means that the sulphate aerosol surface is needed for $\mathrm{HBr}$ and $\mathrm{HCl}$ in the gaseous phase to react.

15 The heterogeneous Reactions (R5a) and (R5b) (resp. Reactions R6a and R6b) are in competition with one another, as they represent the same reaction (reactive uptake of $\mathrm{HOBr}$ and $\mathrm{BrONO}_{2}$, respectively) but with alternative products. $\mathrm{Br}_{2}$ is a product of both heterogeneous Reactions (R5a) and ( $\mathrm{R} 6 \mathrm{a}) . \mathrm{Br}_{2}$ is photolysed to provide $\mathrm{Br}$ radicals (Reaction R7) and then these radicals react with $\mathrm{O}_{3}$. The same process occurs with $20 \mathrm{BrCl}$, which is photolysed and produces $\mathrm{Br}$ and $\mathrm{Cl}$ radicals (Reaction $\mathrm{R} 8$ ). The two last reactions, Reactions (R9) and (R10), convert $\mathrm{Br}$ to $\mathrm{HBr}$ and start again the cycle.

$\mathrm{Br}_{2}+h v \rightarrow 2 \mathrm{Br}$

$\mathrm{BrCl}+h v \rightarrow \mathrm{Br}+\mathrm{Cl}$

25

$\mathrm{Br}+\mathrm{O}_{3} \rightarrow \mathrm{BrO}+\mathrm{O}_{2}$

$\mathrm{HCHO}+\mathrm{Br} \rightarrow \mathrm{HO}_{2}+\mathrm{CO}+\mathrm{HBr}$

$\mathrm{Br}+\mathrm{HO}_{2} \rightarrow \mathrm{HBr}+\mathrm{O}_{2}$

Initially the heterogeneous reactions preferentially produce $\mathrm{Br}_{2}$ (Reactions $\mathrm{R} 5 \mathrm{a}$ and

$\mathrm{R} 6 \mathrm{a})$ rather than $\mathrm{BrCl}$ (Reactions $\mathrm{R} 5 \mathrm{~b}$ and $\mathrm{R6b}$ ) (Roberts et al., 2009). This leads

Towards a

representation of

halogens in volcanic

plumes

L. Grellier et al.

Title Page

Abstract

Introduction

Conclusions

Tables

Figures

14

4

Back

Close

Full Screen / Esc

Printer-friendly Version

Interactive Discussion 
to autocatalytic BrO formation: Reactions (R3), (R5a), (R7) and $2 \times(\mathrm{R} 2)$ can be condensed into a cycle whereby one molecule of $\mathrm{BrO}$ can produce two molecules of $\mathrm{BrO}$ and the loss of one molecule of $\mathrm{HBr}$. This consequently consumes two molecules of ozone. The net reaction of this cycle is given by:

$5 \mathrm{BrO}+\mathrm{HO}_{2}+\mathrm{HBr}$ (sulphate aerosol) $+2 \mathrm{O}_{3} \rightarrow 2 \mathrm{BrO}+3 \mathrm{O}_{2}+\mathrm{H}_{2} \mathrm{O}$

Condensing Reactions (R4), (R6a), (R7) and $2 \times(\mathrm{R} 2)$ leads to the same results.

$\mathrm{BrO}+\mathrm{NO}_{2}+\mathrm{HBr}$ (sulphate aerosol) $+2 \mathrm{O}_{3} \rightarrow 2 \mathrm{BrO}+3 \mathrm{O}_{2}+\mathrm{HNO}_{3}$

When $\mathrm{HBr}$ concentrations decrease, $\mathrm{BrCl}$ becomes the dominant product and Reactions (R5b) and (R6b) start to predominate over Reactions (R5a) and (R5b). However, 10 in this case only one molecule of $\mathrm{BrO}$ is produced - the reaction scheme is no longer autocatalytic.

Once BrO formation has commenced, rapid cycling of reactive bromine via Reactions (R2)-(R8) can thereby induce substantial ozone loss. In addition, the self-reaction of $\mathrm{BrO}$ to yield $2 \mathrm{Br}$ radicals Reaction (R13) followed by Reaction (R2) to re-form $\mathrm{BrO}$ 15 presents a further ozone-loss pathway.

$\mathrm{BrO}+\mathrm{BrO} \rightarrow 2 \mathrm{Br}+\mathrm{O}_{2}$

The reaction rate of $\mathrm{HOBr}$ and $\mathrm{BrONO}_{2}$ on the aerosol surface (Reactions $\mathrm{R} 5$ and $\mathrm{R} 6$ ) is given by the following equation:

$-\frac{\mathrm{d}[A]}{\mathrm{d} t}=\gamma \cdot \frac{C_{\mathrm{rel}}}{4} \cdot S_{\text {aerosol }} \cdot[A]$

Where the parameter $\gamma$ is the uptake coefficient and it is defined for each heterogeneous reaction. $C_{\text {rel }}$ is the average velocity of species $A\left(\mathrm{~cm} \mathrm{~s}^{-1}\right)$ described by the following equation: $C_{\text {rel }}=\sqrt{\frac{8 R T}{\pi M}}$, with $R$ gas constant, $T$ is the temperature and $M$ is the 2594
GMDD

$7,2581-2650,2014$

Towards a

representation of

halogens in volcanic

plumes

L. Grellier et al.

Title Page

Abstract

Introduction

Conclusions

Tables

References

Figures

14

4

Back

Close

Full Screen / Esc

Printer-friendly Version

Interactive Discussion $\rightarrow 1$ 
molar mass of the species. $[A]$ is the concentration of the species $\mathrm{A}$ (molecules cm ${ }^{-3}$ ). $S_{\text {aerosol }}$ is the surface area (aerosols surface. $\mathrm{cm}^{-3}$ of air) of the aerosols. The rate constant of the heterogeneous reactions is therefore written as:

$k=\gamma \cdot \frac{C_{\text {rel }}}{4} \cdot S_{\text {aerosol }}$

An important parameter in the rate constant equation is the surface area $\left(S_{\text {aerosol }}\right)$. This surface area depends on several variables. The aerosols are assumed to have a spherical shape. In this case, their surface is given by:

${ }_{10} S_{\text {aerosol }}=4 \cdot \pi \cdot r^{2} \cdot N_{\text {DROP }}$

Where $r$ is the mean radius of aerosol $(\mathrm{cm})$ and $N_{\text {DROP }}$ is the number of droplets by unit of volume. The expression of the number of droplets by unit of volume is calculated by the following equation:

$N_{\text {DROP }}=\frac{3 \cdot V_{\text {aerosol }}}{4 \cdot \pi \cdot r^{3}}$

$V_{\text {aerosol }}$ is the aerosol volume (per $\mathrm{cm}^{3}$ of air). The sulphate aerosols within a volcanic plume are distributed over a range of sizes that vary for each volcanic emission. Since there is a large uncertainty on the characteristics of the aerosol size distribution and because the final aim is to perform a global study of the volcanic emission where computational constraints become a concern, we choose a constant value for the mean radius leading to a simplification of the calculation of the total aerosol surface area. A few studies give an estimate of the value of the sulphate aerosol radii within Mount Etna plumes (Watson and Oppenheimer, 2000, 2001; and Spinetti and Buongiorno, 2007). The size of the aerosols depends on the environmental conditions and the characteristics of the emission. Watson and Oppenheimer (2000) measure a mean effective radius of $0.83 \mu \mathrm{m}$ during mild strombolian activity of Mount Etna in October 1997. Another 2595
GMDD

$7,2581-2650,2014$

Towards a

representation of

halogens in volcanic

plumes

L. Grellier et al.

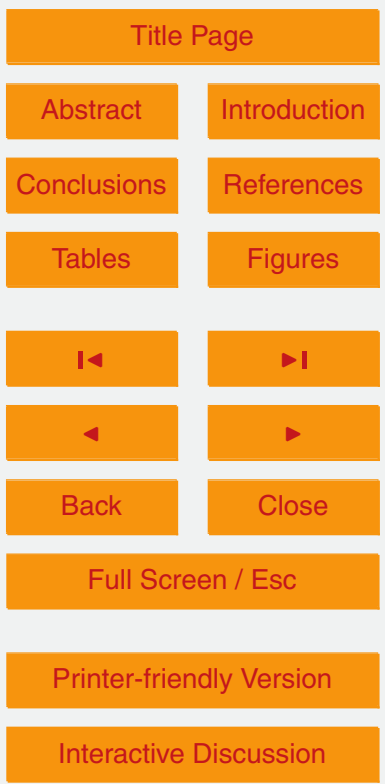


study by Watson and Oppenheimer (2001) shows results of $1 \mu \mathrm{m}$ for the mean effective radius during an activity period at Mount Etna in July 1999 including passive and eruptive emissions. Spinetti and Buongiorno (2007) studied two emission periods of Mount Etna: quiescent (June 1997) and eruptive (July 2001) periods. The data showed 5 small particles for the quiescent plume, with radii around $1 \mu \mathrm{m}$ and for the explosive plume, larger particles with typical radii $>1 \mu \mathrm{m}$. In our case of an eruptive emission, we choose a mean radius of $2 \mu \mathrm{m}$, consistent with the Spinetti and Buongiorno (2007) observations. Since there is a large uncertainty on this parameter, sensitivity tests are presented in Sect. 5.

10 An important variable controlling the total surface area is the composition of the aerosols since this composition has an impact on the aerosol volume, and hence the radius. For this study, it is assumed that the aerosols are composed of only two species: $\mathrm{H}_{2} \mathrm{O}$ and $\mathrm{H}_{2} \mathrm{SO}_{4}$ in aqueous phase (sulphate aerosol). The ratio of sulphuric acid to $\mathrm{H}_{2} \mathrm{O}$ inside the aerosol droplet is called the sulphuric acid weight fraction, and this also determines the volume of the sulphuric acid at a given temperature and water activity.

The sulphuric acid weight fraction takes part in the calculation of the rate coefficient of the Reactions (R5a), (R5b), (R6a) and (R6b) through the volume expression (Eq. 5) then via the radius $r$ (Eq. 4) to obtain the surface area expression (Eq. 3). Aerosol volume (per $\mathrm{cm}^{3}$ of air) is given by the following equation:

${ }_{20} \quad V_{\text {aerosol }}=\frac{N_{\mathrm{S}} \times M_{\mathrm{S}}}{W_{\mathrm{S}} \times \rho\left(W_{\mathrm{S}}\right)}$

$N_{\mathrm{S}}$ is the number of moles per $\mathrm{cm}^{3}$ of sulphuric acid aerosol in each model grid box. This includes $\mathrm{H}_{2} \mathrm{SO}_{4}$ produced via gas-phase oxidation of $\mathrm{SO}_{2}$ as a consequence of ambient plume chemistry, but is dominated by the "direct" volcanic emission, determined by output from the HSC model of the near-vent high-temperature chemistry. Elevated $\mathrm{SO}_{3}$ (and to a lesser extent $\mathrm{OH}$ ) in the $\mathrm{HSC}$ output lead to a volcanic $\mathrm{H}_{2} \mathrm{SO}_{4}$ emission. In addition to this volcanic contribution the total model sulphate includes the background sulphate of MOCAGE. $M_{\mathrm{S}}\left(98 \mathrm{~g} \mathrm{~mol}^{-1}\right)$ is the molar mass of sulphuric acid. 2596
GMDD

7, 2581-2650, 2014

Towards a

representation of

halogens in volcanic

plumes

L. Grellier et al.

Title Page

Abstract

Introduction

Conclusions

Tables

References

Figures

14

4

Back

Close

Full Screen / Esc

Printer-friendly Version

Interactive Discussion $\rightarrow$ 
$\rho$ is the density of the total aerosol $\left(\mathrm{g} \mathrm{cm}^{-3}\right) . W_{\mathrm{S}}$ is the sulphuric acid weight fraction in an aerosol.

In volcanic aerosol studies, in the stratosphere, the acid weight fraction is equal to about $75 \%$ (Chazette et al., 1995; Stothers, 2001). For volcanic eruptions not reaching the stratosphere or for passive emissions, the plume remains mainly in the troposphere. In this part of the atmosphere, the meteorological conditions are different than in the stratosphere and a value of $75 \%$ cannot be applied. Tabazadeh et al. (1997) presented a method to calculate the sulphuric acid content aerosol within an aerosol, i.e. the sulphuric acid weight percentage. The weight fraction depends on the water activity, which varies with the partial pressure and the temperature. The acid weight fraction is less important close to the ground due to the high relative humidity and temperature, which both decrease with altitude, whilst the weight fraction increases. Thus, there is a higher total aerosol volume (hence also surface area) in these lower levels, favouring heterogeneous reactions.

\subsubsection{Chemistry of MOCAGE}

The heterogeneous reactions of the bromine explosion cycle (Reactions R5a, R5b, R6a and R6b), occurring within a volcanic plume, are not present within the chemical schemes of MOCAGE. For the need of this study, we added these four heterogeneous reactions within the chemical scheme. In MOCAGE, $\mathrm{Br}_{2}$ is not explicitly represented because it is a very short-lived species. The chemical reactions, involving $\mathrm{Br}_{2}$ take place too rapidly to be described in a simulation time step. To overcome this issue, $\mathrm{Br}_{2}$ is assumed to be directly photolysed producing $\mathrm{Br}$. In MOCAGE, $\mathrm{BrO}$ and $\mathrm{Br}$ are gathered in the $\mathrm{BrO}_{x}$ species. Thus the heterogeneous Reactions (R5a) and (R6a), produce directly $\mathrm{BrO}_{x}$ instead of $\mathrm{Br}_{2}$. The cycle passes from the Reactions (R5a) and (R6a) directly to Reaction (R8). During the night the reservoir of the $\mathrm{BrO}_{x}$ family becomes $\mathrm{BrO}$ including also $\mathrm{Br}_{2}$ indirectly.

GMDD

Towards a

representation of halogens in volcanic

plumes

L. Grellier et al.

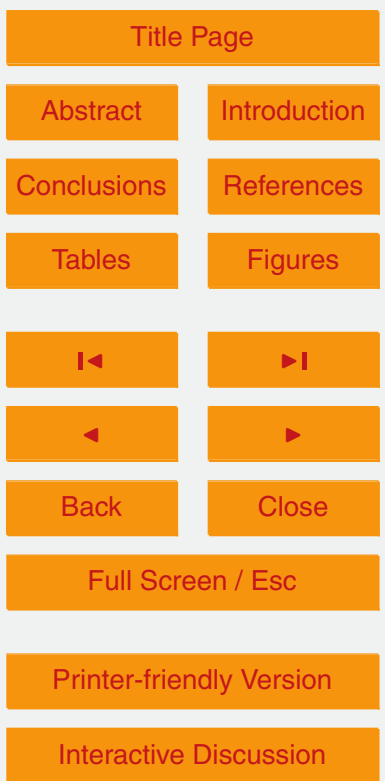


The same rate constant equation (Eq. 2) is used for all the heterogeneous reactions of the halogen cycle (Reactions R5a, R5b, R6a and R6b), with the uptake coefficients $\gamma$ assumed to be high (accommodation-limited) due to the very high aerosol acidity. This follows Roberts et al. (2009) although recent work (Roberts et al., 2014a) has 5 proposed a re-evaluation of $\mathrm{HOBr}$ kinetics in acidic environments. Five other heterogeneous reactions are presented in Roberts et al. (2009) involving $\mathrm{HOCl}, \mathrm{ClONO}_{2}$ and $\mathrm{N}_{2} \mathrm{O}_{5}$. But because the uptake coefficient for the chemical species involved in these heterogeneous reactions is very low, they are not taken into account within the chemical scheme in MOCAGE.

10 Because Reaction (R5a) (resp. Reaction R6a) and Reaction (R5b) (resp. Reaction $\mathrm{R} 6 \mathrm{~b}$ ) are competing, branching ratios need to be defined to know the proportion of $\mathrm{Br}_{2}$ and $\mathrm{BrCl}$ produced by these reactions. After Fickert et al. (1999), the ratio of the $\mathrm{BrCl}$ on $\mathrm{Br}_{2}$ concentrations is:

$\frac{[\mathrm{BrCl}]}{\left[\mathrm{Br}_{2}\right]}=7.2 \times 10^{-5} \frac{\left[\mathrm{Cl}^{-}\right]}{\left[\mathrm{Br}^{-}\right]}$

where the terms in brackets are concentrations in molecule $\mathrm{cm}^{-3}$ of air.

In this study, we assume that the concentrations of $\mathrm{Cl}^{-}$and $\mathrm{Br}^{-}$do not depend on the concentration of the other ions in the volcanic aerosols, except $\mathrm{H}^{+}$.

$\left[\mathrm{Cl}^{-}\right]$and $\left[\mathrm{Br}^{-}\right]$can therefore be written using the effective Henry's constant for strong acids:

$\left[\mathrm{Cl}^{-}\right]=\frac{K_{\mathrm{H} . \mathrm{HCl}} \times K_{\mathrm{A} . \mathrm{HCl}}}{\left[\mathrm{H}^{+}\right]} \times R T \mathrm{~V} \times[\mathrm{HCl}]$

$\left[\mathrm{Br}^{-}\right]=\frac{K_{\mathrm{H} \cdot \mathrm{HBr}} \times K_{\mathrm{A} \cdot \mathrm{HBr}}}{\left[\mathrm{H}^{+}\right]} \times R T V \times[\mathrm{HBr}]$

where $\left[\mathrm{H}^{+}\right]$is in mol $\mathrm{L}^{-1}, R=0.082$ is the gas constant in atm. mol ${ }^{-1} \mathrm{LK}^{-1}, T$ is the atmospheric temperature, $V$ is the aerosol volume by unit volume of air, $K_{\mathrm{H} . \mathrm{X}}$ and $K_{\mathrm{A} . \mathrm{X}}$ are respectively the Henry's constant and the acidity constant of the $\mathrm{X}$ species.
GMDD

$7,2581-2650,2014$

Towards a

representation of

halogens in volcanic

plumes

L. Grellier et al.

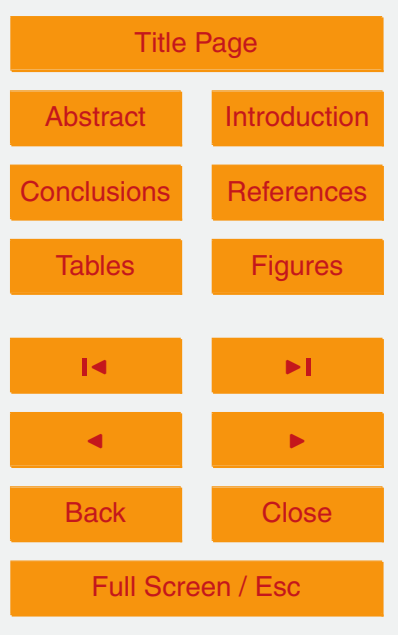

Printer-friendly Version

Interactive Discussion 
After Brimblecombe and Clegg (1988):

$K_{\mathrm{H}: \mathrm{HCl}} \times K_{\mathrm{A}: \mathrm{HCl}}=2 \times 10^{6} \mathrm{~mol}^{2} \mathrm{~L}^{-2} \mathrm{~atm}^{-1}$

$K_{\mathrm{H}: \mathrm{HBr}} \times K_{\mathrm{A}: \mathrm{HBr}}=1.3 \times 10^{9} \mathrm{~mol}^{2} \mathrm{~L}^{-2} \mathrm{~atm}^{-1}$

5 A dependency to the temperature is used with Henry's law:

$K_{\mathrm{HX}}=K_{\mathrm{H} . \mathrm{HX}} \times K_{\mathrm{A} . \mathrm{HX}} \times \exp \left(-\frac{\Delta_{\text {soln }} H_{\mathrm{HX}}}{R}\left(\frac{1}{T}-\frac{1}{298.15}\right)\right)$

$\mathrm{X}$ is $\mathrm{Br}$ and $\mathrm{Cl}, \Delta_{\text {soln }} H_{\mathrm{HX}}$ is the enthalpy of dissolution (see Sander, 1999, for more explanation).

${ }_{10}\left(\frac{\Delta_{\mathrm{soln}} H}{R}\right)_{\mathrm{HBr}}=-10000 \mathrm{~K}$ and $\left(\frac{\Delta_{\mathrm{soln}} H}{R}\right)_{\mathrm{HCl}}=-9000 \mathrm{~K}$.

This leads to:

$\frac{\left[\mathrm{Cl}^{-}\right]}{\left[\mathrm{Br}^{-}\right]}=\frac{K_{\mathrm{HCl}}}{K_{\mathrm{HBr}}} \times \frac{[\mathrm{HCl}]}{[\mathrm{HBr}]}$

and finally:

$15 \frac{[\mathrm{BrCl}]}{\left[\mathrm{Br}_{2}\right]}=7.2 \times 10^{-5} \times \frac{K_{\mathrm{HCl}} \times[\mathrm{HCl}]}{K_{\mathrm{HBr}} \times[\mathrm{HBr}]}$

$X_{\mathrm{Br}_{2}}=\frac{\left[\mathrm{Br}_{2}\right]}{\left[\mathrm{Br}_{2}\right]+[\mathrm{BrCl}]}$

$X_{\mathrm{BrCl}}=\frac{[\mathrm{BrCl}]}{\left[\mathrm{Br}_{2}\right]+[\mathrm{BrCl}]}$

In the presence of $\mathrm{HBr}$, the branching ratio favours $\mathrm{Br}_{2}$ production. When $\mathrm{HBr}$ is depleted the branching ratio will favour $\mathrm{BrCl}$ production.

Towards a

representation of

halogens in volcanic

plumes

L. Grellier et al.

Title Page

Abstract

Introduction

Conclusions

References

Tables

Figures

14

4

Back

Close

Full Screen / Esc

Printer-friendly Version

Interactive Discussion 


\section{Setup of the simulations}

\subsection{General setup of the simulations}

In order to achieve the general aim of this work to estimate the influence of the volcanic emissions on the chemical budget of the atmosphere, this study uses a one di5 mensional chemical model (vertical profile). In this way, the simulations are focused on the chemical reactions without horizontal and vertical transport. Due to the low computational cost, this one dimensional configuration allows us to make a large set of sensitivity tests on the many parameters that can modify the production and the loss of chemical species within a volcanic plume (see the list of the different simulations in 10 Table 3).

Each simulation calculates the chemical concentrations of all species in the vertical levels of the model. The initial conditions of each simulation are the same. They correspond to the 1-D profile of all the chemical species concentrations on 10 May 2008 at 14:00 UTC, extracted from the grid box that contains Mount Etna, in the 3-D MOCAGE simulation started one month before (spin-up period). The 1-D simulations are run from the 10 May 2008 at 14:00 UTC until the 11 May 2008 at 12:00 UTC, the period encompassing satellite observations, by $\mathrm{GOME}-2$, of $\mathrm{BrO}$ and $\mathrm{SO}_{2}$ in the Mount Etna plume presented in Hörmann et al. (2013) (made the morning of the day after the eruption). The results of our simulations are compared to these data. Moreover, the end time of the eruption is very close to night-time. Thus the role played by photochemistry in the plume can only be assessed when light comes back the day after (morning of the 11 May).

The 10 May 2008 eruptive plume reached 5 kilometres in height, corresponding to the 16 lowest levels of MOCAGE. The gaseous composition of the plume immediately after its exit of the crater is given in Table 1 . We assume a total eruptive $\mathrm{SO}_{2}$ output of 8000 tonnes (cumulative output of $4 \mathrm{~h}$ ). The emission is distributed over the model vertical levels evenly in such a way that the number of molecules injected at each level

Towards a

representation of

halogens in volcanic

plumes

L. Grellier et al.

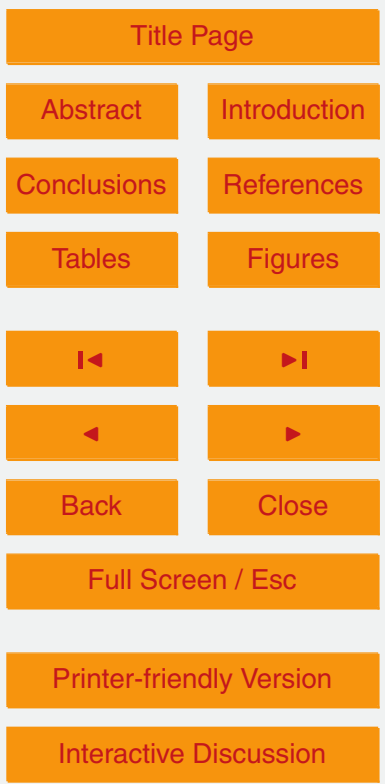


is proportional to each model grid box volume. The time step for the injection of the emissions is $15 \mathrm{~min}$.

The chemical scheme used in this model configuration is a combination of RACM and REPROBUS with the additional heterogeneous Reactions (R5a), (R5b), (R6a) and

5 (R6b). In the model grid box, the chemical time step used to reach steady state is $2.25 \mathrm{~s}$. This time step is much larger than the MOCAGE time step used in standard simulations. This is because the large emissions injected within the model grid require more calculation steps to reach chemical equilibrium. The use of a short time step increases the calculation time of each simulation compared to the standard MOCAGE setup, but, for the present one dimensional study, this is not a limitation.

We define a model configuration that corresponds to the reference simulation (called hereafter "Ref") based on the setup described above that uses the MOCAGE resolution to $0.5^{\circ} \times 0.5^{\circ}$ and the $V_{\mathrm{M}} / V_{\mathrm{A}}$ ratio in the $\mathrm{HSC}$ model to $95 / 5$. Other simulations are run with different sets of parameters, which are summarised in Table 3. Firstly, a sub-grid15 scale parameterization is tested, which calculates the emission in a smaller volume than the grid box volume. Secondly, we tested variations of the parameter $V_{\mathrm{M}} / V_{\mathrm{A}}$ in the HSC model, which results in different compositions after the mixing at high temperature. Thirdly, we investigated the impact of the MOCAGE horizontal resolution on the plume chemistry. Finally, the sensitivity to the mean radius of the sulphate aerosols 20 is tested. All the simulation characteristics are presented in Table 3 and detailed in Sects. 4.2-4.5.

\subsection{Sub-grid-scale parameterization of the plume chemistry}

The study is focused on a 1-D model, but using the characteristics of a 3-D numerical model. Thus the resolution of the horizontal grid is larger than the plume scale. 3-D chemical models resolve the chemical reactions at the grid box scale with the assumption that chemical species are homogeneously distributed within each grid box. However, within a volcanic plume, the bromine chemistry takes place within a smaller volume compared to the usual volume of MOCAGE grid boxes, with large concentrations

Towards a

representation of

halogens in volcanic

plumes

L. Grellier et al.

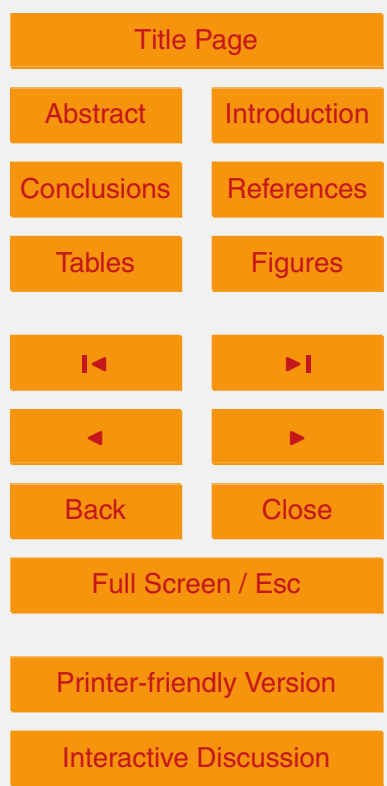


of chemical species present due to the volcanic emission. Thus, at the grid scale of global models, volcanic eruptions can be considered as a sub-grid scale phenomenon. Processes occurring at sub-grid scales are typically represented via parameterizations in atmospheric models.

5 Several studies (Karamchandani et al., 2002; Cariolle et al., 2009; Valari and Menut, 2010) proposed parameterizations designed to improve the description of sub-grid scale emissions and associated chemistry in models. They showed that such subgrid computations give a better description of the phenomenon studied. Karamchandani et al. (2002) proposed a method to investigate the sub-grid scale effects of $\mathrm{NO}_{\mathrm{x}}$ point sources on ozone formation using a Plume-in-Grid model (PiG). The principle of a PiG is to use a reactive plume model in addition to the 3-D model. This reactive plume model is a representation of three-dimensional puffs. The model estimates the transport and chemical reactions within the plume. Using this method requires running the reactive plume model in addition to the 3-D model and is therefore costly. Cari-

olle et al. (2009) parameterized the chemical reactions in aircraft plumes due to the emissions of $\mathrm{NO}_{x}$ from aircraft. They modify the relevant rate coefficients and take into account the dispersion of the plume within the model grid boxes. An introduction of additional tracers is needed with these approaches in the 3-D model. These additional variables represent the chemical state variables within the plume. Valari and Menut (2010) present a parameterization for air quality models that separates the different emissions present in the same grid box by activity sector. The computation is split for the different types of emissions at each time step of the CTM. Thus, there are variabilities due to the heterogeneous surface emissions. These three approaches cannot be applied in our case because our long-term aim is to estimate the impact of the passive and eruptive emission from all volcanoes at the global scale. Thus, the choice of the PiG and Cariolle et al. (2009) approaches would be computationally too expensive. In our case, there are at least 15 species emitted. The method used by Valari and Menut (2010) is not easily applicable to our situation since it treats of emissions with complex spatial distributions but can not treat point or column emission as in a volcanic case.
GMDD

Towards a

representation of halogens in volcanic

plumes

L. Grellier et al.

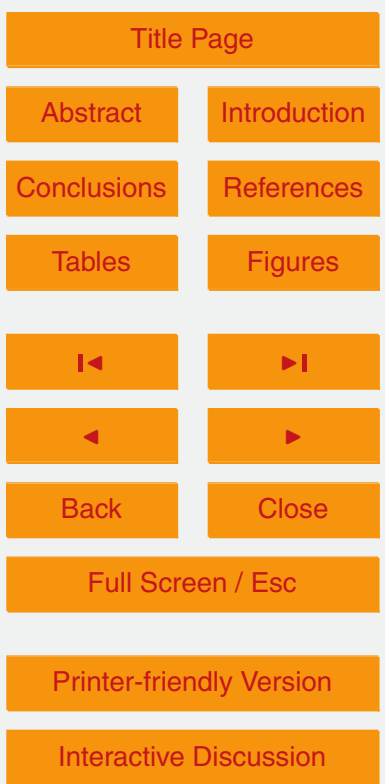


For studying the impact of volcanic eruptions or passive emissions we propose to test a simple parameterization designed to be not too computationally expensive for further use in a 3-D CTM framework.

The aim of this parameterization is to represent the chemical reactions that occur in 5 volcanic plumes. It consists of computing the chemical reactions defined by the model within a volume of $0.025^{\circ} \times 0.025^{\circ}$ (called hereafter plume box) representative of the plume, which is much smaller than the model grid volume. The first step is to include the volume fluxes of the volcanic emissions within the plume box. The second step is to calculate separately the chemical productions and losses within the model grid box 10 and within the plume box. In the third step, the volume fluxes of the chemical species calculated within the plume box are mixed with the concentrations calculated separately within the model box in the second step. Figure 1 schematizes this parameterization.

Once the second step is done we propose two possibilities before the computation of the third step. One is to mix the plume grid box and the model grid box at each model time step. In this case, it is assumed that the plume undergoes complete mixing with the model grid box every $15 \mathrm{~min}$. The name of the simulations that refer to this case of dilution is "Plume 1". The other possibility we explore is to mix the plume box with the model grid box only at the end of the eruption. This means step 1 and step 2 are calculated in parallel throughout the eruption without interaction. The third step is only undertaken at the end of the emission, the plume is diluted only at this moment. We refer to this case as "Plume 2". These two approaches correspond to two extreme assumptions for the dilution in the model grid box.

Since the concentrations of the emitted chemical compounds are very large in the plume box, a shorter time step is used in the plume box compared to that used in the model grid box. A $0.23 \mathrm{~s}$ time step is required to reach the chemical equilibrium in the plume box.
GMDD

$7,2581-2650,2014$

Towards a

representation of halogens in volcanic

plumes

L. Grellier et al.

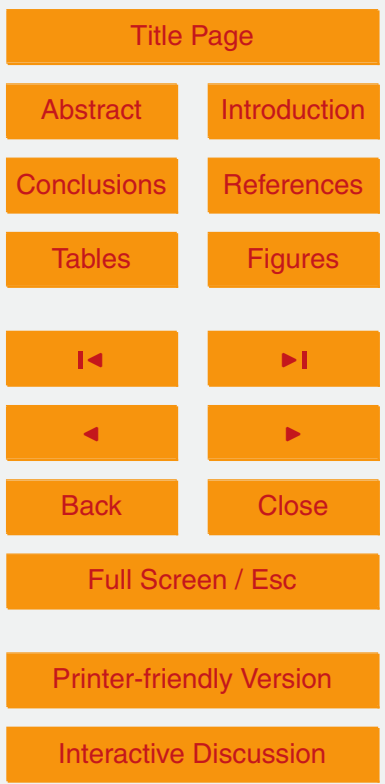




\subsection{Sensitivity to the volcanic gaseous composition}

At the moment when the magmatic gases are released from the lava, they are mixed with the atmospheric air at high temperature. During this mixing process, new chemical species are produced. This phenomenon cannot be simulated by MOCAGE because

5 the temperatures are too high. Thus, we use the HSC model to estimate this new hightemperature gas composition, which is then used as a pseudo-emission in MOCAGE.

Inputs to the HSC model include the initial gaseous composition of the plume given in Table 1 before the mixing, the gaseous atmospheric composition $\left(\mathrm{O}_{2}: 21 \%, \mathrm{~N}_{2}: 78 \%\right.$ and Argon: $1 \%)$, the temperature $\left(1100^{\circ} \mathrm{C}\right.$ following Métrich and Rutherford, 1998) and the ratio $V_{\mathrm{M}} / V_{\mathrm{A}}$. This ratio represents the percentage of the magmatic gas volume over the percentage of the atmospheric gas volume. There is no exact value for $V_{\mathrm{M}} / V_{\mathrm{A}}$. It depends of the strength of the emission, the atmospheric conditions, caldera geometry and other factors relating to the plume dimensions. Three ratios have been used in the HSC model: $95 / 5,90 / 10$ and 60/40. The compositions of the main species, calculated by HSC, are presented in Table 2 for these three ratios. In Bobrowski et al. (2007), the ratio $60 / 40$ was used to simulate the chemical reactions occurring in a volcanic plume and it gave the best results with respect to the observations they presented compared to the other ratios of $V_{\mathrm{M}} / V_{\mathrm{A}}$. But with the initial magmatic gas composition used here as input in $\mathrm{HSC}$ (see Table 1), this ratio gives a larger $\mathrm{H}_{2} \mathrm{SO}_{4}$ (sulphate aerosol) mixing ratio compared to the $\mathrm{SO}_{2}$ mixing ratio, and for this reason, the model study by Roberts et al. (2009) proposed higher $V_{\mathrm{M}} / V_{\mathrm{A}}$ (e.g. 90/10). According to reported filter-pack measurements (see discussions by Roberts et al., 2009, and von Glasow et al., 2009) the sulphate aerosol content of volcanic plumes is typically between 0.5 and $2 \%$ of the total sulphur mass emitted. Thus, Table 1 clearly shows that for the initial gaseous composition used for the eruption on the 10 May 2008, the ratio proposed by Bobrowski et al. (2007) cannot be used. The ratios $90 / 10$ and $95 / 5$ present a proportion of sulphate aerosols consistent with reported volcanic measurements showing that sulphate aerosol composes $0.5-2 \%$ of total sulphur emitted ( $0.99 \%$ and $2.0 \%$ respectively).
GMDD

7, 2581-2650, 2014

Towards a

representation of

halogens in volcanic

plumes

L. Grellier et al.

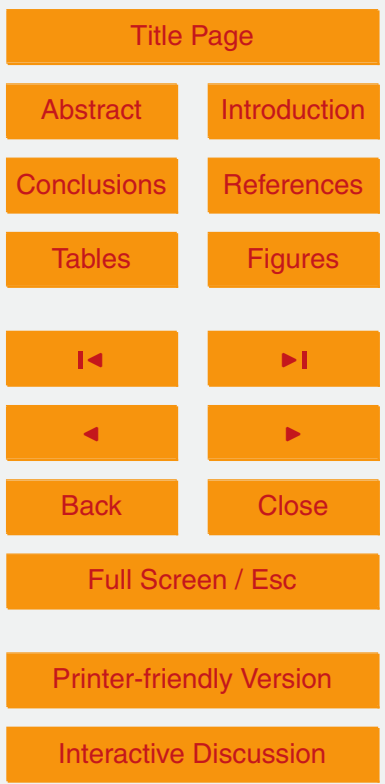


Roberts et al. (2014b) recently highlighted how a modified operation of HSC (Martin et al., 2009) causes higher $V_{\mathrm{M}} / V_{\mathrm{A}}$ to also become suitable for atmospheric model initialisation e.g. $V_{\mathrm{M}} / V_{\mathrm{A}}=95 / 5$. Here the ratio $95 / 5$ is used in the reference simulation and it is used by default. The other ratio $90 / 10$ is used in the "HSC" simulations, used 5

\subsection{Sensitivity to the model horizontal resolution}

Another sensitivity test is focused on the horizontal resolution and the behaviour of the plume chemistry within a larger model grid box. Instead of the $0.5^{\circ} \times 0.5^{\circ}$ resolution used in the simulations described previously (and typical for regional model studies), we set the MOCAGE resolution to $2^{\circ} \times 2^{\circ}$ (identified as "Res"). This is the resolution usually selected for global simulations with MOCAGE. In this case, the initial profiles of chemical species concentrations used for the simulation come from a global MOCAGE run with a $2^{\circ} \times 2^{\circ}$ horizontal resolution, started one month before the studied eruption (as in the case of Ref simulation). For this global resolution, the meteorological data, the pressure and the temperature, and the initial mixing ratio of the chemical species are averaged over a larger box than for the regional resolution $\left(0.5^{\circ} \times 0.5^{\circ}\right.$ compared to $2^{\circ} \times 2^{\circ}$ ). Their values differ from those used for the other simulations. The aim of this test is to evaluate the robustness of the results for possible further use in global simulations. The parameterization presented in Sect. 4.2 , is also tested with the $2^{\circ} \times 2^{\circ}$ resolution setup.

\subsection{Sensitivity to the sulphate aerosol radius}

The radius of the sulphate aerosol determines the effective surface area for the heterogeneous reactions. Therefore, it may have an influence on the $\mathrm{BrO}$ production cycle. Our choice for the sulphate aerosol radius for the Ref simulation is $2 \mu \mathrm{m}$ because the case studied is an eruptive emission (see justification in Sect. 3.2.1). Because of the large uncertainty on this mean radius, we perform sensitivity tests on this parameter.
GMDD

Towards a

representation of halogens in volcanic

plumes

L. Grellier et al.

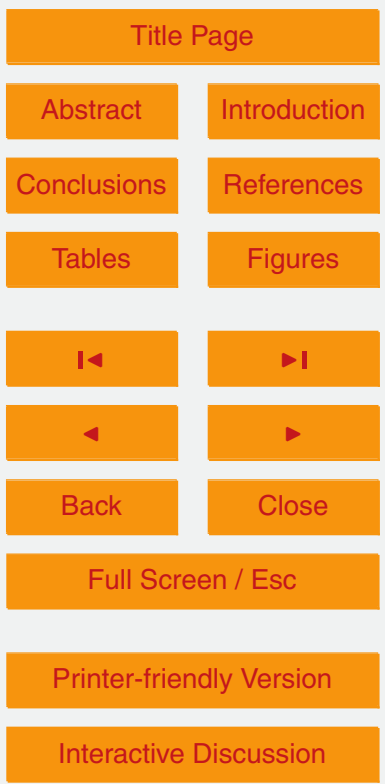


Watson and Oppenheimer (2000) summarize the particle size distributions of volcanic aerosols from several studies in their Table 1. This table presents more cases with fine particles than with coarse particles. Therefore, in these sensitivity tests, we use mean radii of 0.5 and $1 \mu \mathrm{m}$. We also tested $4 \mu \mathrm{m}$ since it too can be characteristic of eruptive 5 emissions (Spinetti and Buongiorno, 2007). These configurations are tested for the Ref and Res simulations. These simulations were all run without the plume parameterizations and with a ratio of $V_{\mathrm{M}} / V_{\mathrm{A}}=95 / 5$ in HSC.

\section{Results}

In the following sections we compare model results of the formation of reactive bromine 10 evolution from the different 1-D plume representations and emission compositions proposed to initialise the MOCAGE model (see Table 3).

\subsection{Ref simulation}

We start with the simulation called Ref where the emission is injected directly into the model grid box of $0.5^{\circ} \times 0.5^{\circ}$ resolution (emission injected over 0 and $5 \mathrm{~km}$, continuously for a $4 \mathrm{~h}$ period as for all simulations). For this Ref simulation, the composition of the emission is determined using a $\mathrm{HSC} V_{\mathrm{M}} / V_{\mathrm{A}}$ ratio of $95 / 5$ (see the values in Table 2). Figure $2 \mathrm{a}$ shows the comparison of the regional box initial conditions (i.e., background atmosphere) and the quantities emitted during a $15 \mathrm{~min}$ for the main chemical species of the emission. Figure $2 \mathrm{~b}$ presents the comparison of the emission fluxes for the Ref simulation to the other simulations. For the Ref simulation the bromine species $(\mathrm{HBr}$, $\mathrm{BrOx}$ (family containing $\mathrm{Br}, \mathrm{BrO}$ and indirectly $\mathrm{Br}_{2}$ ) and $\mathrm{BrCl}$ ) have high emitted values compared to the initial quantities and also for sulphur dioxide $\left(\mathrm{SO}_{2}\right) . \mathrm{O}_{\mathrm{x}}$ has already a significant abundance arising from the background atmosphere in the model box, and the contribution from the volcanic emission is small. The contribution due to the emission of volcanic sulphate is similar to the background.
GMDD

Towards a

representation of

halogens in volcanic

plumes

L. Grellier et al.

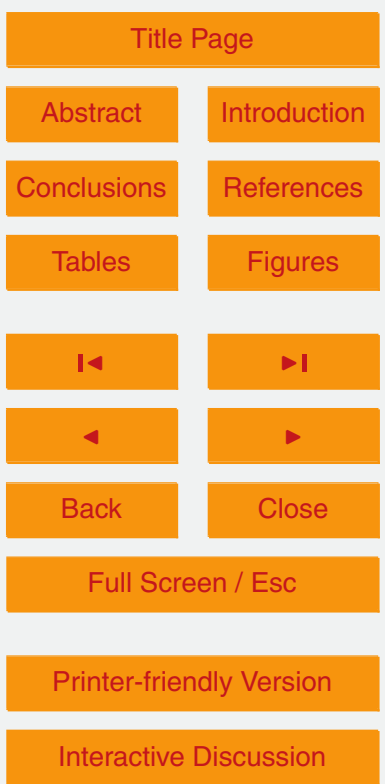


We now consider the Ref run (direct injection into $0.5^{\circ} \times 0.5^{\circ}$ grid box) in detail. Figure 3 presents the temporal evolution of the partial column of $\mathrm{BrO}$ (also shown, the two plume simulations that will be discussed later). The partial column shown in Fig. 3 is only calculated within the levels in which the emission take place, i.e., $0-5 \mathrm{~km}$ altitude. 5 During the simulation $\mathrm{BrO}$ shows four distinct periods of evolution. Firstly, during the $4 \mathrm{~h}$ period of the eruptive emissions, $\mathrm{BrO}$ increases to reach a maximum value of about $1.4 \times 10^{14}$ molecules $\mathrm{cm}^{-2}$ around 17:15 UTC. Secondly, after this maximum, until the end of the eruption and also at night-time, $\mathrm{BrO}$ decreases and remains at low values. Thirdly, the day after, at dawn, BrO increases rapidly and strongly until reaching a max10 imum of about $4.6 \times 10^{14}$ molecules $\mathrm{cm}^{-2}$ around 05:15 UTC. Finally, the last significant behaviour of $\mathrm{BrO}$ is a smooth decline during the day after the emission.

In the supplement of the article Hörmann et al. (2013), observations of $\mathrm{BrO}$ and $\mathrm{SO}_{2}$ in different volcanic plumes are presented. In particular we select those of the Mount Etna eruption on 11 May, originating from the 10 May eruption. The overflight time of 15 GOME-2 above the volcanic plume was 08:40 UTC. The values of the observations and simulation results are both integrated columns in molecules $\mathrm{cm}^{-2}$. For GOME-2, the data of $\mathrm{BrO}$ and $\mathrm{SO}_{2}$ correspond to slant column densities. Some uncertainties about ash content within the volcanic plume can have an influence on the observed data. In the case of the model, the results are the partial columns corresponding only to the levels in which the emissions take place. At the time of the overflight of GOME-2, the observed $\mathrm{BrO}$ maximum value is around $2.3 \times 10^{14}$ molecules $\mathrm{cm}^{-2}$. For the Ref simulation, $\mathrm{BrO}$ is $3.5 \times 10^{14}$ molecules $\mathrm{cm}^{-2}$. At this same time, the observed value of $\mathrm{SO}_{2}$ is about $1.6 \times 10^{18}$ molecules cm ${ }^{-2}$. In the Ref simulation, $\mathrm{SO}_{2}$ is $3.0 \times 10^{18}$ molecules cm $^{-2}$ (not shown in a figure). The observed and simulated values of $\mathrm{BrO}$ and $\mathrm{SO}_{2}$ are reasonably close, although with somewhat higher values simulated by MOCAGE. The main explanation is the absence of transport and deposition in the 1-D MOCAGE simulations, leading to no dilution of the plume or loss by deposition and thus to an expected overestimation compared to observations. Moreover, the concentrations of the chemical species are representative of a larger surface area in the observations compared to
GMDD

$7,2581-2650,2014$

Towards a

representation of

halogens in volcanic

plumes

L. Grellier et al.

Title Page

Abstract

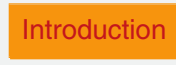

Conclusions

Tables

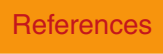

Figures

14

$\triangleleft$

Back

Full Screen / Esc

Printer-friendly Version

Interactive Discussion
$>1$

ose

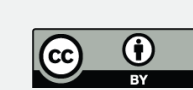


the model grid size. The pixel size of the satellite observation is $40 \mathrm{~km} \times 80 \mathrm{~km}$ and the $0.5^{\circ} \times 0.5^{\circ}$ grid box for the numerical model is approximately $44 \mathrm{~km} \times 55 \mathrm{~km}$. Note also that although we use the best estimates of the volcanic gas fluxes and their composition in MOCAGE, and there is an uncertainty on these estimates.

Figure 4 shows an example of the 1-D profile at the time closest to the GOME-2 observations. For the most part, the BrO profile shows an increasing trend with decreasing pressure (greater altitude). This is due to the volcanic emission being proportional to grid box volume across all model levels (whilst atmospheric density declines with altitude), leading to greater mixing ratios (of all important volcanic species) at higher 10 altitudes. However, the BrO mixing ratio profile shows a different behaviour in the two levels closest to the ground compared to the other levels. The reason is a high aerosol surface area caused by the sulphuric acid weight fraction being low because of the high relative humidity at these levels. This leads to a larger volume and surface area of volcanic sulphate aerosols. Thus, the heterogeneous reactions are more active in these levels, promoting formation of $\mathrm{BrO}$ (via $\mathrm{Br}_{2}$ and $\mathrm{BrCl}$ ) from $\mathrm{HOBr}$ and $\mathrm{BrONO}_{2}$. Because the grid box volume of the two last levels is relatively small compared to those above, their contribution to the BrO column concentration is nevertheless only about $3-5 \%$. Relative humidity is generally high close to the surface and thus increases the efficiency of the heterogeneous reactions and by this way the $\mathrm{BrO}$ production. This effect could be important in the case of a small eruption or a passive emission close to the surface.

During the $4 \mathrm{~h}$ period of the eruptive emission, $\mathrm{Br}$ atoms are provided to the model via the volcanic injection (which greatly exceeds background bromine) mainly in the form $\mathrm{HBr}$, but also as $\mathrm{Br}, \mathrm{BrCl}, \mathrm{BrO}$ and $\mathrm{Br}_{2}$ in the at high temperature mixture as calculated by the HSC model. These $\mathrm{Br}$ atoms act to accelerate the onset of the bromine chemical cycles within the plume. To analyse the plume chemistry during the $4 \mathrm{~h}$ eruptive emission period we present in Fig. 5 the time evolution of $\mathrm{BrO}, \mathrm{BrCl}$ and $\mathrm{HBr}$ for simulation Ref. The same quantity of $\mathrm{HBr}$ and $\mathrm{HCl}$ is emitted every 15 min between 14:15 and 18:15. The production of BrO chemistry acts to deplete $\mathrm{HBr}$ in the model. As
GMDD

Towards a

representation of halogens in volcanic

plumes

L. Grellier et al.

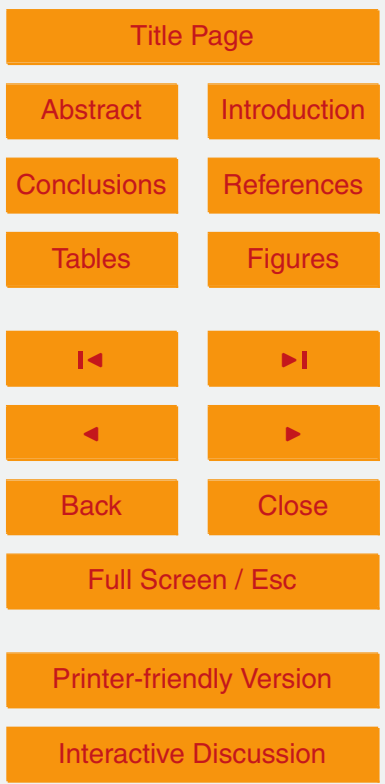


long as $\mathrm{HBr}$ is present in high quantities the model $\mathrm{HBr} / \mathrm{HCl}$ ratio continues to favour the production of $\mathrm{Br}_{2}$ by the heterogeneous Reactions ( $\left.\mathrm{R} 5 \mathrm{a}\right)$ and (R6a) instead of producing $\mathrm{BrCl}$ via Reactions (R5b) and (R6b). But $\mathrm{HBr}$ is continuously depleted and its concentration becomes low, and around 16:15 UTC the branching ratios start to favour 5 mainly the production of $\mathrm{BrCl}$. Figure 6 presents the results of the partial columns of $\mathrm{Br}, \mathrm{BrO}$ and $\mathrm{BrCl}$ in molecules $\mathrm{cm}^{-2}$ integrated over the levels in which the eruptive emissions take place, and also of the evolution of the $\mathrm{HBr} / \mathrm{HCl}$ ratio during the simulation. The strong decrease of the $\mathrm{HBr} / \mathrm{HCl}$ ratio during the emissions is linked to the strong decrease $\mathrm{HBr}$. The branching ratio is calculated for each level of the model at o each chemical time step. The contribution of each level is not similar because the volume is different. The mean of the branching ratio during the beginning of the eruptive event is 0.98 for the production of $\mathrm{Br}_{2}$. But after 16:15 UTC the branching ratio starts to favour the $\mathrm{BrCl}$ production with less $\mathrm{BrO}$ production until the chemical regime changes at 17:30 UTC. From this time, BrO decreases because of the reduction in $\mathrm{BrONO}_{2}$ and $15 \mathrm{HOBr}$ (see Fig. 7) leading to less heterogeneous reactions while the chemical loss reactions for $\mathrm{BrO}$ remain active. $\mathrm{BrCl}$ increases at the end of the emission for two reasons. First, the minor reason, because $\mathrm{HBr}$ is depleted and thus the Reactions (R6b) and (R5b) take over Reactions (R6a) and (R5a). The other reason is because this is the end of the day and so the photolysis becomes less important. $\mathrm{BrCl}$ loss is slow compared to its production. A consequence of the BrO chemistry is the depletion of $\mathrm{O}_{3}$ during the production of $\mathrm{BrO}$ (see Fig. 8 for the partial columns of oxidants as $\mathrm{O}_{3}$ ).

At the end of the eruptive emissions, i.e., 18:15 UTC, the HBr partial columns are at their smallest values. $\mathrm{HCl}$ is still present in a large quantity because it was emitted during the previous hours during the eruption and because of its relatively slow chemical

loss compared to $\mathrm{HBr}$. The decrease in $\mathrm{HBr}$ alters the branching ratio in their heterogeneous reactions to favour $\mathrm{BrCl}$ instead of $\mathrm{Br}_{2}$ after 18:15 UTC leading to an increase in the $\mathrm{BrCl}$ mixing column. The night starts at 18:30 UTC, it is only $15 \mathrm{~min}$ after the end of the eruptive emission. The $\mathrm{BrCl}$ partial column remains high during the night because
GMDD

7, 2581-2650, 2014

Towards a

representation of

halogens in volcanic

plumes

L. Grellier et al.

Title Page

Abstract

Conclusions

Tables

Figures

14

4

Back

Full Screen / Esc

Printer-friendly Version

Interactive Discussion 
it cannot be photolysed (see Fig. 6). $\mathrm{BrCl}$ is the main reservoir of bromine compounds during the night (Fig. 7).

At dawn, the day after the emission at 03:45 UTC, the bromine reservoir $\mathrm{BrCl}$ is photolysed (see Figs. 6 and 7). Br atoms resulting from this photolysis feed the chem5 ical cycle of the bromine explosion. $\mathrm{HBr}$ is produced by Reactions (R9) and (R10) but does not accumulate to any great extent. This leads to a branching ratio that is slowly reversed to favour mainly the production of $\mathrm{Br}_{2}$ at the end of the simulation. The partitioning between the main reactive bromine species ( $\mathrm{BrO}, \mathrm{HOBr}$ and $\mathrm{Br}$ ) is dependent on heterogeneous reactions and also on the availability of oxidants. The partitioning 10 in the bromine compounds is in favour of $\mathrm{BrO}$ and $\mathrm{HOBr} \mathrm{BrONO}_{2}$ increases at the beginning of the day since $\mathrm{NO}_{x}$ remains at high levels during the night and can react with $\mathrm{BrO}(\mathrm{R} 4)$, but when $\mathrm{NO}_{x}$ is depleted $\mathrm{BrONO}_{2}$ decreases (Fig. 8). As expected, the plume $\mathrm{BrO}$ chemistry, specifically the cycling between reactive bromine species given by Reactions (R2)-(R7), as well as cycling between $\mathrm{Br}$ and $\mathrm{BrO}$, leads to a decrease 15 of $\mathrm{O}_{3}$ (see Fig. 8). $\mathrm{HCHO}$ that is another compound reacting with $\mathrm{Br}$ (Reactions $\mathrm{R} 9$ and $\mathrm{R} 10$ ) that decreases during the day after (see Fig. 8). $\mathrm{O}_{3}$ starts to decrease significantly when the sunlight comes back and $\mathrm{HCHO}$ decreases at around 05:00 UTC the day after the emission.

Note that there is no transport in the 1-D model and thus there is no contribution 20 from the neighbouring grid boxes (entraining these gases from the background atmosphere), which would tend to counteract the impact of BrO-mediated depletion on their declining gas abundances. For $\mathrm{HO}_{2}$, a slight decline appears after 10:00 UTC, as expected because of the normal variation during the day. Because the oxidant species decrease, $\mathrm{Br}$ therefore becomes a reservoir species and increases. It is expected that 25 if further mixing with background atmosphere was included in this simulation (e.g. by mixing with adjacent grid boxes), the oxidant species would be (partially) replenished and therefore act to counter or lessen to some degree this trend in $\mathrm{Br}$. The decline in $\mathrm{BrO}$ whilst $\mathrm{Br}$ increases is fundamentally linked to the decline in ozone, via the cycles that interconvert $\mathrm{Br}$ and $\mathrm{BrO}$, which contribute to ozone loss and also exert a control

Towards a

representation of

halogens in volcanic

plumes

L. Grellier et al.

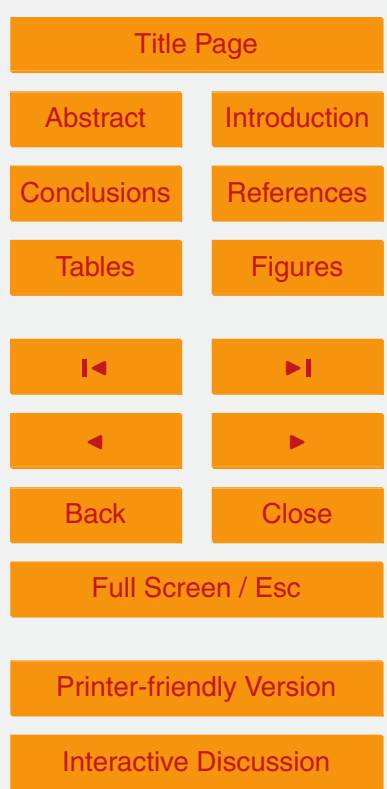


on the $\mathrm{Br}$ and $\mathrm{BrO}$ partitioning. The weak concentration of $\mathrm{NO}_{\mathrm{x}}$ species also has an impact on BrO. $\mathrm{NO}_{x}$ species (Fig. 8) and BrO (Fig. 3) are linked via the intermediate $\mathrm{BrONO}_{2}$. Here the depletion of $\mathrm{NO}_{x}$, shortly after dawn, shows evidence of occurrence of $\mathrm{BrONO}_{2}$ formation and heterogeneous reactive uptake.

\section{$5 \quad 5.2$ Plume 1 and Plume 2 simulations}

The plume parameterization (described in Sect. 4.2) is used for both the Plume 1 and Plume 2 simulations. The emissions only take place within a partial column of the plume box (between the ground and $5 \mathrm{~km}$ in height). The concentrations of the emitted species in the plume box $\left(0.025^{\circ} \times 0.025^{\circ}\right)$ are naturally higher than in the case of Ref 10 where the emissions are emitted in the model grid box $\left(0.5^{\circ} \times 0.5^{\circ}\right)$ as illustrated in Fig. 2a. The main differences between the simulations Ref, Plume 1 and Plume2 are during the emission period when in fact the parameterisation functions. The simulation without the parameterization (Ref) that simply injects the emission in the model grid box presents weaker quantities of $\mathrm{BrO}$ during this period compared to when the plume parameterization is added to the simulation.

For Plume 1, the chemical production and losses are calculated within the two boxes (model grid box and plume box) and then, at each emission time step (i.e., every $15 \mathrm{~min}$ ), the plume and the model grid boxes are fully mixed with one another in such a way as to account for the differences in volume between the two model compart20 ments. The results of $\mathrm{BrO}$ for Plume 1 are shown in Fig. 3 (blue line). The results show a stronger and faster production of $\mathrm{BrO}$ during the eruptive emission period in the Plume 1 simulation compared to the Ref simulation. Despite these higher values, the mixing of the plume box and the model box diminishes the impact of the eruptive emission within the model box because of the change of volume. During the emission $\mathrm{HBr}$ injected is destroyed in favour of $\mathrm{BrO}_{\mathrm{x}}$ in one time step. Consequently there is only a small amount of $\mathrm{HBr}$ that is transferred in the model box at each time step. This is different to Ref where during the first hour $\mathrm{HBr}$ is increasing.

Towards a

representation of halogens in volcanic

plumes

L. Grellier et al.

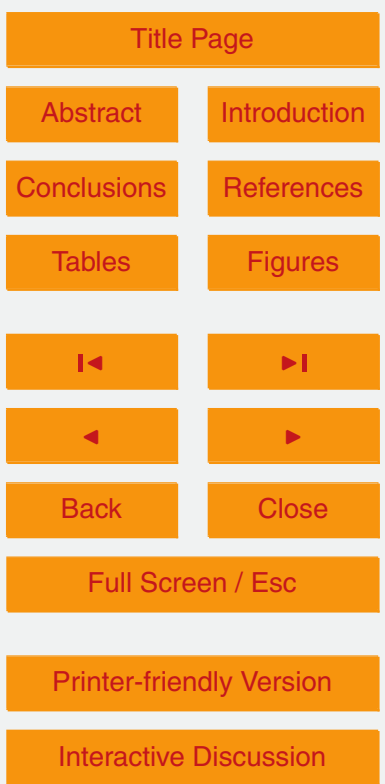


The $\mathrm{BrO}$ increases due to the role of the heterogeneous Reactions (R5) to (R6). Within the volcanic plume box the heterogeneous reaction of $\mathrm{BrONO}_{2}$ (Reaction $\mathrm{R} 6$ ) is particularly important, as the uptake coefficient of $\mathrm{BrONO}_{2}$ onto sulphate aerosol for the heterogeneous reactions is larger than that of $\mathrm{HOBr}$; and the concentrations of $5 \mathrm{BrONO}_{2}$ are higher than $\mathrm{HOBr}$ because of the high concentrations of $\mathrm{NO}_{\mathrm{x}}$ within the plume box. The consumption of $\mathrm{HBr}$ that occurs continuously throughout the emission period means that it is a rate limiting compound in the cycle that leads to the production of $\mathrm{BrO}$.

During the eruptive emission period, the branching ratios of the heterogeneous re10 actions remains in favour of the production of $\mathrm{Br}_{2}$ until $\mathrm{HBr}$ is strongly depleted, then $\mathrm{BrCl}$ becomes the main product. The concentration of $\mathrm{HOBr}$ is linked to $\mathrm{HO}_{2}$ and $\mathrm{BrO}$ by Reaction (R3) and the concentration of $\mathrm{BrONO}_{2}$ is linked to $\mathrm{BrO}$ and $\mathrm{NO}_{\mathrm{x}}$ by Reaction (R4). During the eruptive emission period, $\mathrm{HOBr}$ concentrations are driven by $\mathrm{HO}_{2}$ which has a diurnal cycle, and $\mathrm{HO}_{2}$ therefore decreases. Meanwhile, $\mathrm{NO}_{\mathrm{x}}$ is strongly 15 reduced and slows the $\mathrm{BrONO}_{2}$ production. These reductions in $\mathrm{HO}_{\mathrm{x}}$ and $\mathrm{NO}_{\mathrm{x}}$ lead to a decrease of the efficiency of the heterogeneous reactions. Therefore, there is a sharp reduction of $\mathrm{BrO}$ around 17:15 UTC (see partition figures of bromine compounds Fig. 7).

When the eruptive emissions stop, the behaviour of the plume 1 simulation is very 20 similar to the Ref simulation. The heterogeneous Reactions (R5b) and (R6b) become more efficient than Reactions (R5a) and (R6a), and $\mathrm{BrCl}$ is mainly produced instead of $\mathrm{Br}_{2}$. Therefore, at night time, $\mathrm{BrCl}$ becomes the main reservoir for bromine species. At the onset of night time the production of $\mathrm{BrO}$ is reduced due to the diminishing $\mathrm{HOBr}$ concentrations, linked to $\mathrm{HO}_{2}$, and particularly the lack of photolysis of $\mathrm{BrCl}$, the bromine reservoir. BrO formation recommences at dawn, and during the entire day after the emissions, $\mathrm{BrO}$ in the Plume 1 simulation has the same evolution as the Ref simulation. The partitioning between the bromine compounds is very close to Ref (Fig. 7) because the day after the emission, the main reservoir of bromine atoms is $\mathrm{BrCl}$ in both simulations, and because both models now operate on the same model
GMDD

Towards a

representation of

halogens in volcanic

plumes

L. Grellier et al.

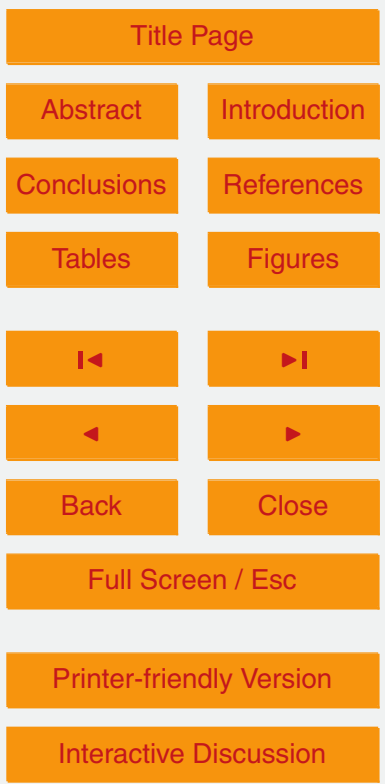


grid-box scale (noting that the plume parameterization is not used during this posteruptive period).

In the Plume 2 simulation, the mixing between the plume box and the model grid box occurs only at the end of the emission, at 18:15 UTC. Prior to this, the emission due to 5 the volcanic eruption and its chemical evolution is contained within the plume grid box. Note that the BrO partial columns presented in Fig. 3 during the time of the eruptive emissions represent those within the (regional) model grid box without emissions (the hatched zone in Fig. 7 represents the BrO evolution of the model grid box without emission). Thus, only the values from the end of the emission are of interest, from when the 10 volcanic emission that has undergone some chemical evolution within the plume box is injected into the model grid box. Within the plume box, the heterogeneous Reactions $(\mathrm{R} 5 \mathrm{a})$ and $(\mathrm{R} 6 \mathrm{a})$ proceed at high rates at the beginning of the eruption and $\mathrm{BrONO}_{2}$ and $\mathrm{HOBr}$ decrease sharply (see Fig. 9). Rapidly, the heterogeneous reactions cannot occur and $\mathrm{HBr}$ becomes one of the two bromine reservoirs. In the same time $\mathrm{O}_{3}$ decreases rapidly and strongly. The emissions of $\mathrm{O}_{\mathrm{x}}$ molecules are too weak compared to the background (Fig. 2) and to the BrO-mediated chemical destruction of ozone, and therefore this does not allow to $\mathrm{O}_{3}$ to remain in large quantities. As a result, then the reaction that produces $\mathrm{BrO}$ from $\mathrm{Br}$ and $\mathrm{O}_{3}$ (Reaction $\mathrm{R} 2$ ) cannot occur. $\mathrm{Br}$ is the second reservoir of the bromine compounds. This evolution of $\mathrm{HBr}$ within the plume box is a limitation of the method used in the Plume 2 simulation.

Right after the molecules produced in the plume box are mixed into the model grid box, the value of the $\mathrm{BrO}$ partial columns (green line in Fig. 3) increase rapidly and are large compared to those in the Ref and Plume 1 simulations. As a reminder, $\mathrm{BrOx}$ in the MOCAGE model includes $\mathrm{BrO}$ and implicitly $\mathrm{Br}_{2}$. Immediately after the mixing 25 at the end of the eruptive emission between the plume box and the model grid box, $\mathrm{BrCl}$ increases, but this occurs less rapidly than in the Ref and Plume 1 simulations (see Fig. 7). This is due to the larger concentrations of $\mathrm{HBr}$ present immediately upon mixing as compared to in the Ref or Plume 1 simulations at the same time. Thus the change in the branching ratio in favour of $\mathrm{BrCl}$ is less fast. $\mathrm{BrO}$ increases rapidly

Towards a

representation of halogens in volcanic

plumes

L. Grellier et al.

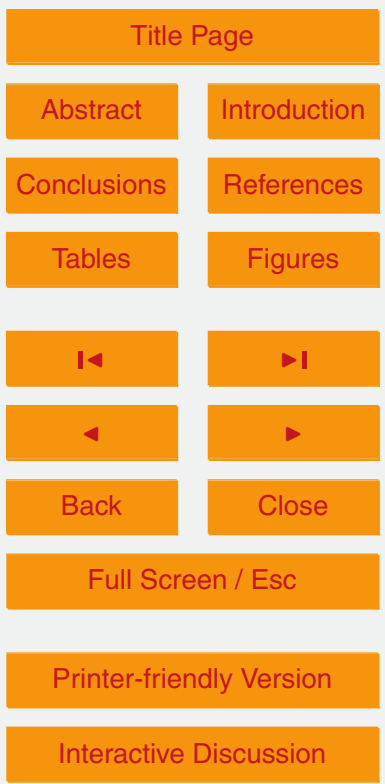


because of the presence of $\mathrm{BrONO}_{2}, \mathrm{HOBr}$ and $\mathrm{HBr}$, enabling heterogeneous reactions that produce $\mathrm{Br}_{2}$, with photolysis and reaction with ozone leading to $\mathrm{BrO}$. After the end of the emission, during a period of around one hour, $\mathrm{BrONO}_{2}$ remains at significant values compared to in the Ref and Plume 1 simulations, due to the high concentrations 5 of $\mathrm{BrO}$. Also, $\mathrm{HOBr}$ increases slightly because of large $\mathrm{BrO}$ concentrations. However, when the night begins $\mathrm{HO}_{2}$ and $\mathrm{NO}_{x}$ decrease due to the Reactions (R3) and (R4) and their diurnal cycle. Therefore, $\mathrm{BrO}$ is not replenished and starts a decreasing trend after 19:15 UTC.

During the night, starting at 18:30 UTC, as $\mathrm{HBr}$ declines the branching ratio begins 10 favouring the production of $\mathrm{BrCl}$ by the heterogeneous (Reactions $\mathrm{R} 5 \mathrm{~b}$ and $\mathrm{R} 6 \mathrm{~b}$ ). In this case, $\mathrm{BrCl}$ cannot be photolysed and remains as a bromine reservoir. $\mathrm{BrO}$ decreases because its loss Reactions (R3) and (R4) are more efficient than the production Reactions (R2), (R5a), (R5b), (R6a) and (R6b), but BrO still remains high compared to Ref and Plume 1 simulations. Thus, at night-time $\mathrm{BrO}$ and $\mathrm{BrCl}$ are the reservoirs of bromine compounds in the Plume 2 simulation (Fig. 7). This is, however, in part a reflection of the model $\mathrm{Br}$-chemistry scheme: $\mathrm{BrO}$ is a reservoir during the night because of the absence of $\mathrm{Br}_{2}$ in the chemical schemes RACM and REPROBUS. Instead of producing $\mathrm{Br}_{2}$ via the heterogeneous Reactions (R5a), (R5b), (R6a) and (R6b), the chemical scheme forms $\mathrm{BrO}_{\mathrm{x}}$. Within the model, the partitioning within the $\mathrm{BrO}_{\mathrm{x}}$ family 20 $(\mathrm{Br}+\mathrm{BrO})$ is completely in favour of $\mathrm{BrO}$ during the night-time period.

At day-time on 11 May, starting at 03:45 UTC, BrCl photolyses and consequently creates $\mathrm{Br}$ atoms which can take part in the chemical cycles. BrO globally increases until 04:15 UTC. At this point, BrO decreases, the supply of $\mathrm{HBr}$ becomes exhausted and the heterogeneous Reactions (R5) and (R6) produce more $\mathrm{BrCl}$. However, photolysis rates are high therefore these heterogeneous reactions simply lead to continued and rapid cycling of reactive bromine species. This chemical cycling (Reactions R2-R8) leads to depletion of the atmospheric oxidants (Ozone, $\mathrm{HCHO}$ and $\mathrm{NO}_{\mathrm{x}}$ ). Additional cycling between $\mathrm{BrO}$ and $\mathrm{Br}$ radicals (the self-reaction of $\mathrm{BrO}$, Reaction $\mathrm{R} 13$, followed by reaction of $\mathrm{Br}$ with ozone to produce $\mathrm{BrO}$, Reaction $\mathrm{R} 2$ ) may also enhance the rate of
GMDD

Towards a

representation of halogens in volcanic

plumes

L. Grellier et al.

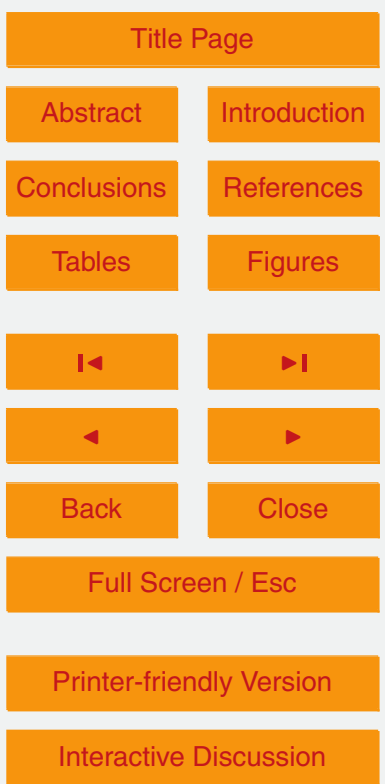


ozone loss. In particular, this BrO-mediated depletion of ozone itself causes a change in the reactive bromine speciation within the model grid box. A decrease in $\mathrm{O}_{3}$ alters the balance between $\mathrm{BrO}$ and $\mathrm{Br}$ defined by the $\mathrm{Br}-\mathrm{BrO}$ cycling, such that $\mathrm{BrO}$ declines and $\mathrm{Br}$ increases. $\mathrm{Br}$ begins to represent a greater proportion of the bromine atom bud5 get with time whilst $\mathrm{BrO}$ and $\mathrm{HOBr}$ decline. This is the same process that occurred in Ref and Plume 1.

The day after the emission, the three configurations (Ref, Plume 1 and Plume 2) have a very similar $\mathrm{BrO}$ evolution. At the time of the observations of GOME-2, the $\mathrm{BrO}$ partial columns are of the same order of magnitude but stronger in the case of 10 the simulations than for the observations. Likely explanations are provided in Sect. 5.1: e.g. the absence of transport within the simulations and because the size of the satellite pixel retrieval and the model grid box are somewhat different.

\subsection{The influence of the mixing of volcanic and atmospheric gases}

Here we compare HSC_Ref, HSC_Plume1 and HSC_Plume2 to Ref, Plume 1 and 15 Plume 2. The $\mathrm{SO}_{2}$ fluxes due to the emissions remain the same for each simulation, but the fluxes for the other chemical species depend on the gaseous composition calculated by the HSC model. In the three simulations presented earlier, the $V_{\mathrm{M}} / V_{\mathrm{A}}$ ratio used in HSC was 95/5. Now we present equivalent simulations instead initialised using HSC with a $V_{M}: V_{A}$ ratio of $90 / 10$. The new gaseous compositions of the emissions are 20 given in Table 2 and displayed in Fig. 2b. The comparison with the ration 95/5 shows that the differences are significant only for sulphate, $\mathrm{NO}_{\mathrm{x}}, \mathrm{BrCl}$ and $\mathrm{O}_{\mathrm{x}}$ in the plume box and in the regional box.

During the eruptive emissions HSC and HSC_Plume1 are very close to Ref and Plume 1 respectively (see Fig. 3 and Fig. 10). The differences are during the night for 25 Plume 2 and HSC_Plume2. At the time of the observations (08:40 UTC the 11 May 2008), BrO in the three configurations with $V_{\mathrm{M}} / V_{\mathrm{A}}=90 / 10$ is close to the three configurations with $V_{\mathrm{M}} / V_{\mathrm{A}}=95 / 5$. Globally the repartitioning of the bromine compounds (Fig. 11) presents very similar temporal evolutions the day after the emissions.

2615
GMDD

7, 2581-2650, 2014

Towards a

representation of

halogens in volcanic

plumes

L. Grellier et al.

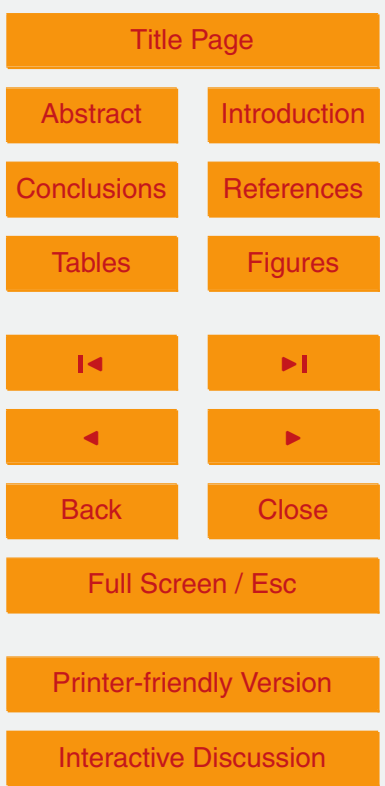


In the HSC simulations (with a ratio of $V_{\mathrm{M}} / V_{\mathrm{A}}=90 / 10$ ), the quantities of sulphate compounds emitted are larger than for the $95 / 5$ ratio: $1 \%$ for the $95 / 5$ ratio and $2 \%$ for the $90 / 10$ ratio (Table 2 ). In this case, the reaction rate coefficients of the heterogeneous reactions are faster because they depend on the available surface area of 5 the sulphate aerosol and thus their concentration. Nevertheless, even if $\mathrm{SO}_{2}$ and $\mathrm{SO}_{4}^{2-}$ are emitted in larger quantities, the rates of production of $\mathrm{BrO}$ from the heterogeneous Reactions (R5a) and (R6a) are limited by the concentrations of the reactants $\mathrm{BrONO}_{2}$, $\mathrm{HOBr}$ and $\mathrm{HBr}$. The plots of the partitioning (Fig. 11) show weak values of $\mathrm{HBr}$ in the three HSC simulations. The gaseous composition of the simulation using the $90 / 10$ 10 ratio is different compared to the 95/5 ratio than for the other chemical species (according to the mixing ratios of Table 2). This is particularly the case for the nitrogenous species partial columns (data not shown) that are larger compared to those simulated using the ratio of $95 / 5$. However, these differences do not lead to an important variation in the bromine species mixing ratios the day after the eruption. Note that these 15 simulations have no horizontal or vertical transport, thus, there is no exchange of gases between the surrounding model grid boxes which could modify the chemical budget.

At the night period, Ref, HSC, Plume 1 and HSC_Plume1 have the same bromine reservoir, $\mathrm{BrCl}$. The bromine reservoirs during the night are $\mathrm{BrCl}$ and $\mathrm{BrO}$ for both the Plume2 and HSC_Plume2 simulations (see Fig. 11) but with weaker values for BrO 20 in HSC_Plume2 simulation. This is due to the differences of emission fluxes between $V_{\mathrm{M}} / V_{\mathrm{A}}=90 / 10$ and $V_{\mathrm{M}} / V_{\mathrm{A}}=95 / 5$. Within the plume box the chemical reactions lead to slight differences in the mixture at the end of the emissions therefore a slight different behaviour during the night.

The behaviour of $\mathrm{O}_{3}$ for the three HSC simulations using a ratio of $90 / 10$ is the 25 and HSC_Ref for $\mathrm{O}_{3}$ ). In all of these simulations this is due to the presence of large quantities of bromine compounds. $\mathrm{O}_{3}$ starts to decrease during the emission because of the reaction with $\mathrm{Br}$ (Reaction $\mathrm{R} 2$ ).

GMDD

Towards a

representation of

halogens in volcanic

plumes

L. Grellier et al.

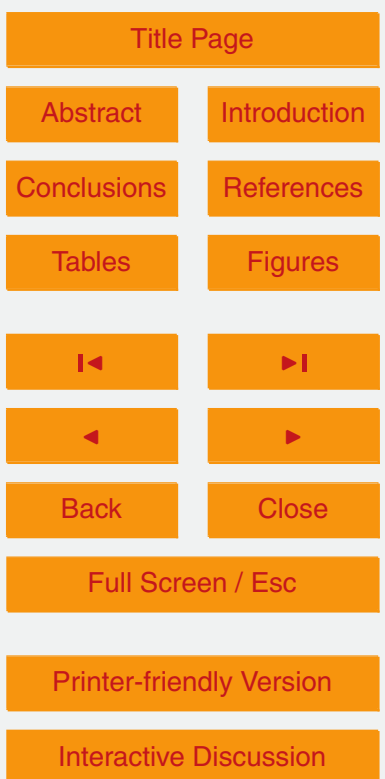


The HSC tests show that the model is not very sensitive to the $V_{\mathrm{M}} / V_{\mathrm{A}}$ ratio used in the HSC model even though this leads to higher sulphate aerosol concentrations and significant differences in other species like $\mathrm{NO}_{\mathrm{x}}$. However, the two $V_{\mathrm{M}} / V_{\mathrm{A}}$ ratios give equivalent proportions of $\mathrm{HBr}$, and the one rate limiting compound for the $\mathrm{BrO}$ chemistry is $\mathrm{HBr}$ because of the importance of the heterogeneous Reactions (R5a) and (R6a).

\subsection{The sensitivity to the model grid box resolution}

We now consider the potential influence of the model grid box size on the simulated plume chemistry. In the case of a regional scale study, the resolution $0.5^{\circ} \times 0.5^{\circ}$ is well adapted to study the chemical budget of the atmosphere. However, at the global scale, the horizontal resolution has to be coarser in order to reduce the simulation duration. The planned next step after this 1-D study is to use the 3-D model at a global scale with volcanic emissions. Therefore, we also test here the sensitivity on the plume evolution to the horizontal resolution. Note that the initial atmospheric conditions are also slightly different between the two simulations using the regional $\left(0.5^{\circ} \times 0.5^{\circ}\right)$ and the global $\left(2^{\circ} \times 2^{\circ}\right)$ resolutions (see Sect. 4.4). One representation of this difference is shown in Fig. 12, with the first value of $\mathrm{O}_{3}$, at 14:00 UTC, larger in the Res simulation than in both the Ref and HSC_Ref simulations. The meteorological parameters are also slightly different in the simulations using the two different resolutions because the average of these variables is not calculated at the same location and with the same resolution. The emission fluxes used in the Res simulation are lower than in the Ref simulation because of the larger grid-box size at the global resolution, as illustrated in Fig. 2b.

Figure 13 presents the predicted temporal $\mathrm{BrO}$ evolution using the coarser model 25 grid resolution of $2^{\circ} \times 2^{\circ}$ and assuming a $V_{\mathrm{M}} / V_{\mathrm{A}}$ ratio of $95 / 5$ in the initialisation (see Table 3). BrO partial columns are lower than those for the $0.5^{\circ} \times 0.5^{\circ}$ resolution as expected because the emissions become more diluted within the chemical background of the larger grid box volume. At the time of the observation, 08:40 UTC, the simulations
GMDD

Towards a

representation of halogens in volcanic

plumes

L. Grellier et al.

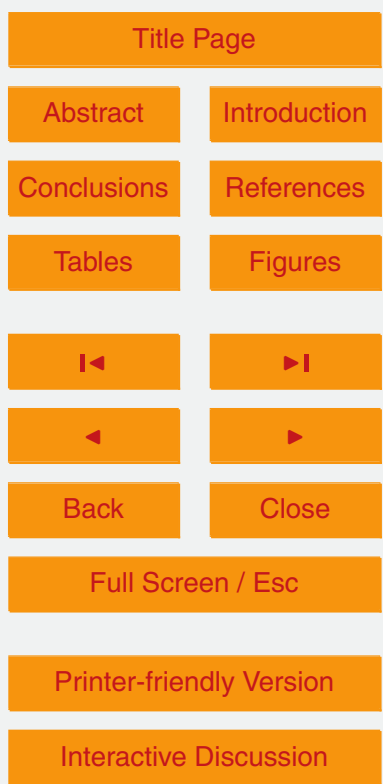

Interactive Discussion 
using the $2^{\circ} \times 2^{\circ}$ resolution have a mean $\mathrm{BrO}$ value of $1.5 \times 10^{13}$ molecules cm $^{-2}$, and the simulations using the resolution of $0.5^{\circ} \times 0.5^{\circ}$ have $\mathrm{BrO}$ partial columns of $3.5 \times$ $10^{14}$ molecules $\mathrm{cm}^{-2}$. The ratio of the two surface areas between the resolutions is 16. Considering that the values of the $2^{\circ} \times 2^{\circ}$ simulation are diluted by this factor, we 5 can compare them to the regional resolution by multiplying by this factor. Doing this, $\mathrm{BrO}$ reaches $2.4 \times 10^{14}$ molecules $\mathrm{cm}^{-2}$. This value is lower than the Ref value but it is reasonably close.

During the eruptive emission phase, the plots of the partitioning for the bromine species (Fig. 14) in the Res simulations present different shapes compared to the Ref simulations (Fig. 7). The differences are due to the low efficiency of the heterogeneous reactions because of the lower concentrations of the chemical species involved in these reactions. This is shown by high quantities of $\mathrm{HBr}$ in the Res simulations. Therefore, $\mathrm{HBr}$ is a bromine reservoir during almost the entire emission period. Res_Plume1 simulation shows a better efficiency of the heterogeneous reactions, and thus for the bromine cycle because $\mathrm{BrO}$ is higher than in the Res simulation and $\mathrm{HBr}$ is in weaker quantities. This is because of the more efficient $\mathrm{BrO}$ production within the plume box than within the model box. During the night, the main bromine species becomes $\mathrm{BrCl}$ for these two simulations. For Res_Plume2 the quantities produced within the plume box are diluted within the model grid box just before night. The production of $\mathrm{BrO}$ is 20 very slow and not as strong as in the Plume 2 simulation. The bromine reservoirs of Res_Plume2 during the night are $\mathrm{HBr}$ and $\mathrm{BrONO}_{2}$ at the beginning of the night and then only $\mathrm{BrCl}$ as for Res and Res_Plume1. There are some variations in $\mathrm{BrO}$ in the Res and Res_Plume2 simulations during the night due to the vertical variability of the equilibrium between production and destruction of $\mathrm{BrO}$ (Reactions R6a and R4) linked 25 to the vertical variability of nitrogeneous species. The day after the emissions, the three Res simulations have almost the same partitions.

In Fig. 12 (comparison of Ref, HSC_Ref and Res $\mathrm{O}_{3}$ ), the depletion of $\mathrm{O}_{3}$ in the Res simulation is smaller and occurs later than for the simulations with the finer resolution, which is consistent with the smaller values of $\mathrm{BrO}$. For the simulations with the
GMDD

Towards a

representation of

halogens in volcanic

plumes

L. Grellier et al.

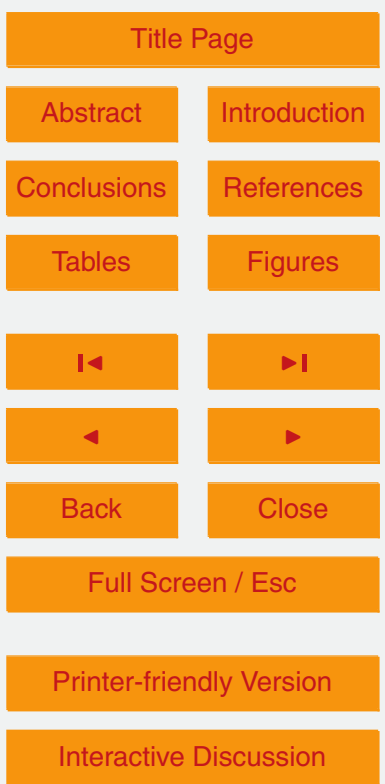


resolution $2^{\circ} \times 2^{\circ}$, the day after the emission, $\mathrm{BrO}$ is still increasing unlike in the finer regional resolution simulations $\left(0.5^{\circ} \times 0.5^{\circ}\right)$ where $\mathrm{BrO}$, after reaching a maximum at around 05:00 UTC, continuously decreases. The differences are mainly due to the nonlinearity of the chemical reactions linked to the change of the grid box volume between 5 regional and global resolutions. At the global resolution, the evolution of $\mathrm{BrO}$ is slower than at the regional resolution. BrO can continuously increase the day after the emission since the oxidant species such as $\mathrm{O}_{3}$ and also $\mathrm{NO}_{x}$ are still present in significant concentrations because of the larger grid box volume than in the $2^{\circ} \times 2^{\circ}$ simulations.

In summary, the general behaviour of the coarse resolution $\left(2^{\circ} \times 2^{\circ}\right)$ simulations presents a different chemical regime compared to the finer resolution $\left(0.5^{\circ} \times 0.5^{\circ}\right)$ simulations during both the periods of the emission and the day after. However, the values of $\mathrm{BrO}$ and $\mathrm{SO}_{2}$ obtained at the time of the observations are reasonable given the coarser model resolution. In the future 3-D simulations, the transport processes added to the simulations may bring modifications in the chemical regime at both resolutions. The exchange of gases between the model grid boxes surrounding the volcano will lead to an increase of oxidants species particularly for the more concentrated $0.5^{\circ} \times 0.5^{\circ}$ resolution simulation.

\subsection{The sensitivity to the sulphate aerosol radius}

The mean radius of the sulphate aerosol is set as a constant value used in the aerosol surface area calculation (Eq. 3). This surface area influences the rate constant of the heterogeneous reactions therefore the $\mathrm{BrO}$ cycle. To determine the influence of the mean radius on the bromine chemistry, we choose 4 radius values consistent with observations in volcanic plumes (Watson and Oppenheimer, 2000): 0.5, 1, 2 and $4 \mu \mathrm{m}$.

Figure 15 presents the time evolution of the BrO partial columns for a regional resolution $\left(0.5^{\circ} \times 0.5^{\circ}\right)$ with the configuration of the Ref simulation and with the 4 different radius values. The results show a larger increase of $\mathrm{BrO}$ with the fine aerosols during the emission period than with the large aerosols. This is because the assumption of a smaller mean radius provides a larger total surface and thus a stronger efficiency of
GMDD

7, 2581-2650, 2014

Towards a

representation of

halogens in volcanic

plumes

L. Grellier et al.

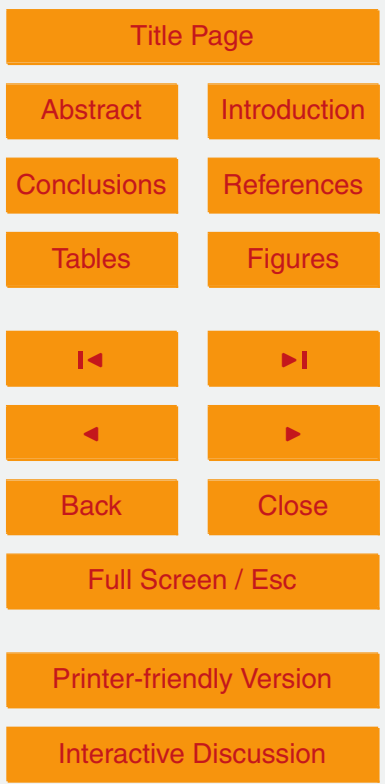


the heterogeneous reactions. During the night, the behaviour is similar for all simulations. The day after, the same differences for $\mathrm{BrO}$ evolution are also observed during the emission, and the assumption of a distribution of fine aerosols leads to an increase of the $\mathrm{BrO}$ production and for the large aerosols a slow down in the cycle. But right be5 fore the end of the simulation period, BrO partial column decreases in different ways, depending on the mean radius. With a radius of $0.5 \mu \mathrm{m}, \mathrm{BrO}$ partial columns are weaker than the values with a radius of $4 \mu \mathrm{m}$ at 12:00 UTC. The chemical reactions involved in the BrO cycle are more efficient with the small aerosol assumption. Therefore the oxidants species are more rapidly destroyed and the $\mathrm{BrO}$ production becomes less o efficient.

With a global resolution $\left(2^{\circ} \times 2^{\circ}\right)$, the results for the partial column of $\mathrm{BrO}$ with the same radii present the same general behaviour compared to the regional resolution (see Fig. 16). The BrO production is more efficient assuming fine particles compared to large particles. The differences with the regional resolution occur at the end of the 15 simulations. With the global resolution, the BrO partial columns continue to increase for Res_05, Res_1 and Res. This is because the chemical species needed for the BrO cycle are still present in the model grid box to continue the $\mathrm{BrO}$ production.

\section{Conclusions}

The formation of $\mathrm{BrO}$ in volcanic plumes is important in the budget, atmospheric 20 fate and impacts of volcanic bromine emissions. Because of its low solubility compared to $\mathrm{HBr}$ and $\mathrm{HCl}$ emitted by volcanoes, and through the occurrence of reactive bromine cycles in the volcanic plume, BrO can remain longer in the atmosphere as the plume disperses into the atmosphere, with the potential to undergo long-range transport and have impacts further a field. The global atmospheric chemistry model a volcanic plume towards future global model investigations of the impacts of vola volcanic plume towards future global model investigations of the impacts of volcanic halogen degassing. We choose a one dimensional configuration to be able to

GMDD

$7,2581-2650,2014$

Towards a

representation of

halogens in volcanic

plumes

L. Grellier et al.

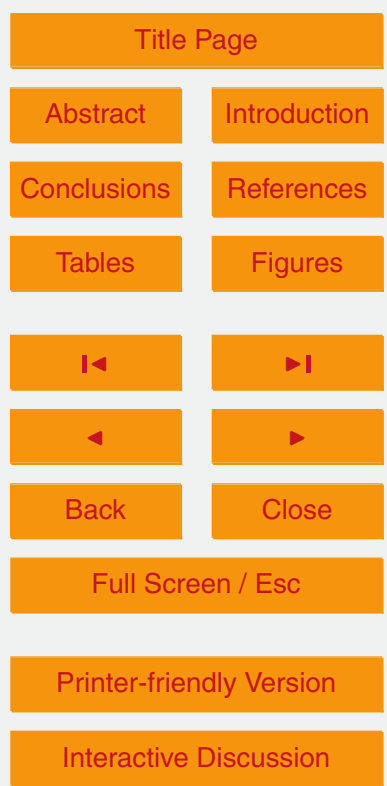


make several sensitivity tests for the chemistry resulting from a volcanic eruptive emission. Different adaptations are made to the model to take into account volcanic conditions within the plume, and to test methods for plume representation on a smaller scale $\left(0.025^{\circ}\right.$ latitude $\times 0.025^{\circ}$ longitude $)$ than the regional or global model grid-scale $5 \quad\left(0.5^{\circ} \times 0.5^{\circ}\right.$ and $2^{\circ} \times 2^{\circ}$, respectively $)$.

As a case study, the eruption of Mount Etna that occurred on the 10 May 2008 from 14:15 UTC to $18: 15$ UTC is used, which injected a total of 8000 tonnes $\mathrm{SO}_{2}$ (as well as lesser quantities of $\mathrm{HBr}$ and $\mathrm{HCl}$ ). The quantities of the species prescribed as the resulting emissions in MOCAGE are determined from this reported $\mathrm{SO}_{2}$ gas flux, and an estimate of the volcanic gas composition including halogens made during a quiescently degassing period close to the eruption. Furthermore, the numerical model (HSC) is used to represent the high-temperature chemistry that occurs upon mixing of the magmatic gases with ambient air during the first moments of the eruptive emission at the crater vent. Radicals produced during this high-temperature initialisation act to accelerate the onset of downwind plume autocatalytic $\mathrm{BrO}$ chemistry (a process which includes photolytic reactions as well as heterogeneous chemistry).

The results obtained with a regional resolution $\left(0.5^{\circ} \times 0.5^{\circ}\right)$, without any sub-grid plume parameterization (Ref simulation), show an increase of $\mathrm{BrO}$ mainly the day after the emission because night comes just after the end of the emission. This BrO production is accompanied by a decrease in $\mathrm{O}_{3}$. This behaviour is expected according to the chemical cycle of the bromine explosion that is known to occur in volcanic plumes (Oppenheimer et al., 2006; Bobrowski et al., 2007; Roberts et al., 2009, 2014b; von Glasow et al., 2009; Kelly et al., 2013). Moreover the quantities of $\mathrm{BrO}$ and $\mathrm{SO}_{2}$ from the model in the plume are close to the observations made by the satellite GOME-2

(supplement of Hörmann et al., 2013) on the morning the day after the eruption. At the levels closest to the surface, the high values of water vapour leads to an increased sulphate aerosol surface area, thereby promoting the efficiency of the heterogeneous reactions, which are important in the bromine explosion cycle. This may act to promote
GMDD

Towards a

representation of halogens in volcanic

plumes

L. Grellier et al.

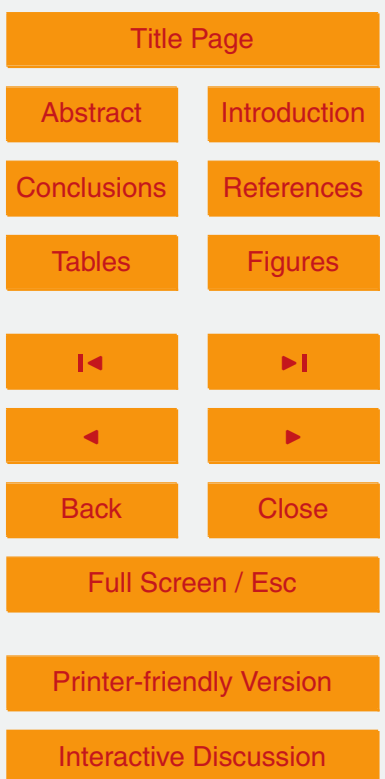


$\mathrm{BrO}$ formation and intercycling of reactive bromine species in volcanic plumes that remain at low altitudes, e.g. from passive degassing.

A simple parameterization was tested during the duration of the emissions in order to represent the computation of the chemical reactions within the volcanic plume,

5 i.e. within a smaller volume than the model grid box. Two configurations were studied with the parameterization. The use of this parameterization together with the assumption that the mixing of the volcanic plume with the wider atmosphere air only occurs at the end of the emission (Plume 2) increases the rapidity and the rates of production of $\mathrm{BrO}$. The other case using a parameterization but with the mixing between the 10 volcanic plume and ambient air made at each emission time step, 15 min (Plume 1), presents higher values of $\mathrm{BrO}$ than for Ref during the emission but weaker than for Plume 2. Since night comes less than one hour after the end of the emission, this leads to differences between the Plume 2 simulation and the Ref or Plume 1 simulations in the partitioning of the bromine compounds during the night. The night time 15 reservoirs of the bromine compounds are either $\mathrm{BrO}$ (which in the model chemical scheme represents both $\mathrm{BrO}$ and $\mathrm{Br}_{2}$ ) and $\mathrm{BrCl}$ (for Plume 2 simulation) or $\mathrm{BrCl}$ only (Ref and Plume 1 simulations). This partitioning is due to the heterogeneous Reactions (R5a), (R5b), (R6a) and (R6b). Note that the chemical scheme used in the 1-D model does not directly simulate $\mathrm{Br}_{2}$. Rather there is a direct production of $\mathrm{BrO}$ by the heterogeneous reactions instead of $\mathrm{Br}_{2}$. During daytime fast photolysis of $\mathrm{Br}_{2}$ will inject $\mathrm{Br}$ radicals in the bromine chemical cycles that can further react with ozone to form $\mathrm{BrO}$. However, during night the chemistry rather forms $\mathrm{Br}_{2}$ instead of $\mathrm{BrO}$ as shown by the model. Nevertheless, the day after the emission the partitioning of these reactive bromine species are all very similar in the simulations with and without the plume parameterization. These one-dimensional simulations are computed without transport (i.e., dilution effects), washout and deposition. In a 3-D model framework including all these processes, a different partitioning of the bromine compounds during the night between Ref, Plume 1 and Plume 2 simulations might also occur, and could lead to model grid-box different compositions at sun rise because of the different solubilities of

Towards a

representation of halogens in volcanic

plumes

L. Grellier et al.

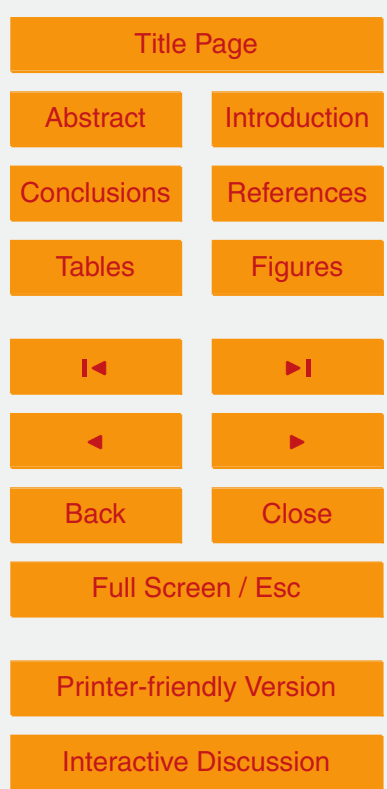


the reservoir species. Because $\mathrm{Br}_{2}$ is less soluble than $\mathrm{BrCl}$, the $\mathrm{Br}$ atoms will remain longer in the atmosphere if $\mathrm{Br}_{2}$ is the main reservoir instead of $\mathrm{BrCl}$.

Plume 1 configuration confines the emissions within a smaller box than the model grid box. The chemical reactions occurring in the plume box are stronger than within 5 the model grid box. Each $15 \mathrm{~min}$, the plume box is mixed to the model grid box. The chemical composition of the plume box during the next step depends on the chemical composition of the model grid box. For the Plume 2 configuration, the mixing occurs only at the end of the emissions. During the emission period, the plume box is confined without interaction with the model grid box. Therefore, the oxidant species are not re10 plenished and thus limit the chemical reactions of the $\mathrm{BrO}$ cycle. This is an important limitation of the Plume 2 configuration.

Simulations were also performed using a grid box resolution typically used in global model studies $\left(2^{\circ} \times 2^{\circ}\right)$. In comparison to the regional model study $\left(0.5^{\circ} \times 0.5^{\circ}\right)$, the emissions become more diluted within the global model grid box. Even with this dilution the model still estimates reasonable $\mathrm{BrO}$ values compared to the values obtained with a regional resolution, and also in general agreement with the GOME-2 satellite observations. Nevertheless, there are differences between the results at the $2^{\circ}$ and $0.5^{\circ}$ resolutions that mainly due to the combination of a different volume and the second order rate kinetics. Some of the differences are also linked to the differences in the initial meteorological and chemical conditions. In particular, in the morning after the emission, $\mathrm{BrO}$ increases in the simulations at the $2^{\circ}$ resolution while it decreases at the $0.5^{\circ}$ resolution. This is because the oxidants species are still available in significant concentrations in the simulations at the $2^{\circ}$ resolution due to the larger supply in the larger grid box volume. Therefore, the resolution issue needs to be further explored in 25 a 3-D global configuration.

Another aspect of the model initialisation is the ratio between magmatic and atmospheric air as a parameter in the HSC model, which is not known precisely. This parameter is tested for two reasonable values that estimate a reasonable quantity of sulphate aerosol in the volcanic plume (estimated to be a small percentage of the total sulfur

GMDD

$7,2581-2650,2014$

Towards a

representation of

halogens in volcanic

plumes

L. Grellier et al.

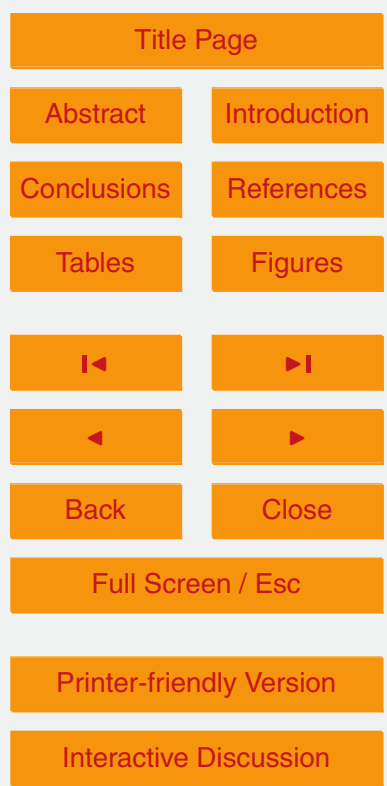


emission, e.g. typically up to $2 \%$ see Roberts et al., 2009 and von Glasow et al., 2009). The results of the 1-D MOCAGE framework present only small differences between the two input values for the HSC model, except during the night where the Plume 2 configuration shows larger differences. But as discussed before, this approach is limited

5 by the exhausted oxidants within the plume box. Simulations have been tested with data for the initial gaseous composition coming from the plume of Etna emissions in 1970 and 2007 (with different partitioning between the main gaseous species: $\mathrm{H}_{2} \mathrm{O}$, $\mathrm{CO}_{2}$ and $\mathrm{SO}_{2}$, not presented here). The HSC model estimated the gaseous composition after the high-temperature mixture. The compositions presented low $\mathrm{HBr}$ and $\mathrm{HCl}$ 10 quantities compared to those used in this study. These simulations predicted lower $\mathrm{BrO}$ abundances such that the partial column of $\mathrm{BrO}$ was too low compared to the reported satellite observation the day after the eruption. This highlights the importance of the halogen species content within the volcanic emission, mainly the $\mathrm{HBr} / \mathrm{SO}_{2}$ and $\mathrm{HCl} / \mathrm{SO}_{2}$ ratios.

15 The mean radius assumed for the sulphate aerosols participates in the surface area calculation for the rate constant of the heterogeneous reactions. In the bromine cycle, these reactions are necessary for the BrO production. They are more efficient when the mean radius decreases since it increases the surface area. Four radius values have been tested with the regional and global resolutions. For the two resolutions, the conclusions are similar. In the simulation with the fine aerosols there is an increase of the $\mathrm{BrO}$ production because of the increase of the effective surface area. Conversely, the larger particles are less efficient for the BrO production. For this 1-D study, the differences between regional and global resolutions appear at the end of the simulation. With the regional resolution the day after the emission, the $\mathrm{BrO}$ partial columns decrease rapidly, which is unlike the $\mathrm{BrO}$ partial columns at the global resolution that continue to slowly increase.

The aim of these simulation runs in 1-D was to prepare a 3-D version of MOCAGE for a global scale study. The 3-D simulations will include all physical and chemical process in order to describe the chemical budget within a volcanic plume and its evolution

Towards a

representation of halogens in volcanic

plumes

L. Grellier et al.

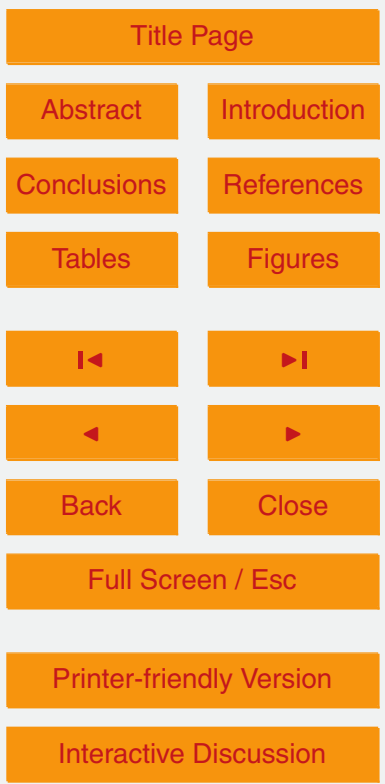


with time in the atmosphere. The next step is to use the modifications tested in the 1-D framework of MOCAGE to study the chemistry and impacts of the same emission of Mount Etna as it disperses within 3-D MOCAGE. The ratio of magmatic and atmospheric air of $95 / 5$ tested in 1-D in this study will be used as a reference point.

5 The sensitivity on mean radius of sulphate aerosol will be tested in 3-D since the BrO concentrations depend on it and since there is limited information so far from measurements on the sulphate distribution within volcanic plumes. 1-D simulations have shown the need to use a short chemical time step compared to the usual MOCAGE setup during the eruption, and also after when chemical compounds linked to the emissions remain in large concentrations in the atmosphere. This can be an important limitation in 3-D simulations because of the computing cost of using short chemical timesteps. Some planned future improvements include a more detailed chemical cycle of sulphur compounds within the numerical model MOCAGE to allow a better description of the sulphate aerosols involved in the bromine chemical cycle by the heterogeneous reactions. The direct simulation of the molecule $\mathrm{Br}_{2}$ within MOCAGE may also be included rather than simulating the immediate photolysis of $\mathrm{Br}_{2}$ upon $\mathrm{BrO}$ formation. $\mathrm{Br}_{2}$ is a short lived species during daytime, but may accumulate during the night, therefore its direct simulation may alter the bromine partitioning between $\mathrm{BrO}, \mathrm{Br}$ and $\mathrm{Br}_{2}$. $\mathrm{Re}$ garding plume processes occurring on scales smaller than the model grid-scale, we have shown here that the plume parameterization provides a different partitioning of the bromine species during the eruption and subsequent night depending on whether the model box and the plume box are mixed at the end of the emission. It will be necessary to test this in the 3-D framework to further evaluate this effect. The comparisons between the 3-D simulations of the Mount Etna emission and the satellite observations will provide a quantitative evaluation of the 3-D MOCAGE simulations. The long-term goal is for MOCAGE to be used to simulate the atmospheric impacts from other eruptive events and passive emissions on a global scale.
GMDD

7, 2581-2650, 2014

Towards a

representation of halogens in volcanic

plumes

L. Grellier et al.

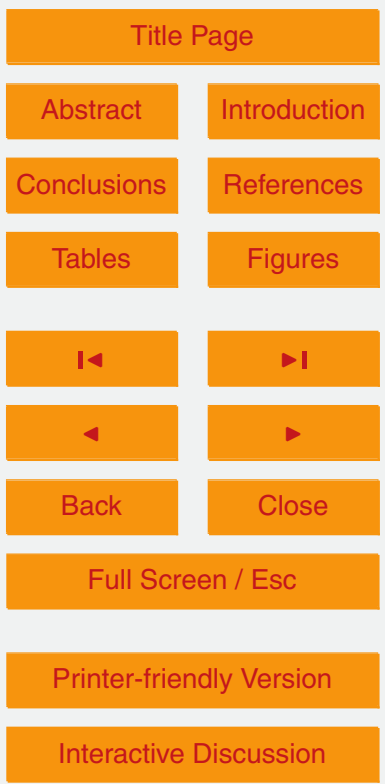


Acknowledgements. This work benefited from the financial support of the program LEFE of the Institut National des Sciences de I'Univers of CNRS (Centre National de la Recherche Scientifique), of Météo-France and of the "Conseil Régional de la Région Midi-Pyrénées" (France). T. J. Roberts acknowledges LABEX VOLTAIRE (VOLatils- Terre Atmosphère Interactions 5 Ressources et Environnement) ANR-10-LABX-100-01 (2011-20) and an NSINK career development allowance that enabled HSC software purchase.

\section{References}

Aiuppa, A., Federico, C., Franco, A., Giudice, G., Gurrieri, S., Inguaggiato, S., Liuzzo, M., McGonigle, A. J. S., and Valenza, M.: Emission of bromine and iodine from Mount Etna volcano, 10 Geochem. Geophy. Geosy., 6, Q08008, doi:10.1029/2005GC000965, 2005.

Aiuppa, A., Moretti, R., Federico, C., Giudice, G., Gurrieri, S., Liuzzo, M., Papale, P., Shinohara, $H_{\text {., }}$ and Valenza, M.: Forecasting Etna eruptions by real-time observation of volcanic gas composition, Geology, 35, 1115-1118, doi:10.1130/G24149A.1, 2007.

Aiuppa, A., Giudice, G., Gurrieri, S., Liuzzo, M., Burton, M., Caltabiano, T., McGonigle, A. J. S., Salerno, G., Shinohara, H., and Valenza, M.: Total volatile flux from Mount Etna, Geophys. Res. Lett., 35, L24302, doi:10.1029/2008GL035871, 2008.

Aiuppa, A., Cannata, A., Cannavò, F., Di Grazia, G., Ferrari, F., Giudice, G., Gurrieri, S., Liuzzo, M., Mattia, M., Montalto, P., Patanè, D., and Puglisi, G.: Patterns in the recent 20072008 activity of Mount Etna volcano investigated by integrated geophysical and geochemical observations, Geochem. Geophy. Geosy., 11, Q09008, doi:10.1029/2010GC003168, 2010.

Allard, P., Burton, M., and Murè, F.: Spectroscopic evidence for a lava fountain driven by previously accumulated magmatic gas, Nature, 433, 407-410, doi:10.1038/nature03246, 2005.

Bechtold, P., Bazile, E., Guichard, F., Mascart, P., and Richard, E.: A mass-flux convection scheme for regional and global models, Q. J. Roy. Meteor. Soc., 127, 869-886, doi:10.1002/qj.49712757309, 2001.

Bobrowski, N. and Giuffrida, G.: Bromine monoxide / sulphur dioxide ratios in relation to volcanological observations at Mt. Etna 2006-2009, Solid Earth, 3, 433-445, doi:10.5194/se3-433-2012, 2012.

Bobrowski, N. and Platt, U.: SO2/BrO ratios studied in five volcanic plumes, J. Volcanol. Geoth. Res., 166, 147-160, 2007.

Towards a

representation of

halogens in volcanic

plumes

L. Grellier et al.

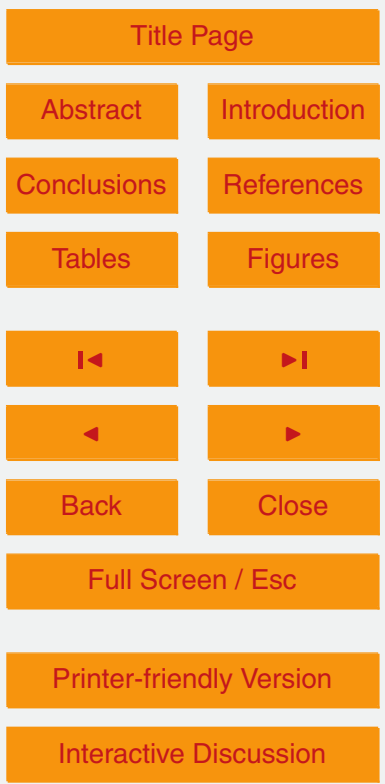


Bobrowski, N., Hönninger, G., Galle, B., and Platt, U.: Detection of bromine monoxide in a volcanic plume, Nature, 423, 273-276, doi:10.1038/nature01625, 2003.

Bobrowski, N., von Glasow, R., Aiuppa, A., Inguaggiato, S., Louban, I., Ibrahim, O. W., and Platt, U.: Reactive halogen chemistry in volcanic plumes, J. Geophys. Res.-Atmos., 112, 5 D06311, doi:10.1029/2006JD007206, 2007.

Boichu, M., Oppenheimer, C., Roberts, T. J., Tsanev, V., and Kyle, P. R.: On bromine, nitrogen oxides and ozone depletion in the tropospheric plume of Erebus volcano (Antarctica), Atmos. Environ., 45, 3856-3866, 2011.

Bonaccorso, A., Bonforte, A., Calvari, S., Del Negro, C., Di Grazia, G., Ganci, G., Neri, M., Vicari, A., and Boschi, E.: The initial phases of the 2008-2009 Mount Etna eruption: a multidisciplinary approach for hazard assessment, J. Geophys. Res., 116, B03203, doi:10.1029/2010JB007906, 2011.

Bousserez, N., Attié, J. L., Peuch, V. H., Michou, M., Pfister, G., Edwards, D., Emmons, L., Mari, C., Barret, B., Arnold, S. R., Heckel, A., Richter, A., Schlager, H., Lewis, A., Avery, M., Sachse, G., Browell, E. V., and Hair, J. W.: Evaluation of the MOCAGE chemistry transport model during the ICARTT/ITOP experiment, J. Geophys. Res., 112, D10S42, doi:10.1029/2006JD007595, 2007.

Brimblecombe, P. and Clegg, S.: The solubility and behaviour of acid gases in the marine aerosol, J. Atmos. Chem., 7, 1-18, doi:10.1007/BF00048251, 1988.

20 Bureau, H., Keppler, H., and Métrich, N.: Volcanic degassing of bromine and iodine: experimental fluid/melt partitioning data and applications to stratospheric chemistry, Earth Planet. Sc. Lett., 183, 51-60, 2000.

Cariolle, D., Caro, D., Paoli, R., Hauglustaine, D. A., Cuénot, B., Cozic, A., and Paugam, R.: Parameterization of plume chemistry into large-scale atmospheric models: application to aircraft NOx emissions, J. Geophys. Res., 114, D19302, doi:10.1029/2009JD011873, 2009.

Chazette, P., David, C., Lefrère, J., Godin, S., Pelon, J., and Mégie, G.: Comparative lidar study of the optical, geometrical, and dynamical properties of stratospheric post-volcanic aerosols, following the eruptions of El Chichon and Mount Pinatubo, J. Geophys. Res., 100, 2319523207, doi:10.1029/95JD02268, 1995.

so Courtier, P., Freydier, C., Geleyn, J.-F., Rabier, F., and Rochas, M.: The ARPEGE project at Météo-France, in: Proceedings of the ECMWF seminar on "Numerical Methods in Atmospheric Models", 193-232, Reading, 9-13 September 1991.

Towards a

representation of

halogens in volcanic

plumes

L. Grellier et al.

Title Page

Abstract

Introduction

Conclusions

Tables

References

Figures

14

4

Back

Full Screen / Esc

Printer-friendly Version

Interactive Discussion 
Dickerson, R. R., Rhoads, K. P., Carsey, T. P., Oltmans, S. J., Burrows, J. P., and Crutzen, P. J.: Ozone in the remote marine boundary layer: a possible role for halogens, J. Geophys. Res., 104, 21385-21395, doi:10.1029/1999JD900023, 1999.

Fickert, S., Adams, J. W., and Crowley, J. N.: Activation of $\mathrm{Br}_{2}$ and $\mathrm{BrCl}$ via uptake of $\mathrm{HOBr}$ onto aqueous salt solutions, J. Geophys. Res., 104, 23719-23727, doi:10.1029/1999JD900359, 1999.

Gerlach, T. M.: Volcanic sources of tropospheric ozone-depleting trace gases, Geochem. Geophy. Geosy., 5, 23719-23727, doi:10.1029/1999JD900359, 2004.

Giorgi, F. and Chameides, W. L.: Rainout lifetimes of highly soluble aerosols and gases as inferred from simulations with a general circulation model, J. Geophys. Res., 91, 1436714376, doi:10.1029/JD091iD13p14367, 1986.

Hörmann, C., Sihler, H., Bobrowski, N., Beirle, S., Penning de Vries, M., Platt, U., and Wagner, T.: Systematic investigation of bromine monoxide in volcanic plumes from space by using the GOME-2 instrument, Atmos. Chem. Phys., 13, 4749-4781, doi:10.5194/acp-1315 4749-2013, 2013.

Josse, B., Simon, P., and Peuch, V.: Radon global simulations with the multiscale chemistry and transport model MOCAGE, Tellus B, 56, 4, doi:10.1111/j.1600-0889.2004.00112.x, 2004.

Karamchandani, P., Seigneur, C., Vijayaraghavan, K., and Wu, S.-Y.: Development and application of a state-of-the-science plume-in-grid model, J. Geophys. Res., 107, 4403, doi:10.1029/2002JD002123, 2002.

Kelly, P. J., Kern, C., Roberts, T. J., Lopez, T., Werner, C., and Aiuppa, A.: Rapid chemical evolution of tropospheric volcanic emissions from Redoubt Volcano, Alaska, based on observations of ozone and halogen-containing gases, J. Volcanol. Geoth. Res., 259, 317-333, 2013.

Law, K. S., Sturges, W. T., Blake, D. R., Blake, N. J., Burkholder, J. B., Butler, J. H., Cox, R. A., Haynes, P. H., Ko, M. K. W., Kreher, K., Mari, C., Pfeilsticker, K., Plane, J. M. C., Salawitch, R. J., Schiller, C., Sinnhuber, B.-M., von Glasow, R., Warwick, N. J., Wuebbles, D. J., and Yvon-Lewis, S. A.: Halogenated very short-lived substances, in: Scientific Assessment of Ozone Depletion: 2006, Global Ozone Research and Monitoring Project, chapter 2, Report No. 50, World Meteorological Organization, Geneva, Switzerland, 2007.

Lefèvre, F., Brasseur, G. P., Folkins, I., Smith, A. K., and Simon, P.: Chemistry of the 19911992 stratospheric winter: three-dimensional model simulations, J. Geophys. Res., 99, 81838195, doi:10.1029/93JD03476, 1994.

Towards a

representation of

halogens in volcanic

plumes

L. Grellier et al.

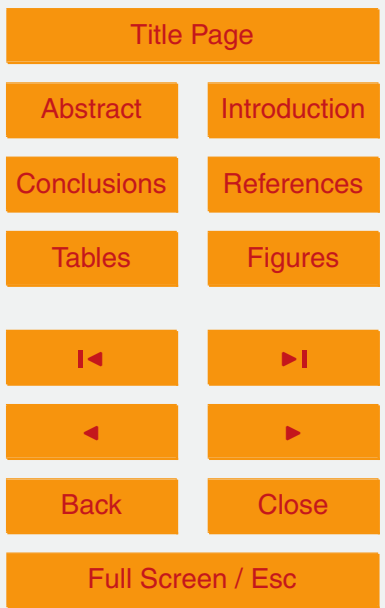

Printer-friendly Version

Interactive Discussion 
Liu, H., Jacob, D. J., Bey, I., and Yantosca, R. M.: Constraints from 210Pb and 7Be on wet deposition and transport in a global three-dimensional chemical tracer model driven by assimilated meteorological fields, J. Geophys. Res., 106, 12109-12128, doi:10.1029/2000JD900839, 2001.

5 Louis, J.-F.: A parametric model of vertical eddy fluxes in the atmosphere, Bound.-Lay. Meteorol., 17, 187-202, doi:10.1007/BF00117978, 1979.

Marchetti, E., Ripepe, M., Ulivieri, G., Caffo, S., and Privitera, E.: Infrasonic evidences for branched conduit dynamics at Mt. Etna volcano, Italy, Geophys. Res. Lett., 36, L19308, doi:10.1029/2009GL040070, 2009.

10 Mari, C., Jacob, D. J., and Bechtold, P.: Transport and scavenging of soluble gases in a deep convective cloud, J. Geophys. Res., 105, 22255-22267, doi:10.1029/2000JD900211, 2000.

Martin, R. S., Mather, T. A., and Pyle, D. M.: High-temperature mixtures of magmatic and atmospheric gases, Geochem. Geophy. Geosy., 7, Q04006, doi:10.1029/2005GC001186, 2006.

Martin, R. S., Roberts, T., Mather, T., and Pyle, D.: The implications of $\mathrm{H}_{2} \mathrm{~S}$ and $\mathrm{H}_{2}$ kinetic stability in high-T mixtures of magmatic and atmospheric gases for the production of oxidized trace species (e.g., BrO and NOx), Chem. Geol., 263, 143-150, 2009.

Métrich, N. and Rutherford, M. J.: Low pressure crystallization paths of $\mathrm{H}_{2} \mathrm{O}$-saturated BasalticHawaiitic melts from Mt Etna: implications for open-system degassing of basaltic volcanoes, Geochim. Cosmochim. Ac., 62, 1195-1205, 1998.

Oppenheimer, C.: 3.04 - Volcanic degassing, in: Treatise on Geochemistry, edited by: Holland, H. D. and Turekian, K. K., 123-166, Pergamon, Oxford, 2003.

Oppenheimer, C., Tsanev, V. I., Braban, C. F., Cox, R. A., Adams, J. W., Aiuppa, A., Bobrowski, N., Delmelle, P., Barclay, J., and McGonigle, A. J.: BrO formation in volcanic plumes, Geochim. Cosmochim. Ac., 70, 2935-2941, 2006.
Patanè, D., Privitera, E., Gresta, S., Akinci, A., Arpalone, S., Barberi, G., Chiaraluce, L., Cocina, O., D’amico, S., Gori, P. D., Grazia, G. D., Falsaperla, S., Ferrari, F., Gambino, S., Giampiccolo, E., Langer, H., Maiolino, V., Moretti, M., Mostaccio, A., Musumeci, C., Piccinini, D., Reitano, D., Scarfi, L., Spampinato, S., Ursino, A., and Zuccarello, L.: Seismological constraints for the dyke emplacement of the July-August 2001 lateral eruption at Mt. Etna volcano, Italy, Ann. Geophys.-Italy, 46, 4, doi:10.4401/ag-6302, 2003.

Platt, U. and Hönninger, G.: The role of halogen species in the troposphere, Chemosphere, 52, 325-338, 2003.
GMDD

Towards a

representation of

halogens in volcanic

plumes

L. Grellier et al.

Title Page

Abstract

Introduction

Conclusions

Tables

References

Figures

14

Back

Full Screen / Esc

Printer-friendly Version

Interactive Discussion 
Platt, U. and Lehrer, E.: Arctic Tropospheric Ozone Chemistry, ARTOC, Final Report of the EU-Project No. EV5V-CT93-0318, 1997.

Roberts, T. J., Braban, C., Martin, R., Oppenheimer, C., Adams, J., Cox, R., Jones, R., and Griffiths, P.: Modelling reactive halogen formation and ozone depletion in volcanic plumes,

5 Chem. Geol., 263, 151-163, 2009.

Roberts, T. J., Jourdain, L., Griffiths, P. T., and Pirre, M.: Re-evaluating the reactive uptake of $\mathrm{HOBr}$ in the troposphere with implications for the marine boundary layer and volcanic plumes, Atmos. Chem. Phys. Discuss., 14, 2717-2771, doi:10.5194/acpd-14-2717-2014, 2014 a.

Roberts, T. J., Martin, R. S., and Jourdain, L.: Reactive bromine chemistry in Mt. Etna's volcanic plume: the influence of total $\mathrm{Br}$, high temperature processing, aerosol loading and plumeair mixing, Atmos. Chem. Phys. Discuss., 14, 5445-5494, doi:10.5194/acpd-14-5445-2014, 2014b.

Salawitch, R. J., Weisenstein, D. K., Kovalenko, L. J., Sioris, C. E., Wennberg, P. O., Chance, K., Ko, M. K. W., and McLinden, C. A.: Sensitivity of ozone to bromine in the lower stratosphere, Geophys. Res. Lett., 32, L05811, doi:10.1029/2004GL021504, 2005.

Sander, R.: Modeling atmospheric chemistry: interactions between gas-phase species and liquid cloud/aerosol particles, Surv. Geophys., 20, 1-31, doi:10.1023/A:1006501706704, 1999.

Spinetti, C. and Buongiorno, M.: Volcanic aerosol optical characteristics of Mt. Etna tropospheric plume retrieved by means of airborne multispectral images, J. Atmos. Sol.-Terr. Phy., 69, 981-994, 2007.

Stockwell, W. R., Kirchner, F., Kuhn, M., and Seefeld, S.: A new mechanism for regional atmospheric chemistry modeling, J. Geophys. Res., 102, 25847-25879, doi:10.1029/97JD00849, 1997.

Stothers, R. B.: A chronology of annual mean effective radii of stratospheric aerosols from volcanic eruptions during the twentieth century as derived from ground-based spectral extinction measurements, J. Geophys. Res., 106, 32043-32049, doi:10.1029/2001JD000414, 2001.

Tabazadeh, A., Toon, O. B., Clegg, S. L., and Hamill, P.: A new parameterization of $\mathrm{H}_{2} \mathrm{SO}_{4} / \mathrm{H}_{2} \mathrm{O}$ aerosol composition: Atmospheric implications, Geophys. Res. Lett., 24, 19311934, doi:10.1029/97GL01879, 1997.

Theys, N., Van Roozendael, M., Dils, B., Hendrick, F., Hao, N., and De Mazière, M.: First satellite detection of volcanic bromine monoxide emission after the Kasatochi eruption, Geophys. Res. Lett., 36, L03809, doi:10.1029/2008GL036552, 2009.

Towards a

representation of

halogens in volcanic

plumes

L. Grellier et al.

Title Page

Abstract

Introduction

Conclusions

Tables

References

Figures

14

4

Back

Full Screen / Esc

Printer-friendly Version

Interactive Discussion $\rightarrow$

ose

(n) 
Valari, M. and Menut, L.: Transferring the heterogeneity of surface emissions to variability in pollutant concentrations over urban areas through a chemistry-transport model, Atmos. Environ., 44, 3229-3238, 2010.

von Glasow, R.: Atmospheric chemistry in volcanic plumes, P. Natl. Acad. Sci. USA, 107, 65946599, doi:10.1073/pnas.0913164107, 2010.

von Glasow, R. and Crutzen, P.: 4.02 - Tropospheric halogen chemistry, in: Treatise on Geochemistry, edited by: Holland, H. D. and Turekian, K. K., Pergamon, Oxford, 1-67, 2003.

von Glasow, R., Bobrowski, N., and Kern, C.: The effects of volcanic eruptions on atmospheric chemistry, Chem. Geol., 263, 131-142, 2009.

10 Watson, I. M. and Oppenheimer, C.: Particle size distributions of Mount Etna's aerosol plume constrained by Sun photometry, J. Geophys. Res., 105, 9823-9829, doi:10.1029/2000JD900042, 2000.

Watson, I. M. and Oppenheimer, C.: Photometric observations of Mt. Etna's different aerosol plumes, Atmos. Environ., 35, 3561-3572, 2001.

Wennberg, P.: Atmospheric chemistry: bromine explosion, Nature, 397, 299-301, doi:10.1038/16805, 1999.

Wesely, M.: Parameterization of surface resistances to gaseous dry deposition in regional-scale numerical models, Atmos. Environ., 23, 1293-1304, 1989.

Williamson, D. L. and Rasch, P. J.: Two-dimensional semi-Lagrangian transport with shapepreserving interpolation, Mon. Weather Rev., 117, 102-129, 1989.

Wofsy, S. C., McElroy, M. B., and Yung, Y. L.: The chemistry of atmospheric bromine, Geophys. Res. Lett., 2, 215-218, doi:10.1029/GL002i006p00215, 1975.

Yung, Y. L., Pinto, J. P., Watson, R. T., and Sander, S. P.: Atmospheric bromine and ozone perturbations in the lower stratosphere, J. Atmos. Sci., 37, 339-353, 1980.
GMDD

$7,2581-2650,2014$

Towards a

representation of

halogens in volcanic

plumes

L. Grellier et al.

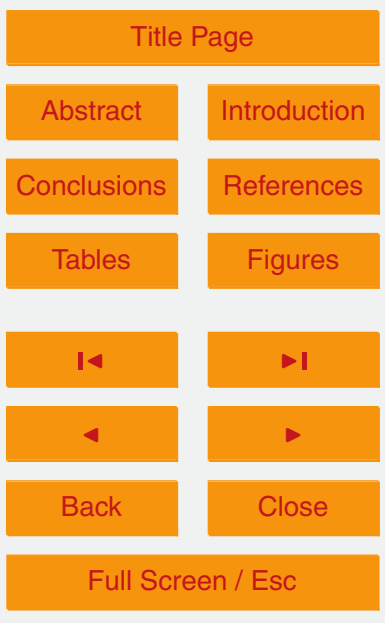

Printer-friendly Version

Interactive Discussion 
Table 1. Molar ratio of the main species emitted by Mount Etna volcano, the 14 May 2008.

\begin{tabular}{ll}
\hline Species & Molar ratio (mol \%) \\
\hline $\mathrm{H}_{2} \mathrm{O}$ & 90 \\
$\mathrm{CO}_{2}$ & 8 \\
$\mathrm{SO}_{2}$ & 0.7 \\
$\mathrm{HCl}$ & 0.21 \\
$\mathrm{HF}$ & 0.09 \\
$\mathrm{HBr}$ & $2.3 \times 10^{-4}$ \\
$\mathrm{HI}$ & $5.4 \times 10^{-6}$ \\
$\mathrm{H}_{2} \mathrm{~S}$ & $4.45 \times 10^{-3}$ \\
$\mathrm{H}_{2}$ & 0.162 \\
$\mathrm{CO}$ & $2.18 \times 10^{-3}$ \\
\hline
\end{tabular}

GMDD

7, 2581-2650, 2014

Towards a

representation of

halogens in volcanic

plumes

L. Grellier et al.

Title Page

Abstract

Introduction

Conclusions

References

Tables

Figures

14

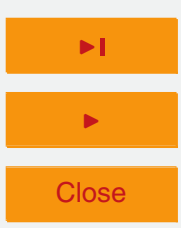

Back

Close

Full Screen / Esc

Printer-friendly Version

Interactive Discussion 
Table 2. Gaseous composition after the mixing, between magmatic and atmospheric air, calculated by the $\mathrm{HSC}$ model at $1100^{\circ} \mathrm{C}$ and for the ratios of $V_{\mathrm{M}} / V_{\mathrm{A}}: 95 / 5,90 / 10$ and $60 / 40$.

\begin{tabular}{|c|c|c|c|}
\hline Espèces & $95 / 5\left(V_{\mathrm{M}} / V_{\mathrm{A}}\right)$ & $90 / 10\left(V_{\mathrm{M}} / V_{\mathrm{A}}\right)$ & $60 / 40\left(V_{M} / V_{\mathrm{A}}\right)$ \\
\hline $\mathrm{SO}_{2}$ & $6.63 \times 10^{-3}$ & $6.22 \times 10^{-3}$ & $2.05 \times 10^{-3}$ \\
\hline $\mathrm{HCl}$ & $2.00 \times 10^{-3}$ & $1.90 \times 10^{-3}$ & $1.27 \times 10^{-3}$ \\
\hline $\mathrm{SO}_{3}$ & $6.67 \times 10^{-5}$ & $1.29 \times 10^{-4}$ & $2.17 \times 10^{-3}$ \\
\hline NO & $2.56 \times 10^{-5}$ & $3.60 \times 10^{-5}$ & $7.14 \times 10^{-6}$ \\
\hline $\mathrm{OH}$ & $2.00 \times 10^{-5}$ & $1.22 \times 10^{-5}$ & $6.44 \times 10^{-8}$ \\
\hline $\mathrm{Cl}$ & $2.64 \times 10^{-6}$ & $2.10 \times 10^{-6}$ & $1.04 \times 10^{-7}$ \\
\hline $\mathrm{HBr}$ & $1.65 \times 10^{-6}$ & $1.52 \times 10^{-6}$ & $9.99 \times 10^{-7}$ \\
\hline $\mathrm{Br}$ & $5.50 \times 10^{-7}$ & $5.56 \times 10^{-7}$ & $2.47 \times 10^{-7}$ \\
\hline $\mathrm{CO}$ & $2.03 \times 10^{-7}$ & $4.53 \times 10^{-8}$ & $1.30 \times 10^{-12}$ \\
\hline $\mathrm{NO}_{2}$ & $5.66 \times 10^{-8}$ & $1.41 \times 10^{-7}$ & $3.80 \times 10^{-7}$ \\
\hline $\mathrm{HOCl}$ & $5.49 \times 10^{-8}$ & $6.90 \times 10^{-8}$ & $5.33 \times 10^{-8}$ \\
\hline $\mathrm{HO}_{2}$ & $3.90 \times 10^{-8}$ & $3.94 \times 10^{-8}$ & $1.55 \times 10^{-9}$ \\
\hline $0^{2}$ & $2.96 \times 10^{-8}$ & $1.55 \times 10^{-8}$ & $7.05 \times 10^{-12}$ \\
\hline $\mathrm{Cl}_{2}$ & $2.78 \times 10^{-8}$ & $4.72 \times 10^{-8}$ & $4.47 \times 10^{-7}$ \\
\hline $\mathrm{H}_{2} \mathrm{SO}_{4}$ & $1.78 \times 10^{-8}$ & $4.63 \times 10^{-8}$ & $1.03 \times 10^{-5}$ \\
\hline $\mathrm{ClO}$ & $7.80 \times 10^{-9}$ & $9.58 \times 10^{-9}$ & $1.92 \times 10^{-9}$ \\
\hline $\mathrm{H}_{2} \mathrm{O}_{2}$ & $4.99 \times 10^{-9}$ & $4.39 \times 10^{-9}$ & $1.69 \times 10^{-10}$ \\
\hline $\mathrm{BrCl}$ & $1.83 \times 10^{-9}$ & $3.57 \times 10^{-9}$ & $1.30 \times 10^{-7}$ \\
\hline $\mathrm{BrO}$ & $8.20 \times 10^{-11}$ & $1.10 \times 10^{-10}$ & $5.96 \times 10^{-11}$ \\
\hline $\mathrm{Br}_{2}$ & $2.66 \times 10^{-11}$ & $5.92 \times 10^{-11}$ & $7.93 \times 10^{-9}$ \\
\hline OClO & $1.09 \times 10^{-12}$ & $1.93 \times 10^{-12}$ & $8.89 \times 10^{-13}$ \\
\hline $\mathrm{HNO}_{3}$ & $8.38 \times 10^{-13}$ & $2.82 \times 10^{-12}$ & $3.55 \times 10^{-11}$ \\
\hline $\mathrm{O}_{3}$ & $7.53 \times 10^{-13}$ & $1.21 \times 10^{-12}$ & $8.30 \times 10^{-14}$ \\
\hline $\mathrm{NO}_{3}$ & $4.52 \times 10^{-15}$ & $1.34 \times 10^{-14}$ & $1.84 \times 10^{-14}$ \\
\hline
\end{tabular}

GMDD

7, 2581-2650, 2014

Towards a

representation of

halogens in volcanic

plumes

L. Grellier et al.

Title Page

Abstract

Introduction

Conclusions

References

Tables

Figures

14

$\triangleleft$

Back

Close 
Table 3. Characteristics of the different simulations.

\begin{tabular}{llllll}
\hline & $\begin{array}{l}\text { Resolution of } \\
\text { the model grid }\end{array}$ & $\begin{array}{l}\mathrm{HSC} \text { ratio } \\
V_{\mathrm{M}} / V_{\mathrm{A}}\end{array}$ & $\begin{array}{l}\text { Use of the } \\
\text { parameterization }\end{array}$ & $\begin{array}{l}\text { If parameterization : dilution } \\
\text { of the plume box }\end{array}$ & Radii $(\mu \mathrm{m})$ \\
\hline Ref & $0.5^{\circ} \times 0.5^{\circ}$ & $95 / 5$ & No & $\mathrm{N} / \mathrm{A}$ & 2 \\
Plume 1 & $0.5^{\circ} \times 0.5^{\circ}$ & $95 / 5$ & Yes & $15 \mathrm{~min}$ & 2 \\
Plume 2 & $0.5^{\circ} \times 0.5^{\circ}$ & $95 / 5$ & Yes & $240 \mathrm{~min}$ & 2 \\
HSC_Ref & $0.5^{\circ} \times 0.5^{\circ}$ & $90 / 10$ & No & N/A & 2 \\
HSC_Plume1 & $0.5^{\circ} \times 0.5^{\circ}$ & $90 / 10$ & Yes & $15 \mathrm{~min}$ & 2 \\
HSC_Plume2 & $0.5^{\circ} \times 0.5^{\circ}$ & $90 / 10$ & Yes & $240 \mathrm{~min}$ & 2 \\
Res & $2^{\circ} \times 2^{\circ}$ & $95 / 5$ & No & N/A & 2 \\
Res_Plume1 & $2^{\circ} \times 2^{\circ}$ & $95 / 5$ & Yes & $15 \mathrm{~min}$ & 2 \\
Res_Plume2 & $2^{\circ} \times 2^{\circ}$ & $95 / 5$ & Yes & $240 \mathrm{~min}$ & 2 \\
Ref_0.5 & $0.5^{\circ} \times 0.5^{\circ}$ & $95 / 5$ & No & N/A & 0.5 \\
Ref_1 & $0.5^{\circ} \times 0.5^{\circ}$ & $95 / 5$ & No & N/A & 1 \\
Ref_4 & $0.5^{\circ} \times 0.5^{\circ}$ & $95 / 5$ & No & N/A & 4 \\
Res_0.5 & $2^{\circ} \times 2^{\circ}$ & $95 / 5$ & No & N/A & 0.5 \\
Res_1 & $2^{\circ} \times 2^{\circ}$ & $95 / 5$ & No & N/A & 1 \\
Res_4 & $2^{\circ} \times 2^{\circ}$ & $95 / 5$ & No & N/A & 4 \\
\hline
\end{tabular}

\section{GMDD}

\section{7, 2581-2650, 2014}

Towards a

representation of

halogens in volcanic

plumes

L. Grellier et al.

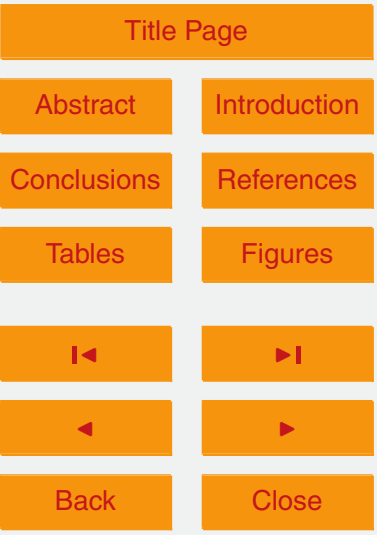

Full Screen / Esc

Printer-friendly Version

Interactive Discussion 


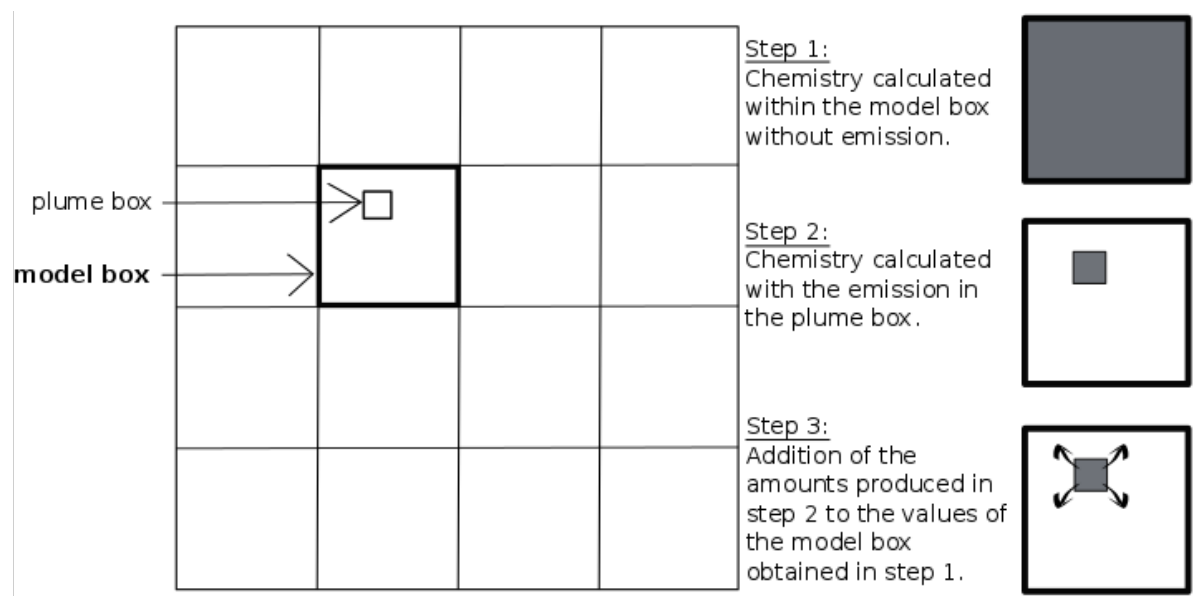

Fig. 1. Schematic representation of the parameterization used to calculated the chemical reactions during the emission.

\section{GMDD}

$7,2581-2650,2014$

Towards a

representation of

halogens in volcanic

plumes

L. Grellier et al.

\section{Title Page}

Abstract

Conclusions

Tables

14

Back
Introduction

References

Figures

$\rightarrow 1$

$>$

Close
Full Screen / Esc

Printer-friendly Version

Interactive Discussion 


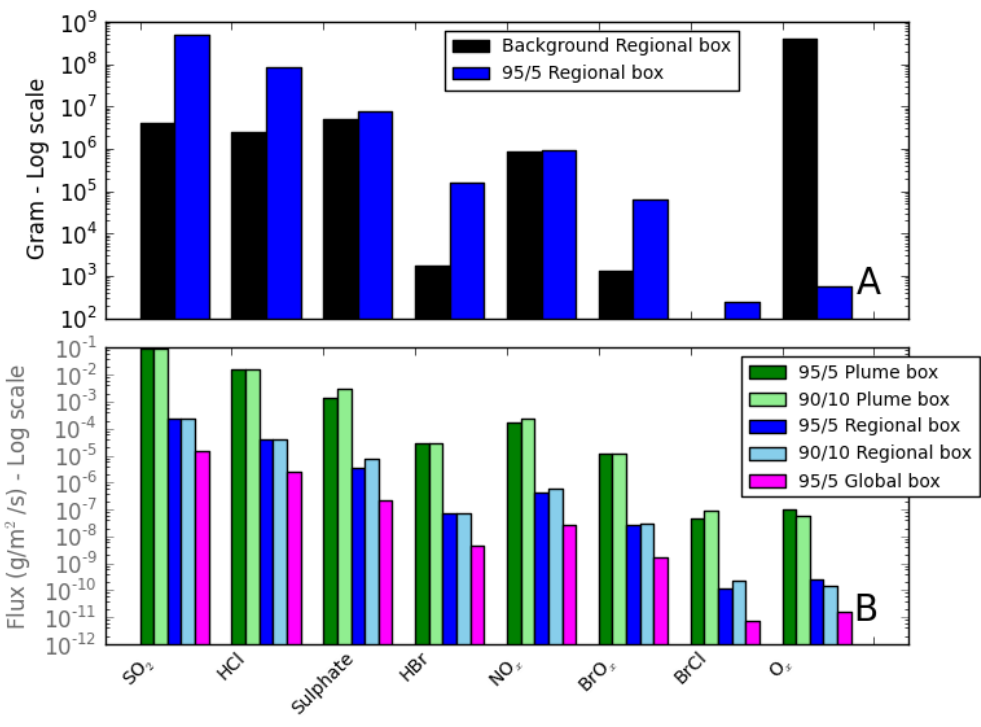

Fig. 2. In plot (A): the total mass in the partial column $(0-5 \mathrm{~km})$ of the eruption in grams for the main chemical species of the emission for the regional $\left(0.5^{\circ} \times 0.5^{\circ}\right)$ model box; the initial conditions are shown in black and the mass of the emissions emitted during 15 min using the $V_{\mathrm{M}} / V_{\mathrm{A}}$ ratio of $95 / 5$ are in blue (Ref simulation). In plot (B), the flux of the same chemical species is presented for each emissions depending on the grid box size and the $V_{\mathrm{M}} / V_{\mathrm{A}}$ ratio. 95/5 Plume box fluxes are used in Plume 1, Plume 2, Res_Plume1 and Res_Plume2 simulations, representing the plume box size (sub-grid scale $0.025^{\circ} \times 0.025^{\circ}$ ). $90 / 10$ Plume box fluxes are also for the plume size, it is used for HSC_Plume1 and HSC_Plume2 simulations. 95/5 regional box fluxes are used in Ref, Ref_ 0.5, Ref_1 and Ref_4 simulations, for the regional boxes $\left(0.5^{\circ} \times 0.5^{\circ}\right) .90 / 10$ regional box fluxes are also for the regional boxes used by the HSC simulation. And 95/5 global box fluxes represent the global boxes $\left(2^{\circ} \times 2^{\circ}\right)$ used in the Res, Res_0.5, Res_1 and Res_4 simulations.
GMDD

Towards a

representation of

halogens in volcanic

plumes

L. Grellier et al.

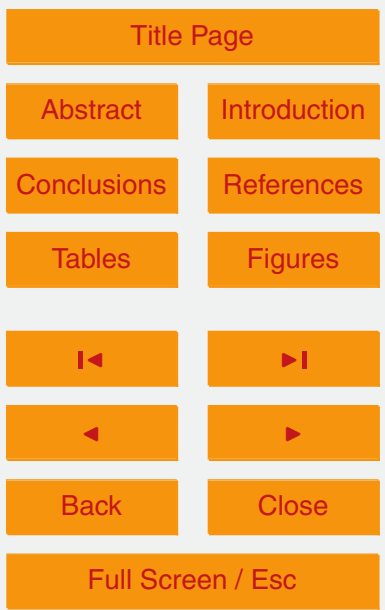

Printer-friendly Version

Interactive Discussion 


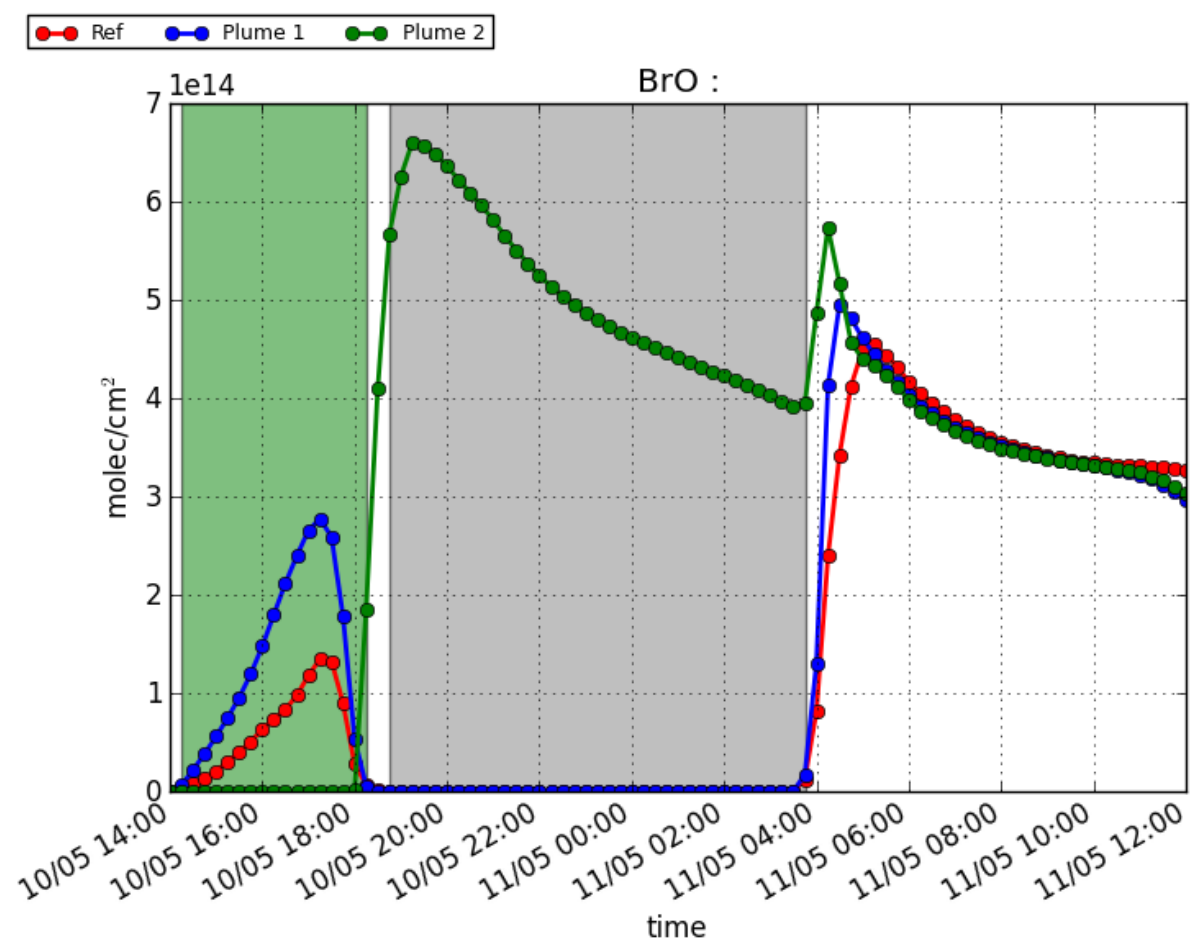

Fig. 3. Time evolution of the number of molecules of $\mathrm{BrO}$ by unit surface within the regional model grid box $\left(0.5^{\circ} \times 0.5^{\circ}\right)$, for the Ref (red line), Plume 1 (blue line) and Plume 2 (green line) configurations. The quantities are integrated vertically on the emission levels (between the ground and $5 \mathrm{~km}$ ). The green zone corresponds to the emission time, and the grey zone is the night-time.

\section{GMDD}

7, 2581-2650, 2014

\section{Towards a \\ representation of \\ halogens in volcanic \\ plumes \\ L. Grellier et al.}

\section{Title Page}

\section{Abstract}

Introduction

Conclusions

References

Tables

Figures

14

4

Back

\section{Full Screen / Esc}

Printer-friendly Version

Interactive Discussion 


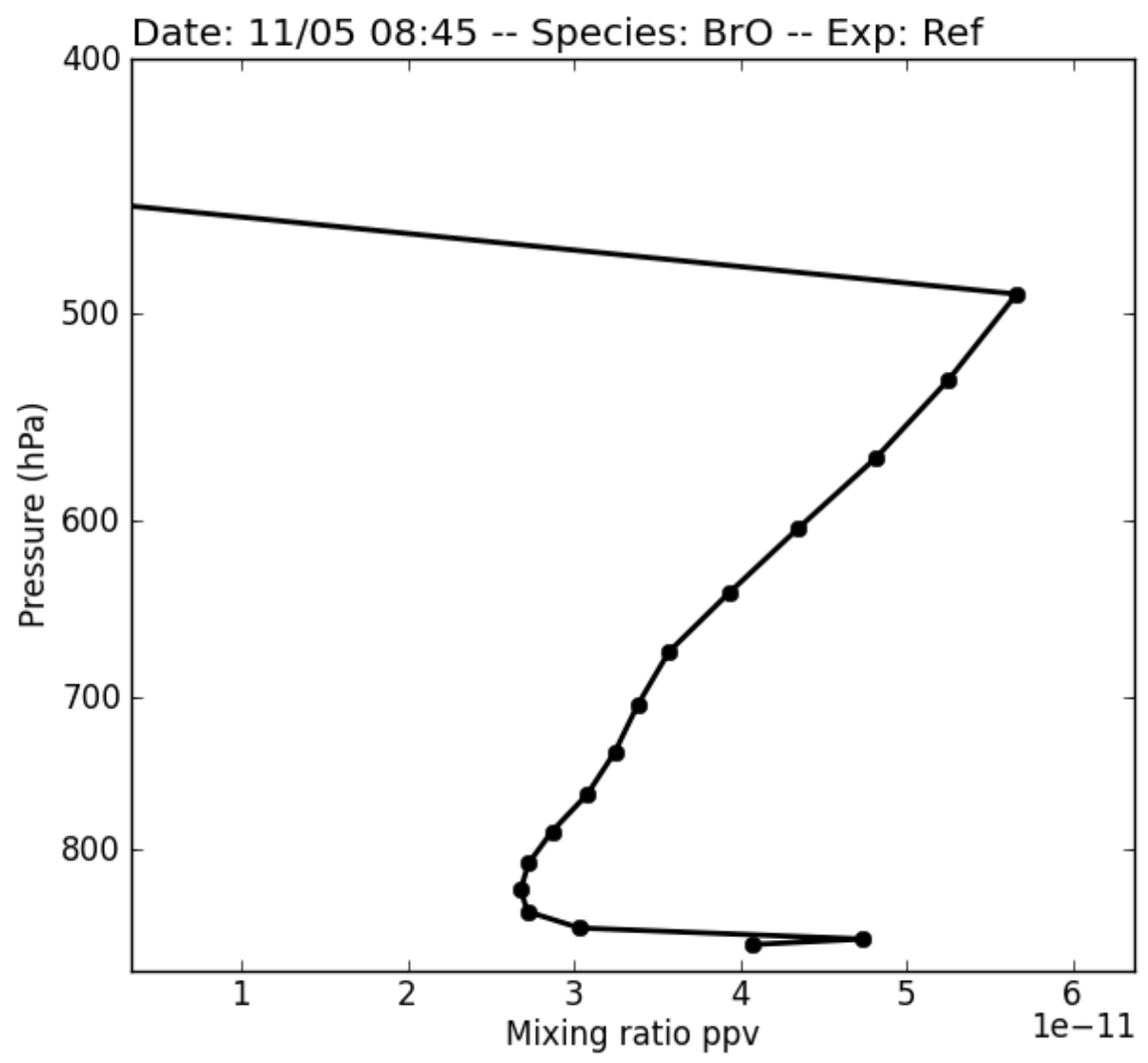

GMDD

\section{7, 2581-2650, 2014}

Towards a

representation of

halogens in volcanic

plumes

L. Grellier et al.

Title Page

Abstract

Introduction

Conclusions

References

Tables

Figures

14

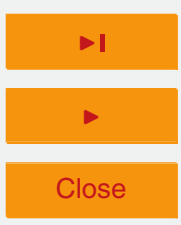

Back

Full Screen / Esc

Fig. 4. Vertical profile of the mixing ratio (ppv) of BrO the 11 May 2008, the day after the emission, at 08:45 UTC, for the Ref simulation.

Printer-friendly Version

Interactive Discussion 


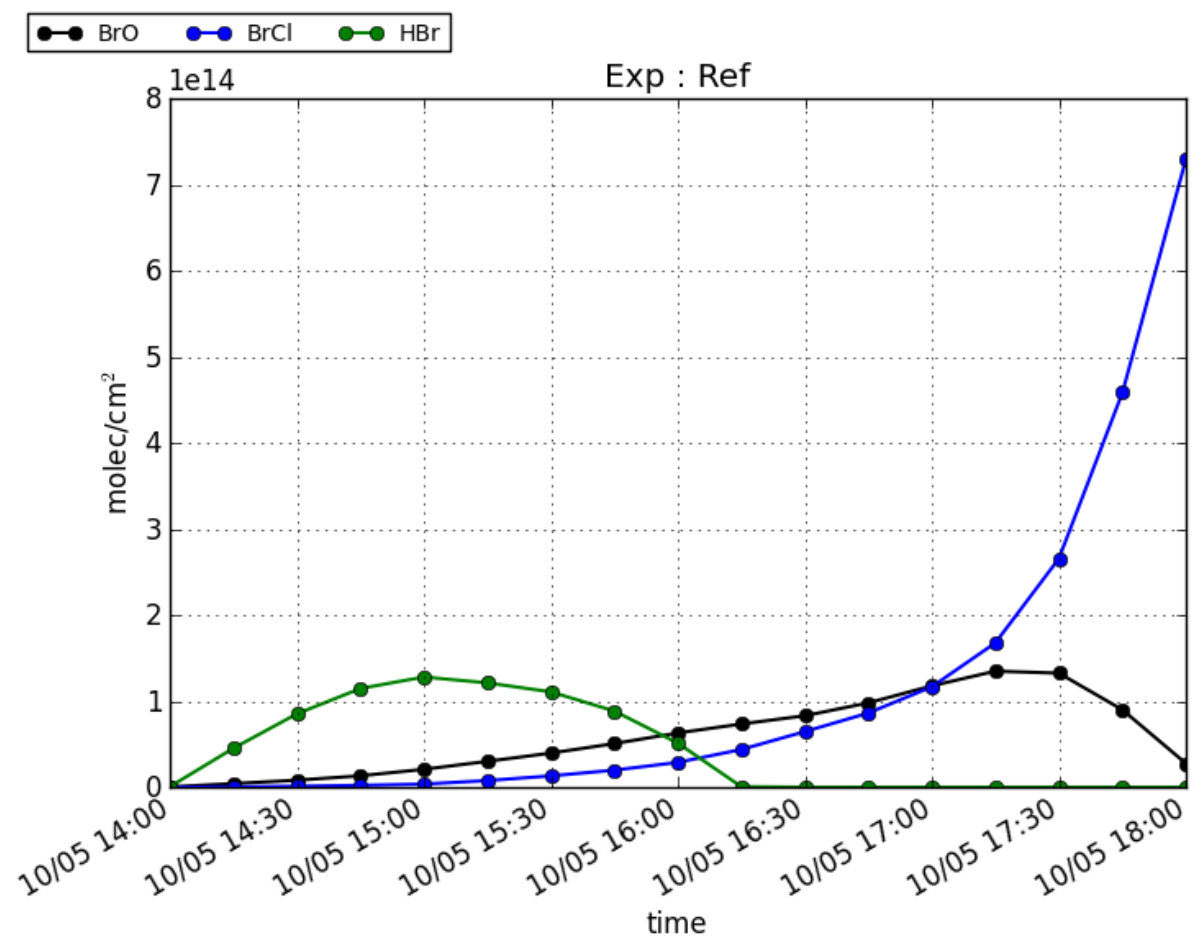

Fig. 5. Time evolution of the partial column of the emission levels for $\mathrm{BrO}, \mathrm{BrCl}$ and $\mathrm{HBr}$, in molecules $\mathrm{cm}^{-2}$, during the emission period, for the simulation Ref.

\section{GMDD}

\section{$7,2581-2650,2014$}

\section{Towards a \\ representation of \\ halogens in volcanic \\ plumes \\ L. Grellier et al.}

\section{Title Page}

Abstract

Introduction

Conclusions

References

Tables

Figures

14

4

Back

Full Screen / Esc

Printer-friendly Version

Interactive Discussion 


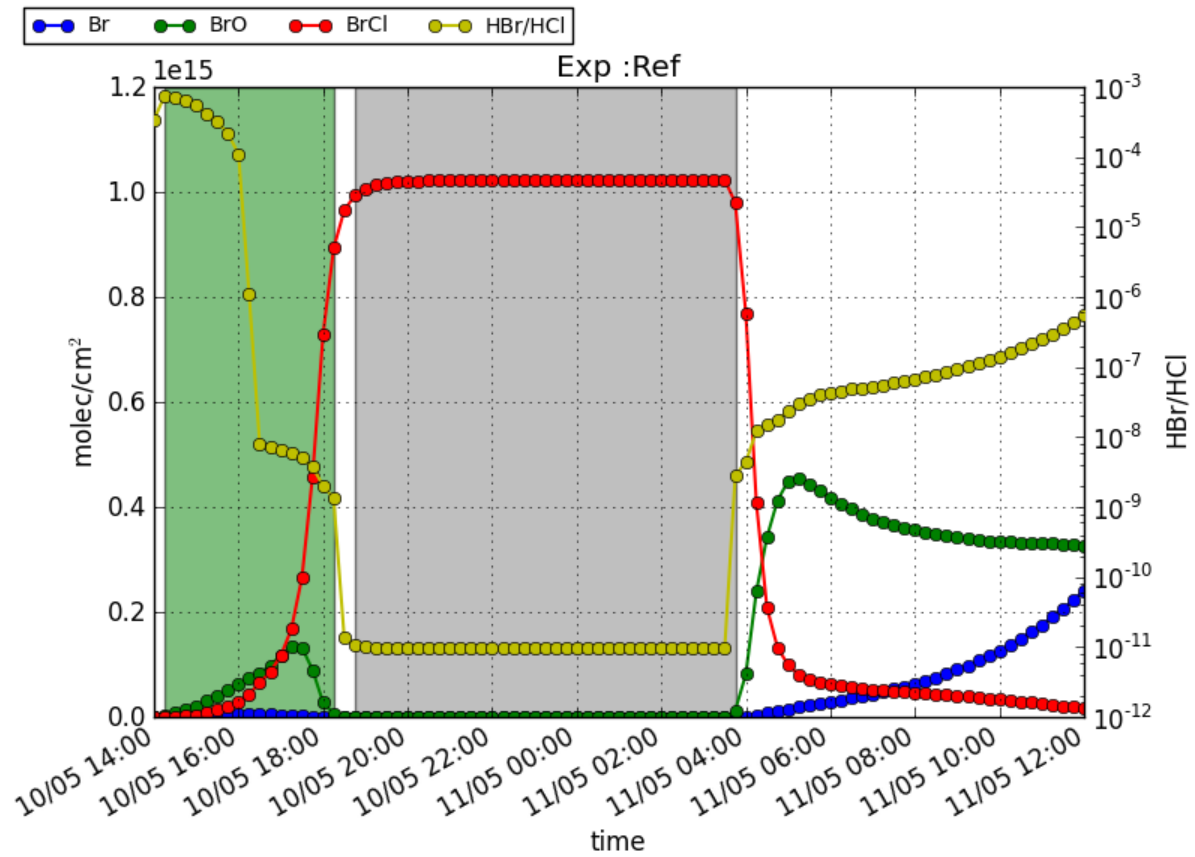

Fig. 6. Time evolution of the partial column of $\mathrm{Br}, \mathrm{BrO}$ and $\mathrm{BrCl}$ of the emission levels in molecules $\mathrm{cm}^{-2}$, for the simulation Ref. The yellow line is the $\mathrm{HBr} / \mathrm{HCl}$ ratio used in the calculation of the branching ratio. The green zone corresponds to the emission time, and the grey zone is the night-time.

\section{GMDD}

\section{7, 2581-2650, 2014}

Towards a

representation of

halogens in volcanic

plumes

L. Grellier et al.

\section{Title Page}

\section{Abstract}

Introduction

Conclusions

References

Tables

Figures

14

$\rightarrow 1$

4

Back

Close

\section{Full Screen / Esc}

Printer-friendly Version 


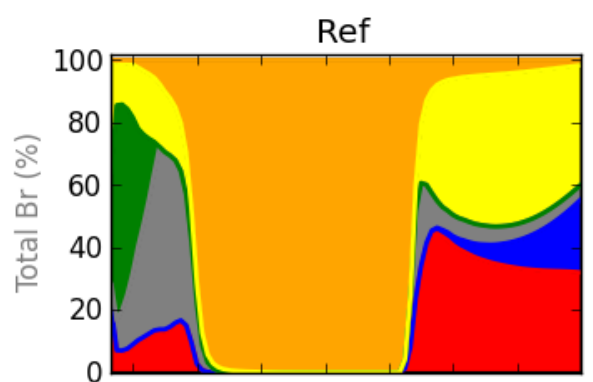

Plume 1
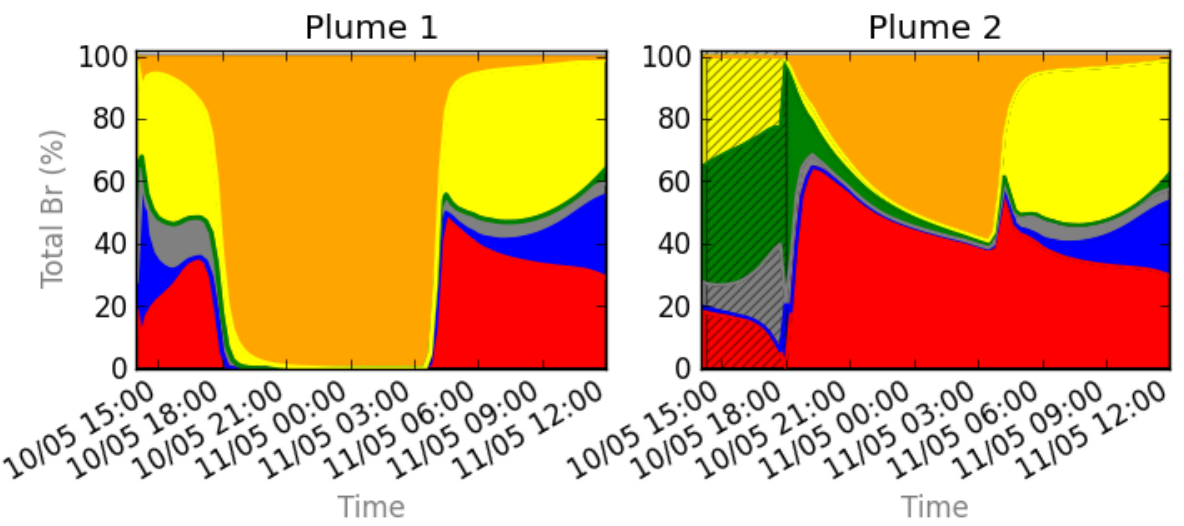

Fig. 7. Time evolution of the partitioning of the bromine species present in MOCAGE for the Ref, Plume 1 and Plume 2 simulations within the model grid box. The beginning of the Plume 2 simulation is hatched because those values are for the model grid box and remain without the influence of the plume box until the end of the emission, thus it is not comparable to the emission period of Ref and Plume 1 simulation.

\section{GMDD}

$7,2581-2650,2014$

\section{Towards a \\ representation of \\ halogens in volcanic \\ plumes \\ L. Grellier et al.}

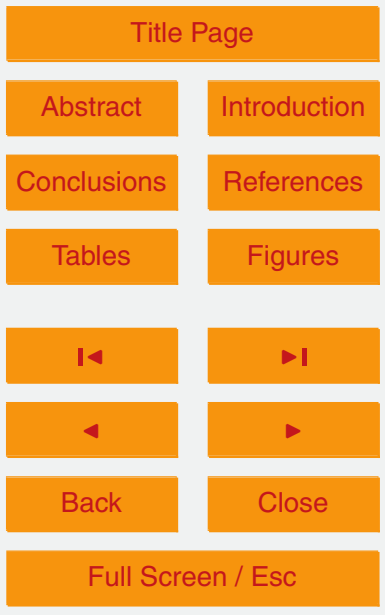

Printer-friendly Version

Interactive Discussion 


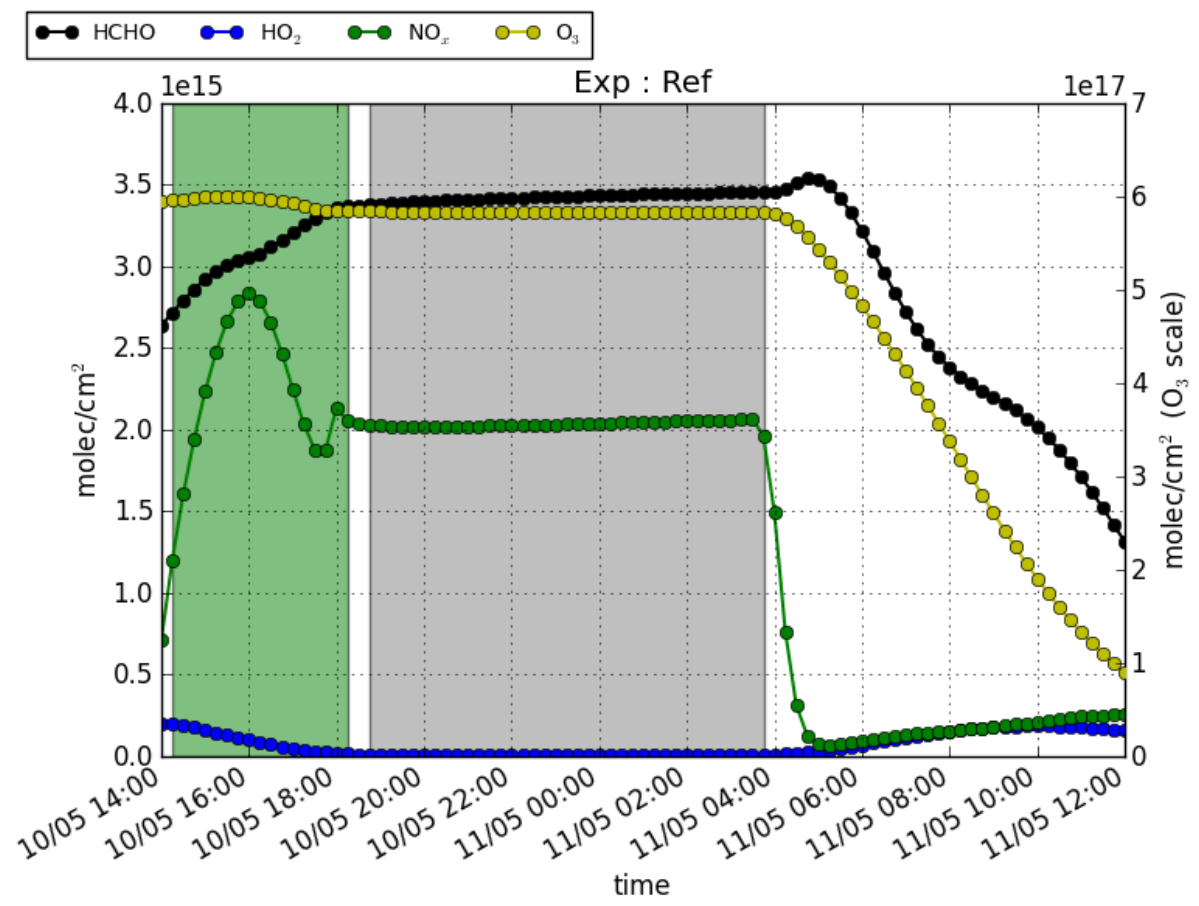

Fig. 8. Time evolution of the partial column of $\mathrm{HCHO}, \mathrm{HO}_{2}, \mathrm{NO}_{x}$ and $\mathrm{O}_{3}$ for the emission levels in molecules $\mathrm{cm}^{-2}$, for the simulation Ref.

\section{GMDD}

\section{7, 2581-2650, 2014}

Towards a

representation of

halogens in volcanic

plumes

L. Grellier et al.

\section{Title Page}

Abstract

Introduction

Conclusions

References

Tables

Figures

14

4

Back

Close

Full Screen / Esc

Printer-friendly Version

Interactive Discussion 


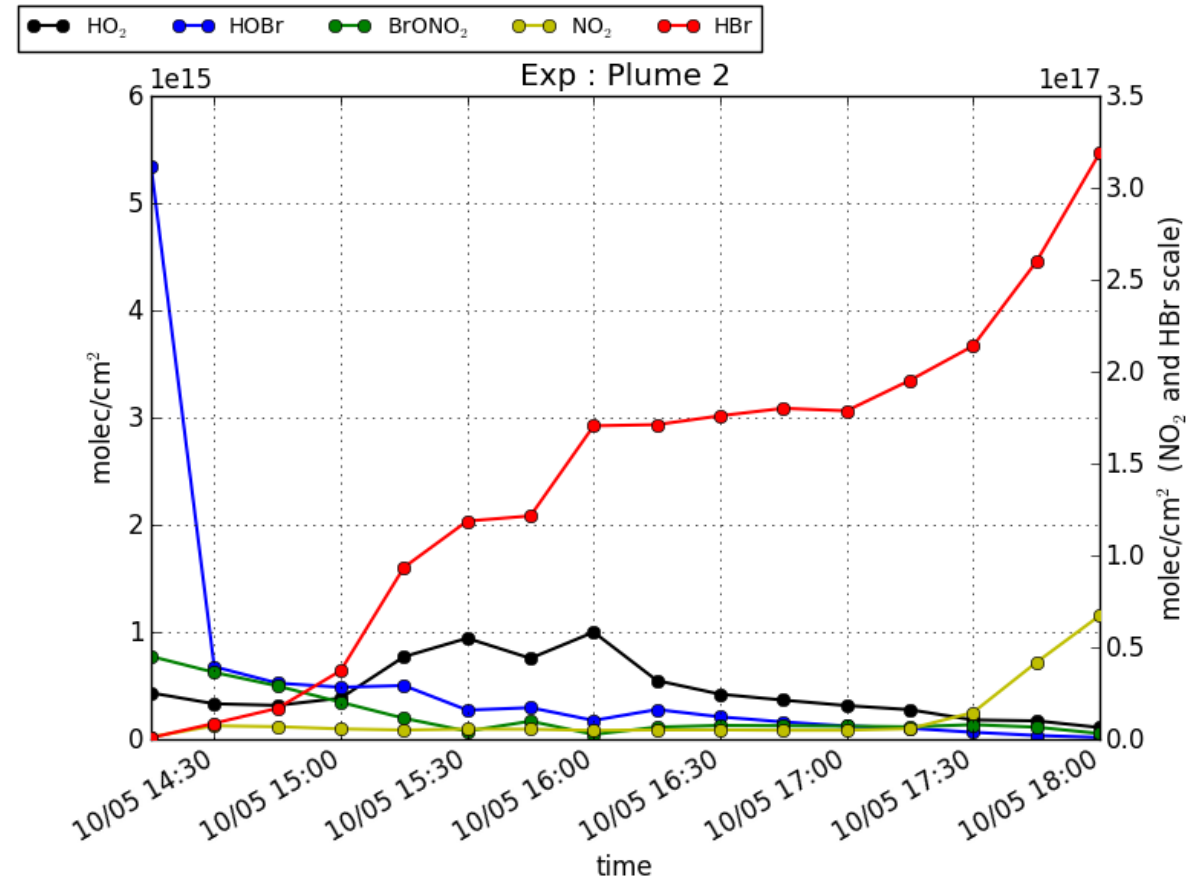

Fig. 9. Time evolution of the partial column of the emission levels for $\mathrm{NO}_{2}, \mathrm{BrONO}_{2}, \mathrm{HBr}, \mathrm{HO}_{2}$ and $\mathrm{HOBr}$ in molecules $\mathrm{cm}^{-2}$, during the emission period, for the simulation Plume 2. The partial columns are obtained with the values within the plume box $\left(0.025^{\circ} \times 0.025^{\circ}\right)$.

\section{GMDD}

7, 2581-2650, 2014

Towards a

representation of

halogens in volcanic

plumes

L. Grellier et al.

\section{Title Page}

Abstract

Introduction

Conclusions

References

Tables

Figures

14

$\rightarrow 1$

4

Back

Close

\section{Full Screen / Esc}

Printer-friendly Version

Interactive Discussion 


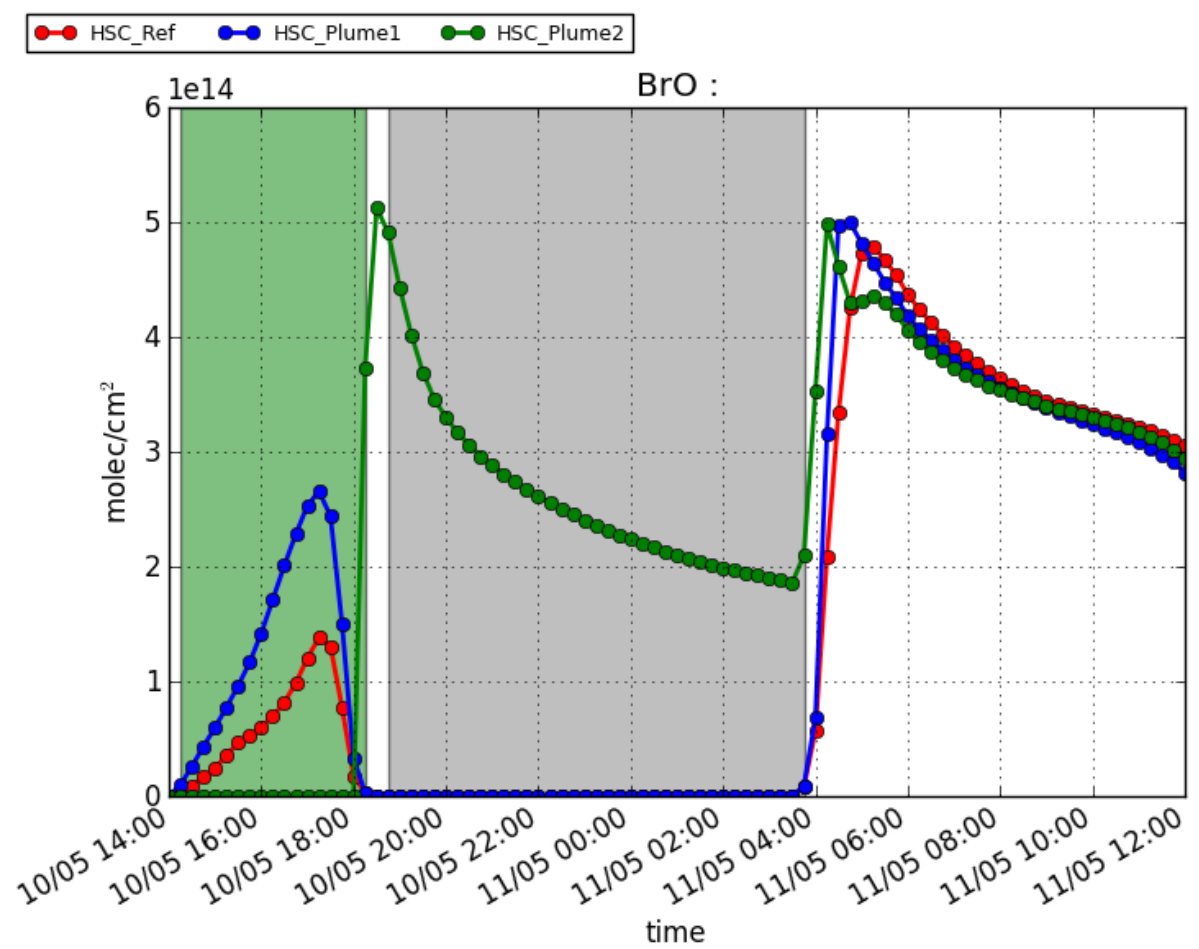

Fig. 10. As Fig. 3 but for the simulations with the $90 / 10$ ratio used for the emission in three configurations: HSC_Ref (red line), HSC_Plume1 (blue line) and HSC_Plume2 (green line).

\section{GMDD}

\section{$7,2581-2650,2014$}

\section{Towards a \\ representation of \\ halogens in volcanic \\ plumes \\ L. Grellier et al.}

\section{Title Page}

Abstract

Introduction

Conclusions

References

Tables

Figures

14

4

Back

Full Screen / Esc

Printer-friendly Version

Interactive Discussion 

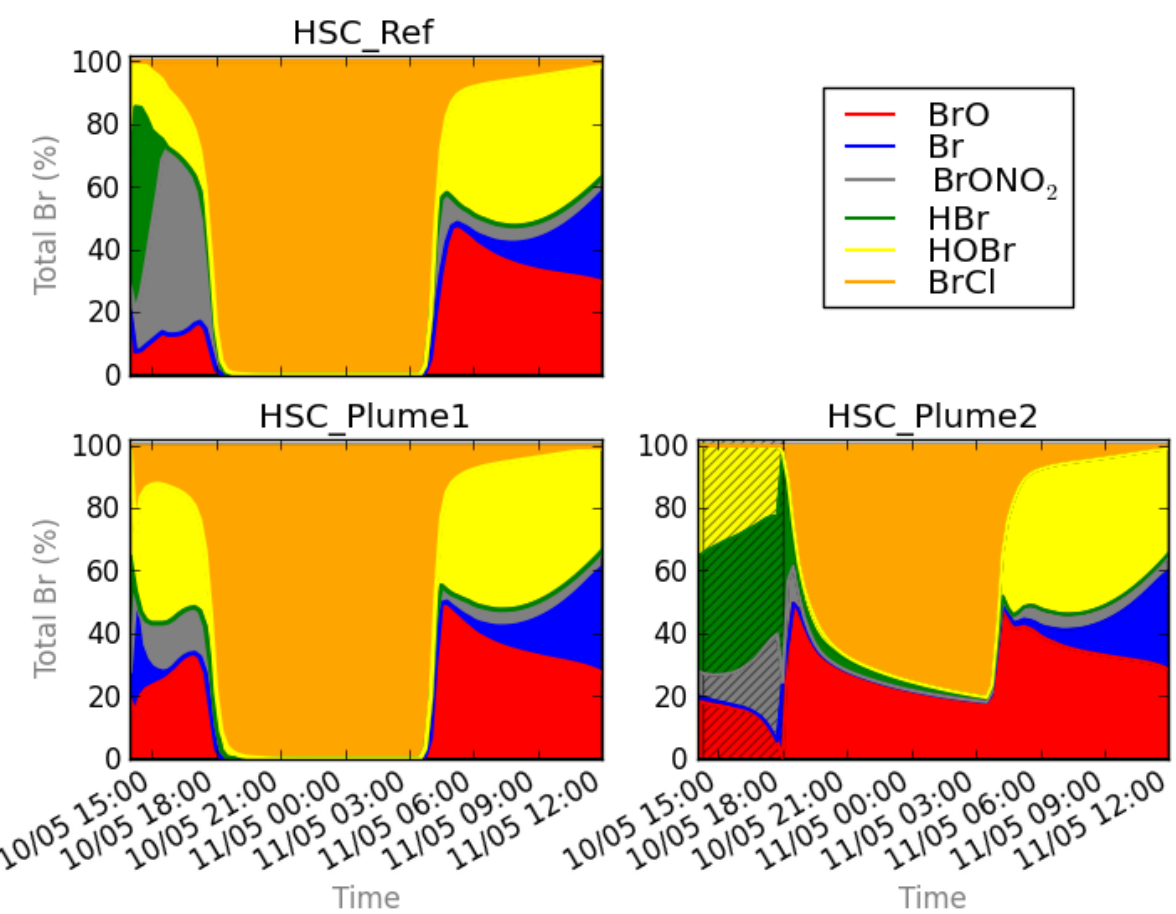

Fig. 11. As Fig. 7, partitioning of the bromine species present in MOCAGE during all the simulation, for the HSC_Ref, HSC_Plume1 and HSC_Plume2 within the model grid box.

\section{GMDD}

\section{7, 2581-2650, 2014}

Towards a

representation of

halogens in volcanic

plumes

L. Grellier et al.

\section{Title Page}

Abstract

Introduction

Conclusions

References

Tables

Figures

14

$\rightarrow 1$

4

Back

Close

\section{Full Screen / Esc}

Printer-friendly Version

Interactive Discussion 


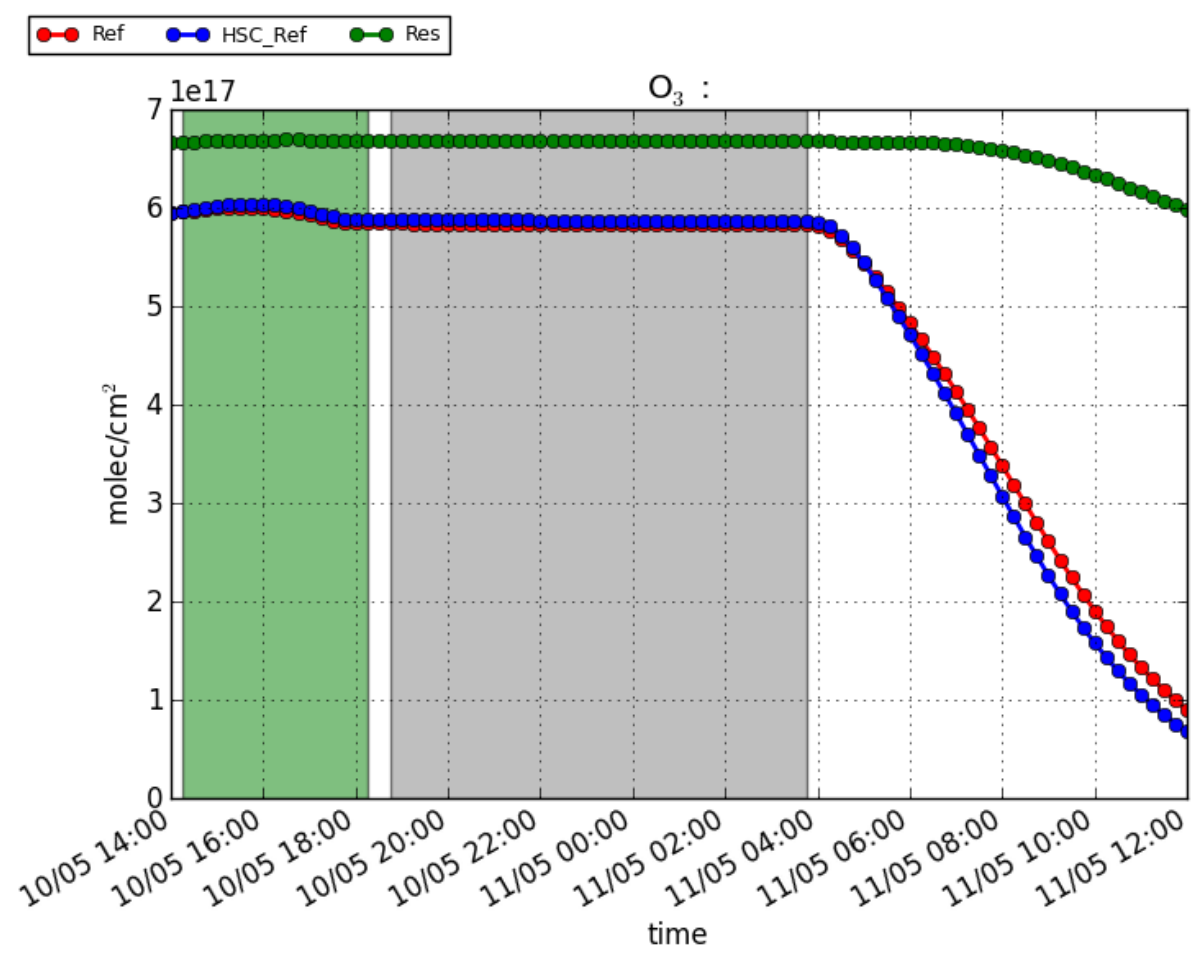

Fig. 12. Time evolution of the partial column of $\mathrm{O}_{3}$ species, in molecules $\mathrm{cm}^{-2}$, for the emission levels. Ref is the red line, HSC_Ref in blue and Res in green.

\section{GMDD}

\section{$7,2581-2650,2014$}

\section{Towards a}

representation of

halogens in volcanic

plumes

L. Grellier et al.

\section{Title Page}

\section{Abstract}

Introduction

Conclusions

References

Tables

Figures

14

4

Back

Full Screen / Esc

Printer-friendly Version

Interactive Discussion 


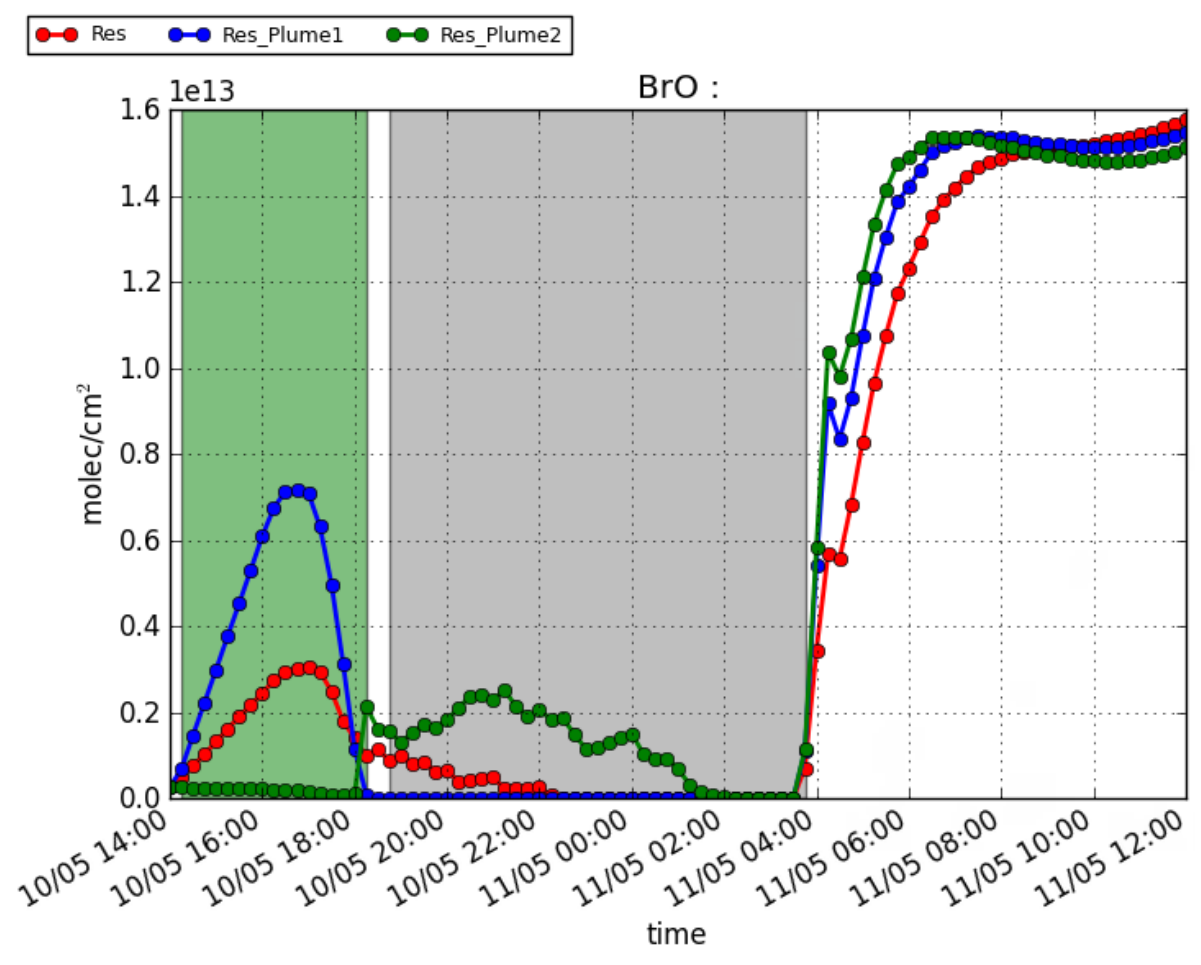

Fig. 13. As Fig. 3 but for the simulations with the model grid box resolution of $2^{\circ} \times 2^{\circ}$ and with the 95/5 ratio: Res (red line), Res_Plume1 (blue line) and Res_Plume2 (green line).

\section{GMDD}

\section{$7,2581-2650,2014$}

\section{Towards a \\ representation of \\ halogens in volcanic \\ plumes \\ L. Grellier et al.}

\section{Title Page}

Abstract

Introduction

Conclusions

References

Tables

Figures

14

4

Back

Full Screen / Esc

Printer-friendly Version

Interactive Discussion 

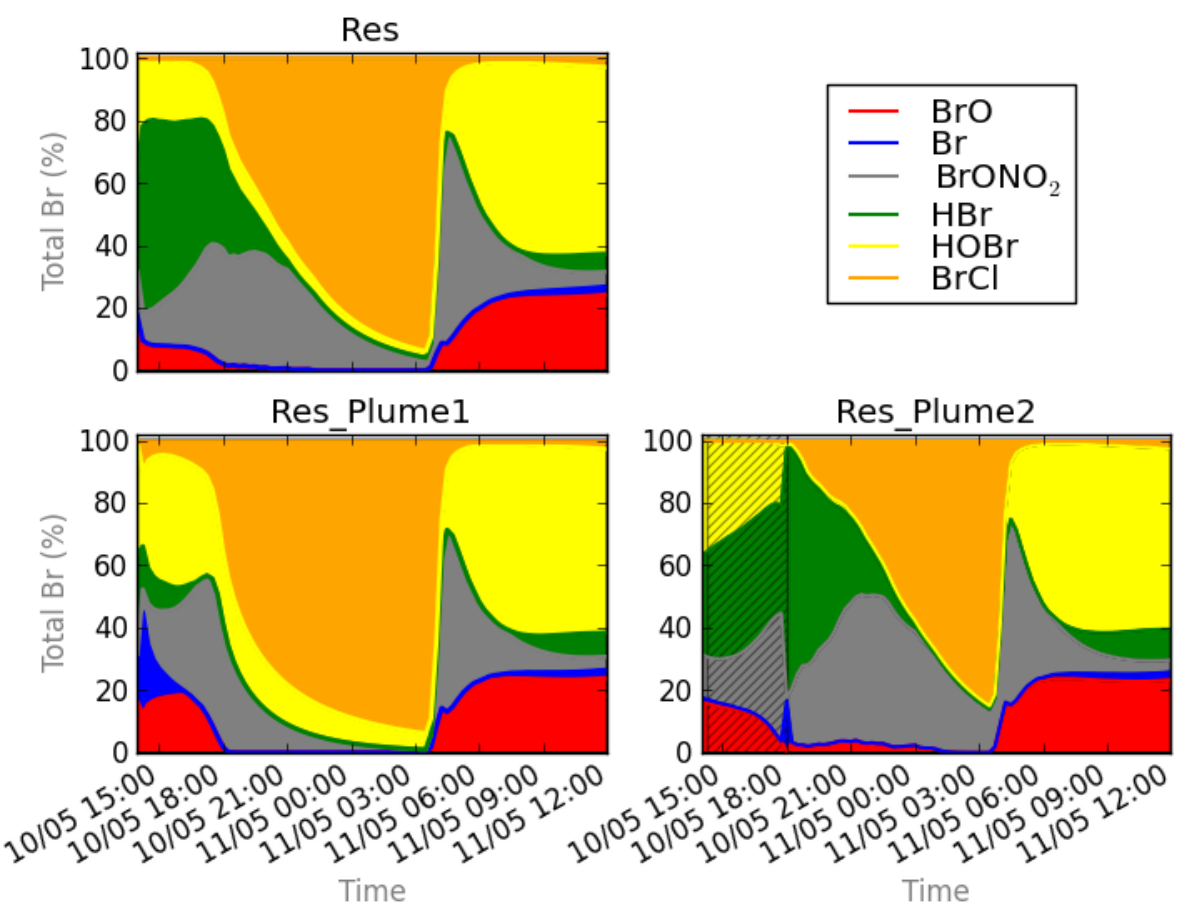

Fig. 14. As Fig. 7, partitioning of the bromine species present in MOCAGE during all the simulation, for the Res, Res_Plume1 and Res_Plume2 within the model grid box.

\section{GMDD}

\section{$7,2581-2650,2014$}

\section{Towards a \\ representation of \\ halogens in volcanic \\ plumes \\ L. Grellier et al.}

\section{Title Page}

Abstract

Introduction

Conclusions

References

Tables

Figures

14

4

Back

Full Screen / Esc

Printer-friendly Version

Interactive Discussion 


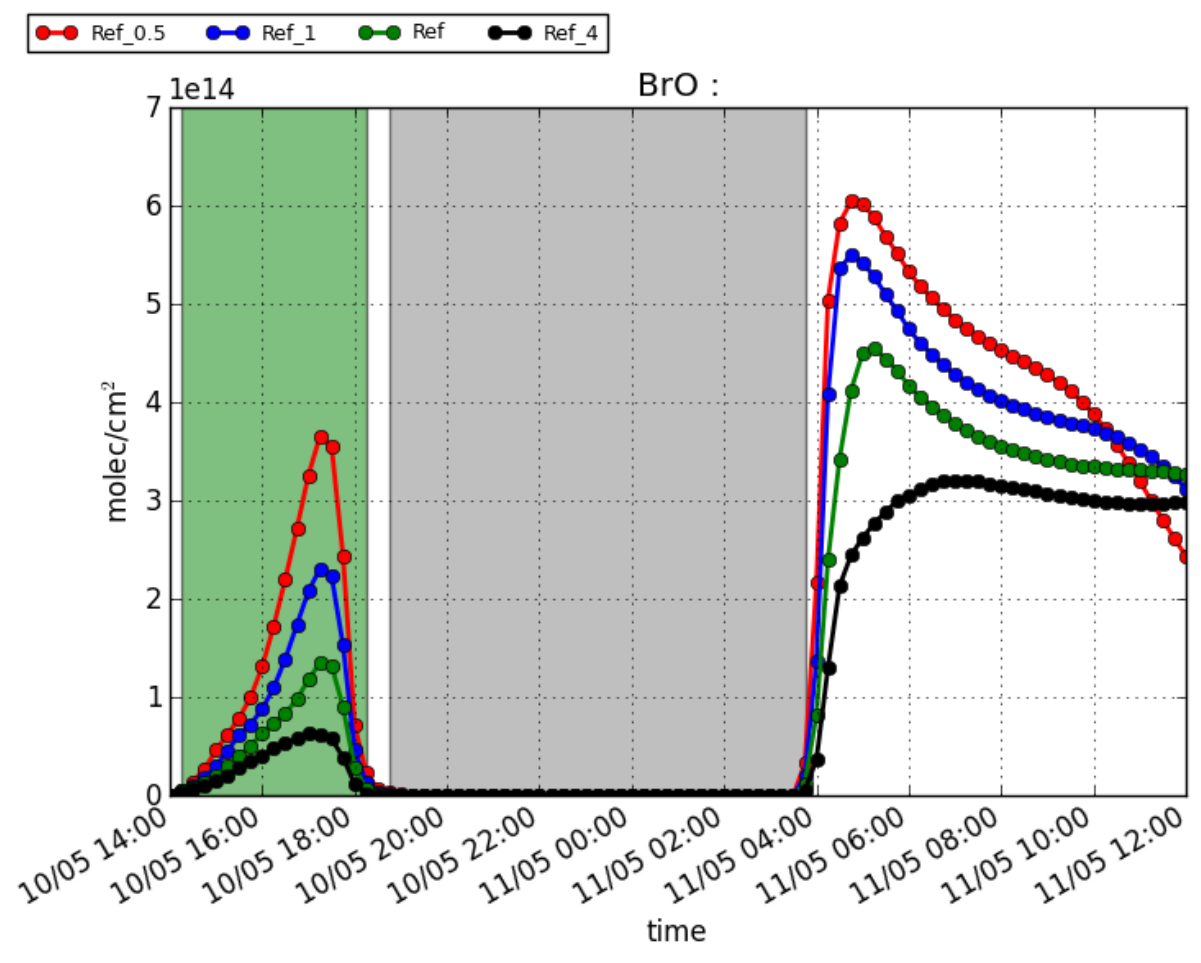

Fig. 15. Partial column as for Fig. 3. The simulations are with the model grid box resolution of $0.5^{\circ} \times 0.5^{\circ}$ and with the $95 / 5$ ratio. The radius of the sulphate aerosols is $0.5 \mu \mathrm{m}$ (red line), $1 \mu \mathrm{m}$ (blue line), $2 \mu \mathrm{m}$ (green line) and $4 \mu \mathrm{m}$ (black line).

\section{GMDD}

7, 2581-2650, 2014

\section{Towards a \\ representation of \\ halogens in volcanic \\ plumes \\ L. Grellier et al.}

\section{Title Page}

Abstract

Introduction

Conclusions

References

Tables

Figures

14

4

Back

Full Screen / Esc

Printer-friendly Version

Interactive Discussion 


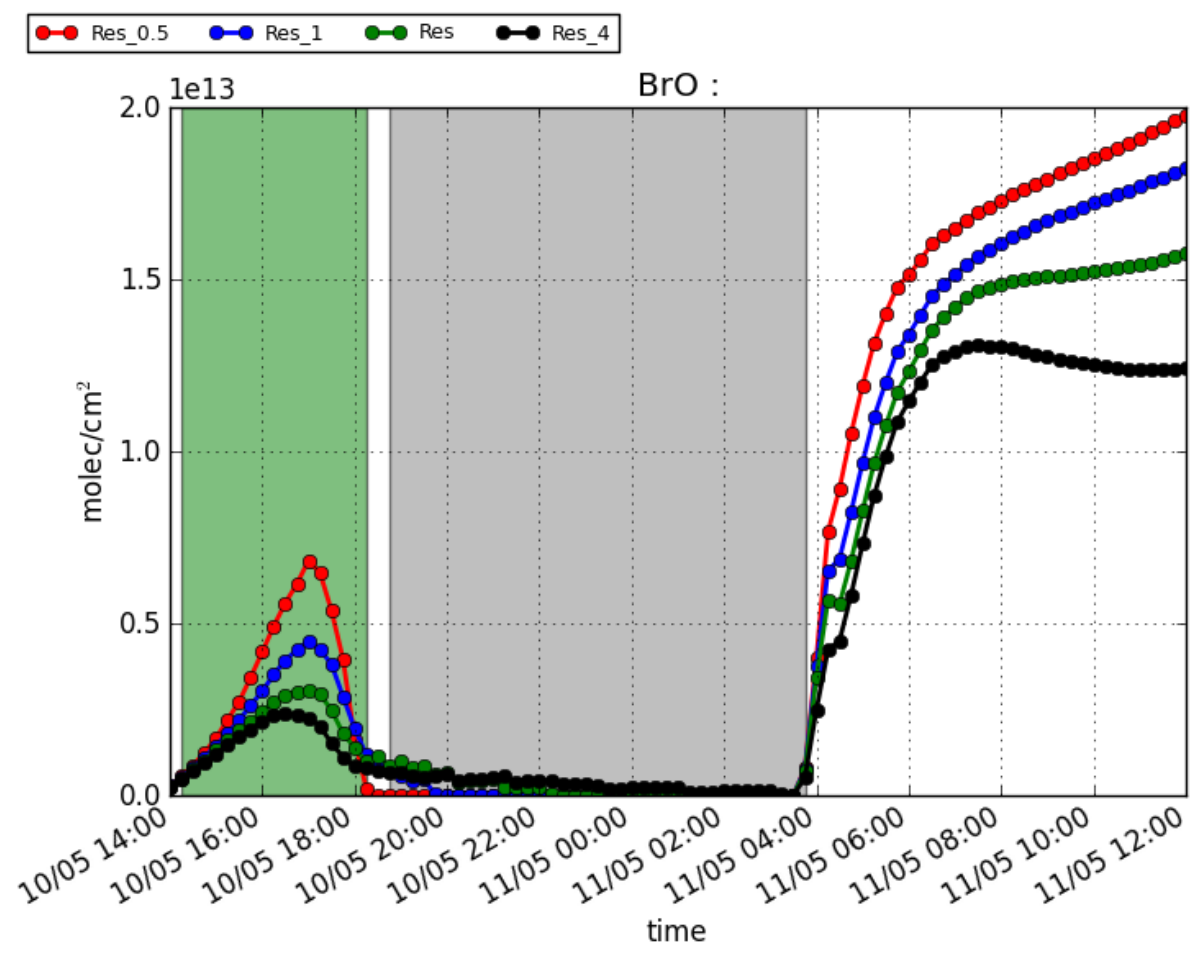

Fig. 16. Partial column as for Fig. 3. The simulations are with the model grid box resolution of $2^{\circ} \times 2^{\circ}$ and with the 95/5 ratio. The radius of the sulphate aerosols is $0.5 \mu \mathrm{m}$ (red line), $1 \mu \mathrm{m}$ (blue line), $2 \mu \mathrm{m}$ (green line) and $4 \mu \mathrm{m}$ (black line).

\section{GMDD}

\section{$7,2581-2650,2014$}

\section{Towards a \\ representation of \\ halogens in volcanic \\ plumes \\ L. Grellier et al.}

\section{Title Page}

Abstract

Introduction

Conclusions

References

Tables

Figures

14

4

Back

\section{Full Screen / Esc}

Printer-friendly Version

Interactive Discussion 